PNL-6709

UC-125

$\rightarrow A$

\title{
Multielement Detector for Gas Chromatography
}

D. S. Sklarew

J. C. Evans

K. B. Olsen

November 1988

Prepared for the U.S. Department of Energy under Contract DE-AC06-76RLO 1830

Pacific Northwest Laboratory Operated for the U.S. Department of Energy by Battelle Memorial Institute 


\title{
DISCLAIMER
}

This report was prepared as an account of work sponsored by an agency of the United States Government. Neither the United States Government nor any agency thereof, nor Battelle Memorial Institute, nor any or their employees, makes any warranty, expressed or implied, or assumes any legal liability or responsibility for the accuracy, completeness, or usefulness of any information, apparatus, product, or process disclosed, or represents that its use would not infringe privately owned rights. Reference herein to any specific commercial product, process, or service by trade name, trademark, manufacturer, or otherwise does not necessarily constitute or imply its endorsement, recommendation, or favoring by the United States Government or any agency thereof, or Battelle Memorial Institute. The views and opinions of authors expressed herein do not necessarily state or reflect those of the United States Government or any agency thereof.

\author{
PACIFIC NORTHWEST LABORATORY \\ operated by \\ BATTELLE MEMORIAL INSTITUTE \\ for the \\ UNITED STATES DEPARTMENT OF ENERGY \\ under Contract DE-AC06-76RLO 1830
}

\begin{tabular}{|c|c|}
\hline \multicolumn{2}{|c|}{ Printed in the United States of America } \\
\hline \multicolumn{2}{|c|}{ Available from } \\
\hline \multicolumn{2}{|c|}{ National Technical Informatıon Service } \\
\hline \multicolumn{2}{|c|}{ United Stales Department of Commerce } \\
\hline \multicolumn{2}{|c|}{5285 Port Royal Road } \\
\hline \multicolumn{2}{|c|}{ Springfield, Virginia 22161} \\
\hline \multicolumn{2}{|c|}{ NTIS Price Codes } \\
\hline \multicolumn{2}{|c|}{ Microfiche A01 } \\
\hline \multicolumn{2}{|c|}{ Printed Copy } \\
\hline & Price \\
\hline Pages & Codes \\
\hline $001-025$ & $\mathrm{~A} 02$ \\
\hline $026-050$ & $\mathrm{~A} 03$ \\
\hline $051-075$ & $\mathrm{~A}, 04$ \\
\hline $076-100$ & A05 \\
\hline $101-725$ & A06 \\
\hline $726-150$ & $\mathrm{~A} 07$ \\
\hline $151-175$ & $\mathrm{~A} 0 \mathrm{~B}$ \\
\hline $176-200$ & $\mathrm{~A} 0 \mathrm{9}$ \\
\hline 207.225 & A 10 \\
\hline $226-250$ & A11 \\
\hline $251-275$ & $\mathrm{~A} 12$ \\
\hline $276-300$ & $A 13$ \\
\hline
\end{tabular}


MULTIELEMENT DETECTOR FOR

GAS CHROMATOGRAPHY

D. S. Sklarew

J. C. Evans

K. B. 01 sen

November 1988

Prepared for

the U.S. Department of Energy

under Contract DE-AC06-76RLO 1830

Pacific Northwest Laboratory

Richland, Washington 99352 


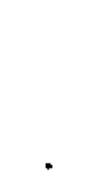




\section{ABSTRACT}

This report describes the results of a study to improve the capabilities of a gas chromatography-microwave-induced plasma (GC-MIP) detector system, determine the feasibility of empirical formula determination for simple mixtures containing elements of interest to fossil fuel analysis and, subsequently, explore applications for analysis of the complex mixtures associated with fossil fuels. The results of this study indicate that the GC-MIP system is useful as a specific-element detector that provides excellent elemental specificity for a number of elements of interest to the analysis of fossil fuels. It has reasonably good sensitivity for carbon, hydrogen, sulfur, and nickel, and better sensitivity for chlorine and fluorine. Sensitivity is poor for nitrogen and oxygen, however, probably because of undetected leaks or erosion of the plasma tube. The GC-MIP can also provide stoichiometric information about components of simple mixtures. If this powerful technique is to be available for complex mixtures, it will be necessary to greatly simplify the chromatograms by chemical fractionation. 


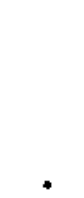




\section{SUMMARY}

The microwave-induced plasma detector was first interfaced to a gas chromatograph in 1965. Since then, its usefulness as a multielement detector has been demonstrated for a number of different applications, mainly involving organometallic or halogenated organic compounds. It has also been used to determine empirical formulae for simple mixtures of chlorine-containing and hydrocarbon compounds. This report describes the results of a study to improve the capabilities of the gas chromatography-microwave-induced plasma (GC-MIP) detector system, determine the feasibility of empirical formula determination for simple mixtures containing elements of interest to fossil fuel analysis and, subsequently, explore applications for analys is of the complex mixtures associated with fossil fuels.

Two GC-MIP systems, an echelle system and an MPD-850 system (see Section 2.2), were modified as part of the program, greatly improving their capability and ease of operation. The final configuration of the echelle system consisted of the following major components: a capillary gas chromatograph, a fiber-optic light pipe that eliminated the need for a heated transfer line, three different but easily interchangeable microwave sources, a multielement cassette for the detector with a set of emission lines pertinent to this program, and a computerized data system capable of handling up to six elements simultaneously. The existing MPD-850 system did not require as many modifications but was improved by incorporation of the computerized data system.

A low-pressure version of a Beenakker source was designed and constructed that combined the most attractive features of the existing atmospheric-pressure Beenakker and the low-pressure Evenson sources. This new source proved to be excellent for the measurement of carbon, hydrogen, and sulfur, showing reasonably good sensitivity and good stability. 0ptimal operating parameters, including helium flow, scavenge gas flow, power level, and operating pressure, were determined for this source for $\mathrm{C}, \mathrm{H}, \mathrm{N}, \mathrm{S}$, and C1. Parameters were chosen to minimize variation in elemental ratios resulting from instabilities in flow rates and power setting. 
Radiofrequency-induced plasma detection was considered as an alternate method of element-specific chromatographic characterization, but does not appear to offer any clear advantages over the MIP source. It exhibits similar sensitivity for carbon and hydrogen and worse sensitivity for sulfur, nitrogen, and oxygen using the emission lines available on the echelle spectrometer. It also does not appear to be suitable for stoichiometric determinations.

The MIP system can correct for interelement interferences using the analog "ghosting" correction, thereby allowing it to attain excellent elemental specificity. Ghosting corrections were successfully applied to the sulfur, chlorine, fluorine, nitrogen, deuterium, and nickel channels. For sulfur species, this ghosting correction gives the MIP system a major advantage over the flame photometric detector (FPD). Though both provide similar qualitative information, quantitation should be more reliable with the GC-MIP than with the GC-FPD because the former is not subject to hydrocarbon quenching at the concentrations studied. A second advantage is that the MIP provides a more linear response compared to the nonlinear compounddependent power function response of the FPO.

Much of the emphasis in this study was on determining the parameters that affect empirical formula determinations. The precision of elemental ratio determinations is 1 imited to $1 \%$ by spectrometer instability, not taking into account any other factors. Precision and accuracy are strongly influenced by chromatographic factors. Even for relatively simple chromatograms, integration accuracy is the major source of error in empirical formula caiculations. Another major 7 imitation is that $\mathrm{H} / \mathrm{C}$ elemental response ratios are somewhat dependent on concentration, requiring application of a secondary correction factor for empirical formula calculations; this 1 imitation is not evident for $S / C$ elemental response ratios except at very high concentrations. An advantage for empirical formula calculations is that responses are independent of compound type for a given concentration. For empirical formulae of pseudo-unknown components in simple mixtures, results typically deviated from the correct formulae by $5-10 \%$ for hydrogen, sulfur, and chlorine. Precision varied from 1 to $5 \%$. 
Application of the GC-MIP technique to the complex mixtures found in fossil fuels was the final part of this study. Three different types of fossil fuels were used to explore these applications. Sulfur-, oxygen-, and nickel-containing species were considered.

A series of alkylthiophenes and dimethyl disulfide were identified and quantitated in an oil shale retort gas condensate. The GC-MIP technique was successful in selectively detecting the sulfur components in this complex mixture, in concentrations ranging from 1.5 to $10.7 \mathrm{~mol} \mathrm{ppm}$. The detection limit was approximately 2 ng methylthiophene injected into the GC-MIP system. Attempts to determine stoichiometry of the sulfur components by comparison of carbon, hydrogen, and sulfur ratios with those of standards were unsuccessful because of the complexity of the carbon and hydrogen chromatograms.

Aluminum-coated methyl-silicone capillary columns, which could withstand oven temperatures as high as $400^{\circ} \mathrm{C}$, were successfully used to chromatograph several relatively nonvolatile porphyrin compounds. The GC-MIP system was able to detect a nickel(II)-etioporphyrin standard at a detection limit of approximately $200 \mathrm{ng}$ porphyrin injected (or about $20 \mathrm{ng}$ nickel injected). However, it was not able to detect nickel porphyrins in the appropriate fractions of two crude oils.

Derivatization of a phenolic fraction of $\mathrm{H}$-Coal with PFAA (pentafluoroacylation) was successful as seen by the shift in the carbon chromatogram to lower retention times and the generation of a fluorine chromatogram. Similar derivatization with TMS (trimethylsilylation) al so shifted the carbon chromatogram; however, the silicon channel was not sufficiently sensitive to detect any response. Empirical formula calculations using a simple mixture of PFAA-derivatized standards indicate that useful stoichiometric information can be provided by this technique, providing that chromatograms can be sufficiently simplified.

The results of this study indicate that the GC-MIP system is useful as a specific-element detector that provides excellent elemental specificity for a number of elements of interest to the analysis of fossil fuels. It has reasonably good sensitivity for carbon, hydrogen, sulfur, and nickel, and better sensitivity for chlorine and fluorine. However, sensitivity is poor for 
nitrogen and oxygen, probably because of undetected leaks or erosion of the plasma tube. The GC-MIP can also provide stoichiometric information about components of simple mixtures. If this powerful technique is to be available for complex mixtures, it will be necessary to greatly simplify the chromatograms by chemical fractionation. 


\section{ACKNOWLEDGMENTS}

The authors wish to thank $\mathrm{Dr}$. Stuart Scheppele and Mr. William Peters for their support and interest in this project, Dr. Peter Uden for his encouragement and suggestions, Ms. Cherylyn Wright for her comments and for providing the H-Coal samples, Mr. Art Graf for instrumentation support, Ms. Sylvia Downey and Mr. Charles Veverka for technical assistance, and Ms. Julie Gephart for technical editing.

This project was funded by the U.S. Department of Energy, Office of Fossil Energy, under Contract DE-AC06-76RLO 1830 through the Bartlesville Project Office. 


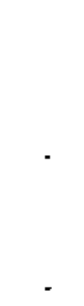




\section{CONTENTS}

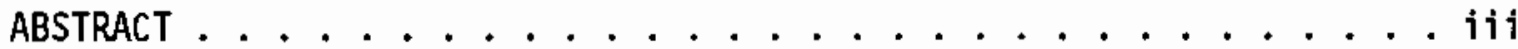

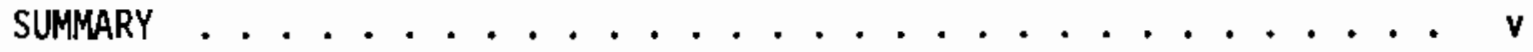

ACKNOWLEDGMENTS ...................... ix

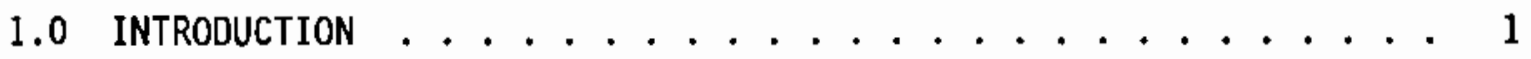

2.0 DEVELOPMENT OF INSTRUMENTATION .............. 3

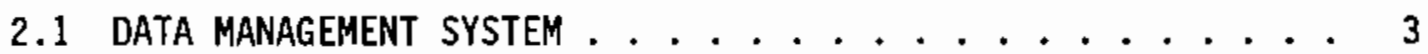

2.2 GC-MPD 850 SYSTEM ................ 4

2.3 ECHELLE SYSTEM ................. 6

2.4 FIBER-OPTIC LIGHT PIPE . . . . . . . . . . . 10

2.5 MICROWAVE SOURCES ................. 11

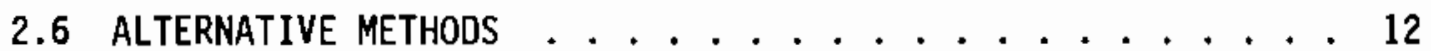

2.6.1 Radiofrequency-Induced Plasma Detection . . . . . 12

2.6.2 Alternate Sample Introduction . . . . . . . . 13

2.6.3 Adaptations for Compounds with Higher Molecular Weights ............ 14

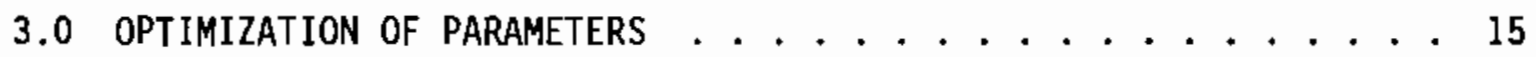

3.1 IDENTIFICATION OF BACKGROUND SOURCES . . . . . . . 15

3.2 INTERELEMENT INTERFERENCES . . . . . . . . . . 17

3.3 OPTIMIZATION OF LOW-PRESSURE BEENAKKER SOURCE ...... 19

4.0 EMPIRICAL FORMULA DETERMINATION FOR SIMPLE MIXTURES . . . . 41

4.1 SOURCES OF UNCERTAINTY .............. 41

4.2 SIMPLE HYDROCARBON MIXTURES USING THE MPD-850

WITH EVENSON SOURCE ............... . . 42

4.3 SIMPLE MIXTURES OF SULFUR- AND NITROGEN-CONTAINING COMPOUNDS USING THE MPD-850 WITH EVENSON

SOURCE 
4.4 SIMPLE MIXTURES OF HYDROCARBONS AND NITROGEN-, SULFUR-, AND CHLORINE-CONTAINING COMPOUNDS USING THE ECHELLE SYSTEM

WITH ATMOSPHERIC-PRESSURE BEENAKKER SDURCE . . . . . . . 54

4.5 SIMPLE MIXTURES OF HYDROCARBONS AND SULFUR-CONTAINING COMPOUNDS USING THE LOW-PRESSURE BEENAKKER SOURCE WITH THE MPD-850 AND ECHELLE SYSTEMS .......... 57

5.0 FOSSIL FUEL APPLICATIONS . . . . . . . . . . 71

5.1 SULFUR SPECIES IN AN OIL SHALE RETORT OFFGAS--

EMPIRICAL FDRMULA DETERMINATIONS .......... . 71

5.2 ANALYSIS OF SHALE OIL AND H-COAL FRACTIONS-DERIVATIZATION OF OXYGEN-CONTAINING SPECIES . . . . . 77

5.3 PORPHYRIN ANALYSIS . . . . . . . . . . 86

6.0 CONCLUSIONS ........................... 89

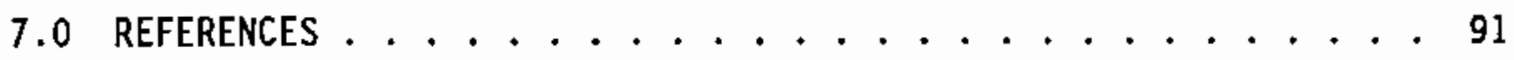




\section{FIGURES}

1 GC-MPD 850 Schematic . . . . . . . . . . . . 5

2 GC-MIP Echelle Schematic . . . . . . . . . . . 9

3 Low-Pressure Beenakker Source ............... 12

4 Multichannel Capillary Column GC-MIP . . . . . . . . . . 18

5 Helium Line Intensity Versus Forward Power Leve]: Low-Pressure Beenakker-Echelle .............. 20

6 Helium Line Intensity Versus Pressure: Low-Pressure Beenakker-Echelle ................ 21

7 Helium Line Intensity Versus Scavenge Flow: Low-Pressure Beenakker-Echelle ............. 23

8 Silicon Line Intensity Versus Scavenge Flow: Low-Pressure Beenakker-Echelle .............. 24

9 Background Versus Power Leve1: Low-Pressure Beenakker-Echelle . . . . . . . . . . . 25

10 Elemental Response Versus Power Level: Low-Pressure Beenakker-Echelle ............... 26

11 Elemental Response Ratio Versus Power Leve1: Low-Pressure Beenakker-Echelle .............. 27

12 Elemental Response Versus Hetium Flow: Low-Pressure Beenakker-Echelle . . . . . . . . . . . . 29

13 Elemental Response Ratios Versus Helium Flow: Low-Pressure Beenakker-Echelle ..............

14 Signa7-to-Background Ratio Versus Plasma Power: Low-Pressure Beenakker-Echelle ................

15 Signal-to-Background Ratio Versus Carrier Flow: Low-Pressure Beenakker-Echelle .................

16 Elementa] Response Versus Scavenge Flow: Low-Pressure Beenakker-Echelle ...............

17 Elemental Response Ratios Versus Scavenge Flow: Low-Pressure Beenakker-Echelle 
18 Carbon Response Versus Amount Injected: Low-Pressure Beenakker-Echelle .............. 36

19 Hydrogen Response Versus Amount Injected: Low-Pressure Beenakker-Echelle ............... 37

20 Sulfur Response Versus Amount Injected: Low-Pressure Beenakker-Echelle .............. 38

$21 \mathrm{H} / \mathrm{C}$ Ratio Versus Amount Injected: Low-Pressure Beenakker-Echelle ................ 39

22 S/C Ratio Versus Amount Injected: Low-Pressure Beenakker-Echelle .............. 40

$23 \mathrm{C} / \mathrm{H}$ Response Ratio of $\mathrm{n}$-Alkanes at $0.01-0.02 \mathrm{mg} / \mathrm{mL}$ Concentration: Evenson-MPD $850 \ldots \ldots 44$

$24 \mathrm{C} / \mathrm{H}$ Response Ratio of $\mathrm{n}$-Alkanes at $0.1-0.2 \mathrm{mg} / \mathrm{mL}$ Concentration: Evenson-MPD $850 \ldots \ldots 45$

$25 \mathrm{C} / \mathrm{H}$ Response Ratio of $\mathrm{n}-\mathrm{Al}$ kanes at $1-2 \mathrm{mg} / \mathrm{mL}$ Concentration: Evenson-MPD $850 \ldots \ldots 46$

$26 \mathrm{C} / \mathrm{H}$ Response Versus Carbon Injected for Alkanes, Alkenes, and Aromatics: Evenson-MPD $850 \ldots \ldots 48$

$27 \mathrm{C} / \mathrm{H}$ Response Ratio for Alkanes, Alkenes, and Aromatics at $0.1 \mathrm{mg} / \mathrm{mL}$ Concentration: Evenson-MPD $850 \ldots . . . . . .49$

28 Detector Response of Alkanes, Alkenes, and Aromatics at $0.1 \mathrm{mg} / \mathrm{mL}$ Concentration: Evenson-MPD $850 \ldots . . . . .50$

29 Multielement Chromatogram: Atmospheric-Pressure Beenakker-Echelle ............. 56

30 Carbon Response Factor: Atmospheric-Pressure Beenakker-Echelle .............. 58

31 C/H Response Ratio: Atmospheric-Pressure Beenakker-Echelle ............... 59

32 C/S Response Ratio: Atmospheric-Pressure Beenakker-Echelle .............. 60

33 Multielement Chromatogram for Carbon, Hydrogen, and Sulfur Channels: Low-Pressure Beenakker-Echelle ......... 62

34 Measured S/C Ratios Normalized to the Known Value for Each Sulfur Compound: Low-Pressure Beenakker ......... 66 
35 Measured H/C Ratios for Sulfur Compounds Normalized to the Known Value: Low-Pressure Beenakker .......... 67

36 Measured $\mathrm{H} / \mathrm{C}$ Ratios for Hydrocarbons Normalized to the Known Value: Low-Pressure Beenakker .......... 68

37 GC-MIP Analysis of Condensed Retort Offgas from a 6-kg 011 Shale Retort .............. 73

38 Chromatograms of Sulfur Standards by GC-Low-Pressure Beenakker-Echelle ............... 74

39 Calibration Plot for Sulfur, Carbon, and Hydrogen Response as a Function of the Concentration of Compound Injected . . . 75

40 Analysis of Western Shale $0 i 1$ High-Sulfur Fraction by GC-MIP Compared with GC-MS Total Ion Chromatogram ........ 78

41 GC-MS Analysis of Western Shale 0i1 High Sulfur Fraction at $m / \mathrm{e}=184 \ldots \ldots \ldots \ldots 79 \ldots \ldots \ldots$

42 Analysis of Western Shale 0i1 Moderately Polar Fraction by GC-MIP .................. 80

43 Comparison of PFAA-Derivatized H-Coal Distillate Blend Phenolic Fraction with Underivatized Fraction on MIP Carbon Channel ................ 82

44 Comparison of PFAA-Derivatized H-Coal Distillate Blend Phenolic Fraction with Underivatized Fraction on MIP Fluorine Channel............... 83

45 PFAA-Derivatized H-Coal Distillate Blend Phenolic Fraction . . 84

46 Chromatogram of PFAA-Derivatized Phenolic Standards ..... 85 


\section{$\underline{\text { TABLES }}$}

1 ElementaT Emission Lines on the MPD-850 System . . . . . . 6

2 Elemental Emission Lines on the Echelle System . . . . . . 8

3 GC and Plasma Detector Conditions ............. 43

$4 \mathrm{H} / \mathrm{C}$ Ratio Determination ................ 51

5 Integrator Counts per Nanomole Injected .......... 53

6 Empirical Formulae .................. 54

$7 \mathrm{GC}$ and PTasma Detector Conditions ............ 55

8 Empirical Formulae ................. 61

9 Relative Molar Response ............... 61

$10 \mathrm{GC}$ and Plasma Detector Conditions ........... 64

11 Empirical Formulae Using the Low-Pressure Beenakker Source on the Echelle and MPD-850 Systems ........... 65

12 Empirical Formulae Using the Low-Pressure Beenakker Source on the MPD-850 .................. 70

13 Sulfur Species Emitted in Retort Gas Condensate . . . . . . 76

14 Empirical Formulae of Standards . . . . . . . . . . . 76

15 Empirical Formulae of Retort Gas Condensate Components . . . . 77

16 Stoichiometry Test Case for PFAA Derivatives . . . . . . . . 86

17 Empirical Formula for Chlorodifluoroacetyl Derivative . . . . 87 


\subsection{INTRODUCTION}

The microwave-induced plasma (MIP) has been used as a gas chromatography (GC) detector since McCormack, Tong, and Cooke (1965) first demonstrated the feasibility of interfacing a GC with atomic emission spectroscopy. Its major strength lies in its ability to simultaneously monitor a wide range of elements in the individual components of a mixture separated by GC. In its initial stages, most of the work with the GC-MIP used packed columns and dealt with standard compounds in single-element mode. Later studies incorporated the use of capillary columns (e.g., Quimby et al. 1980; Wasik and Schwarz 1980; Hanie et a7. 1981; Estes, Uden, and Barnes 1981) or polychromators (e.g., Bonnekesse 1 and K1 ier 1978; Brenner 1978; Windsor and Denton 1979; Eckhoff, Ridgway, and Caruso 1983). The plasma portion of the GC-MIP technique has also evolved since its introduction. Both argon and helium have been used as plasma support gases with two different cavities, the low-pressure, Evenson-type 1/4-wave cavity (Dagnall et a]. 1970) and the atmospheric-pressure Beenakker $\mathrm{TM}_{010}$ cavity (Beenakker 1976, 1977). Hel ium has proven particulariy effective for the detection of elements such as nitrogen, sulfur, and the halogens that are difficult to excite (Carnahan, Mulligan, and Caruso 1981).

The usefulness of the GC-MIP as an element-specific detector has been demonstrated for a number of different applications. For example, Bache and Lisk (1971) and Talmi (1975) examined organomercury compounds in aqueous and biological materials. Other organometallic compounds in environmental samples have also been studied by GC-MIP, including organolead (Estes, Uden, and Barnes 1982) and organoarsenic (Talmi and Bostick 1975) compounds. Quimby et al. (1979) and Chiba and Haraguchi (1983) distinguished between chlorinated and brominated organic compounds in environmental water samples. Hagen et a1. (1981) studied the biotransformation of fluorinated metabolites in rats.

Whereas other types of detectors are available for detecting certain specific elements, the GC-MIP is unique in its potential for generating stoichiometric information about unknown compounds. Such calculations would be based on the property that the sensitivity of the emission lines appears to be generally independent of the molecule (Beenakker 1977). Quimby et al. 
(1979) also found that the relative response per mole of halogen varied little from one compound to another. In contrast, Dingjan and de Jong (1981) claimed that poor precision prevented the accurate determination of molecular formulae. Brenner (1978) found that empirical formula calculations were possible with high concentrations $(0.05-0.1 \mu \mathrm{g} / \mathrm{sec})$ of analyte. Dagna 1 , West, and whitehead (1972) discussed the factors that affect the ratio of some nonmetallic elementa] responses to that of carbon in an argon plasma. They found that the ratios were independent of carrier gas flow rate and concentration for suifur, iodine, or phosphorus. Windsor and Denton (1979) demonstrated that empirical formulae could be calculated for simple mixtures of compounds containing carbon, hydrogen, and a halogen. Slatkavitz et al. (1984); Zerezghi, Mulligan, and Caruso (1984); Hagen, Marhevka, and Haddad (1985); and Uden et al. (1986) found that empirical formulae could be determined for simple mixtures of chlorine-containing and hydrocarbon compounds. This type of calculation has not yet been applied to complex mixtures.

Pacific Northwest Laboratory (PNL) conducted a program for the Office of Fossil Energy of the U.S. Department of Energy entitled "Multielement Detector for Gas Chromatography." The purpose of this program was to 1) develop a state-of-the-art system consisting of a fused-silica capillary GC combined with a multielement MIP detector interfaced to a multichannel, computerized data acquisition system; 2) determine optimum operating parameters for elements of interest to fossil fuel analysis; 3 ) determine the feasibility of empirical formula determination for simple mixtures containing elements of interest; and 4) develop applications of this detector for fossil fuel analysis, including exploration of the feasibility of empirical formula determination for fossil fuel components in complex mixtures. This report summarizes the results of each of these four objectives in Sections 2.0-5.0, respectively; Section 6.0 contains the conclusions; and Section 7.0 lists references. 


\subsection{DEVELOPMENT OF INSTRUMENTATION}

A GC-MIP system consists of the GC, the interface, the plasma source, the spectrometer, and the data system. Two GC-MIP systems with a common data management package were available for this program, an MPD-850 system and an echelle system. Both systems were used because they provided somewhat different and complementary capabilities. The MPD-850 system had a more stable response than the echelle, but the echelle provided better elemental selectivity and a different, though overlapping, suite of elements available for study. During the course of this program, modifications were made to all components to improve the capability of both systems (Sections 2.1-2.5). In addition, alternative but related or complementary methods of detection or sample introduction were also explored briefly (Section 2.6).

\subsection{DATA MANAGEMENT SYSTEM}

One of the key goals early in the program was to set up a state-ofthe-art data management system capable of simultaneously taking data from at least six channels at a rate compatible with integration of capillary column data. After extensive evaluation of alternatives, a Nelson Analytical Model 3000 chromatography package (Nelson Analytical, Cupertino, CA) was chosen. Initially, the package was mounted on a Compaq Plus personal computer for testing and evaluation purposes. Subsequent]y, the Compaq Plus was replaced by an IBM-PC/AT, which increased the speed of the system by a factor of four. The increased speed was useful for routine operations, particularly post-run data reduction. The system was interfaced into the Hewlett-Packard (HP) 5880A GC controller so that the computer data acquisition could be remotely started. Each of the six intelligent interfaces could acquire data at a rate of up to 100 points per second per channel and store up to 100,000 points per interface independent of the host computer. Data were displayed in real time during the run for any two channels selected. Channel selection could be changed at any time during the run to interrogate all channels. Data reduction options were quite flexible in the post-run mode, including very sophisticated interactive graphics. The graphics system was modified to add a high-resolution color capability. 
The capabilities of the software package were evaluated during the initial phases of the program. of particular concern for stoichiometry determinations was the integration accuracy for capillary column chromatograms under a variety of conditions. In this work, only single-compound or simple mixtures were used to simplify interpretation and isolate problems. For very high signal-to-background ratios, the integration algorithm was found to perform very well using an option that forced individual baselines for each peak. This gave an overall integration precision estimated to be $1-2 \%$. This option could be implemented automatically, yielding acceptable results immediately after run termination. As the signal-to-noise ratio decreased, the automatic baseline setting tended to give unacceptable accuracy more frequently. In that case, it was necessary to reset the baseline using the interactive graphics feature of the software. Differences between integration results ranging from $10 \%$ to as much as $200 \%$ were noted for the uncorrected baselines. The situation became even more critical as the complexity of the chromatogram increased. While the interactive procedure was somewhat more labor intensive, the software was very well designed to accommodate this option and provided a much greater degree of confidence than an automatic system.

\subsection{GC-MPD 850 SYSTEM}

The GC-Tow-pressure MIP system consisted of two commercially available components: an HP 5880A GC and an Applied Chromatography Systems MPD-850 with a low-pressure Evenson MIP source, which has been described in detail by 07 sen, Sk7arew, and Evans (1985) (Figure 1). This system was used during the initial phases of the program because it was fully functional and required a minimal amount of hardware modification for optimization. Before work started, a service engineer from Applied Chromatography Systems carried out a thorough optical alignment of the system. He also added emission lines for deuterium and selenium and changed the mercury to a more sensitive emission line. The emission lines available on the system are given in Table 1. At the same time, an Applied Chromatography version of the Beenakker source was delivered and tested. This source appeared to be the best-designed version of the Beenakker type of source available, having very stable 


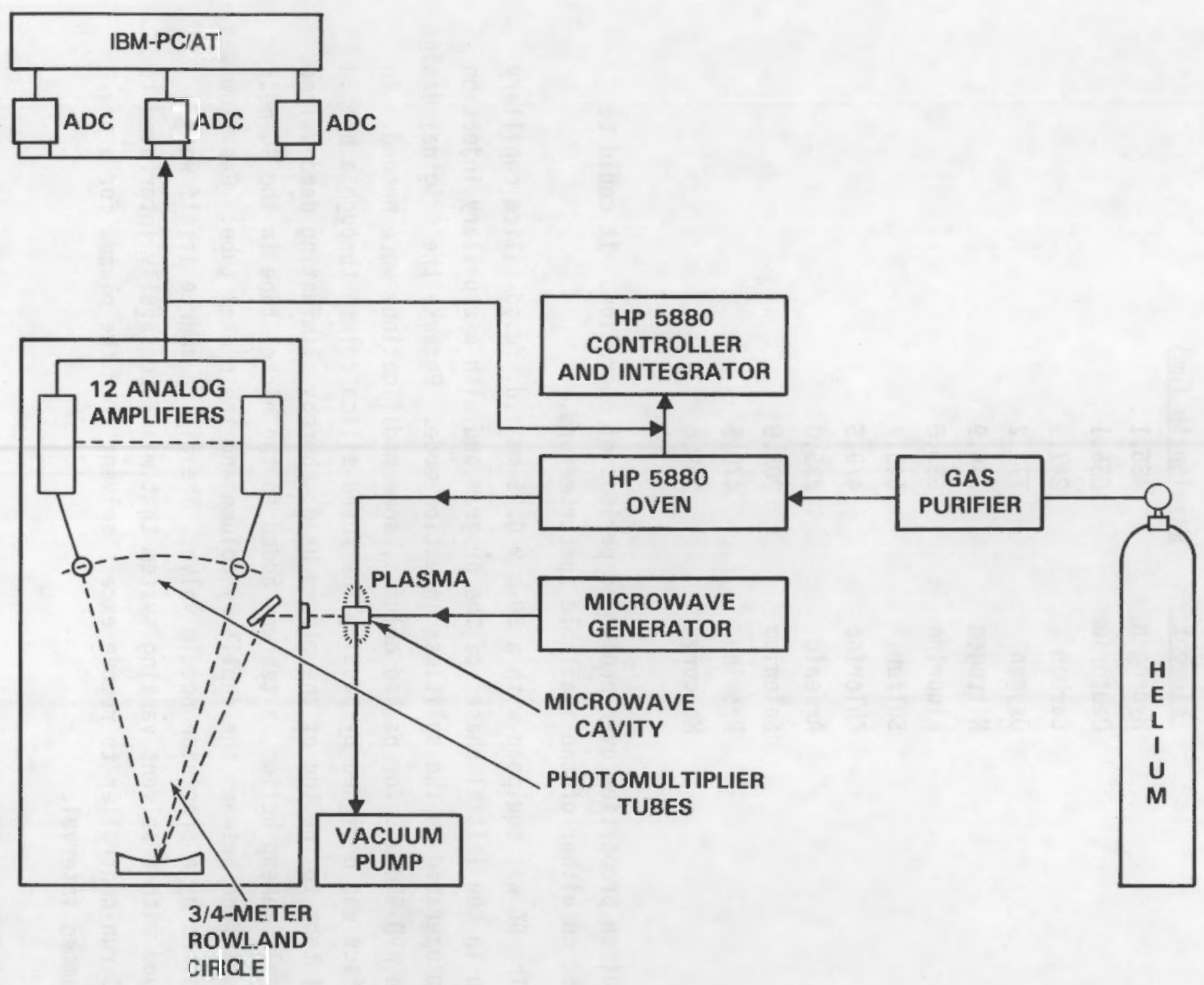

FIGURE 1. GC-MPD 850 Schematic 
TABLE 1. Elemental Emission Lines on the MPD-850 System

\begin{tabular}{lcc} 
Element & Wavelength (nm) \\
\cline { 1 - 1 } Hydrogen & & 486.1 \\
Deuterium & & 656.1 \\
Carbon & & 247.9 \\
Oxygen & & 777.2 \\
Nitrogen & & 746.9 \\
Fluorine & 685.6 \\
Sulfur & & 545.4 \\
Chlorine & 479.5 \\
Arsenic & 235.0 \\
Selenium & 203.9 \\
Bromine & 470.5 \\
Mercury & 253.6
\end{tabular}

excitation properties over prolonged periods of operation. It could be mounted on either of the available spectrometers.

The GC was equipped with a $30-\mathrm{m} \times 0.25-\mathrm{mm}-i . d$. fused-silica capillary column in the initial phases of the program and with a capillary injection system operated in the splitless injection mode. Because the original design of the MPD-850 was for packed columns, some modifications were needed. An interface was designed by passing the fused-silica column through a heated nickel tube to the top of the plasma head, thereby eliminating dead volume. To supply makeup helium, a tee was added to the nickel tube in the GC near the interface between the capillary column and the nickel tube. Gas flow was controlled by a precision needle valve. The plasma source itself was equipped with a solvent venting system that was successfully interfaced to the GC run-controller to remove excess solvent from the plasma for a preprogrammed interval.

\subsection{ECHELLE SYSTEM}

The original GC-MIP system with echelle spectrometer used at PNL has been described in detail by 01 sen, Sklarew, and Evans (1985). A substantial 
effort was required to make the echelle system fully operational. A multielement cassette was fabricated for the system by the instrument manufacturer (Beckman Instruments, Irvine, CA). This required close consultation between PNL and Beckman to determine an acceptable set of lines free of physical or spectral overlap problems. It was necessary to revise the list of analytical lines several times to take into account physical restrictions in the manufacture of the cassette resulting from close spacing of lines or inter-order interferences. The emission lines chosen reflected consideration of potential applications for the system in addition to the needs of this program. A helium line was included to monitor plasma stability and to align the source. An argon line was also added to allow potential applications using an argon plasma. The chosen emission lines are given in Table 2. Red-sensitive phototubes were added for hydrogen, nitrogen, oxygen, and fluorine.

The multielement cassette was aligned by a representative of Beckman Instruments assisted by PNL personnel. This procedure had never before been attempted with a helium excitation source. A 70-W Beenakker excitation source was used with a variety of calibration gases plumbed directly into the helium stream through a mass flow controller. This allowed alignment of $\mathrm{H}$, $\mathrm{C}, \mathrm{N}, \mathrm{O}, \mathrm{F}, \mathrm{S}, \mathrm{Cl}, \mathrm{Ar}, \mathrm{As}, \mathrm{Se}$, and $\mathrm{Hg}$ using the very intense He line as a reference. Silicon was also aligned using the natural background from the quartz plasma tube. The silicon and helium lines were very useful in routine operation for real-time checks on wavelength and source alignment, plasma stability, and tube erosion. These lines were connected to a set of picoammeters to allow a continuous display. Elements for which no gaseous calibration source was available were aligned using a DC-argon excitation source substituted for the helium source. This source was capable of sample introduction in solution form by direct aspiration. Elements aligned in this manner included $\mathrm{Be}, \mathrm{P}, \mathrm{V}, \mathrm{Fe}, \mathrm{Ni}, \mathrm{Ge}$, and $\mathrm{Sb}$ with $\mathrm{Hg}$ used as a crossreference. The cassette was originally aligned at Beckman to approximate line locations before in-field alignment. No unusual problems were encountered using this method. 
TABLE 2. Elemental Emission Lines on the Echelle System

\begin{tabular}{llll} 
Element & & Wavelength $(\mathrm{nm})$ \\
\cline { 3 - 3 } Hydrogen & & 656.3 \\
Helium & & 388.9 \\
Beryllium & & 313.0 \\
Carbon & & 247.9 \\
Nitrogen & & 746.9 \\
Oxygen & & 777.2 \\
Fluorine & & 685.6 \\
Silicon & & 251.6 \\
Phosphorus & & 213.6 \\
Sulfur & & 545.4 \\
Chlorine & & 479.5 \\
Argon & & 415.9 \\
Vanadium & & 292.4 \\
Iron & & 259.9 \\
Nickel & & 221.7 \\
Germanium & & 265.1 \\
Arsenic & & 235.0 \\
Selenium & & 204.0 \\
Antimony & 206.8 \\
Mercury & 253.6
\end{tabular}

Following the alignment of the echelle spectrometer, the system was reassembled in an improved form (Figure 2). An HP 5880A GC replaced the older HP 5840 originally used in the first version of this system. The newer GC had a considerably better geometric arrangement for interfacing to the plasma source. The original interface included a heated, zero-dead-volume, 4-port valve to allow bypass of the solvent peak; a heated tee to permit introduction of makeup helium and a scavenger gas (normally oxygen); and a heated nickel tube jacketing the fused-silica capillary column. The capillary column ended within 2 to $3 \mathrm{~mm}$ of the excitation region in the plasma 


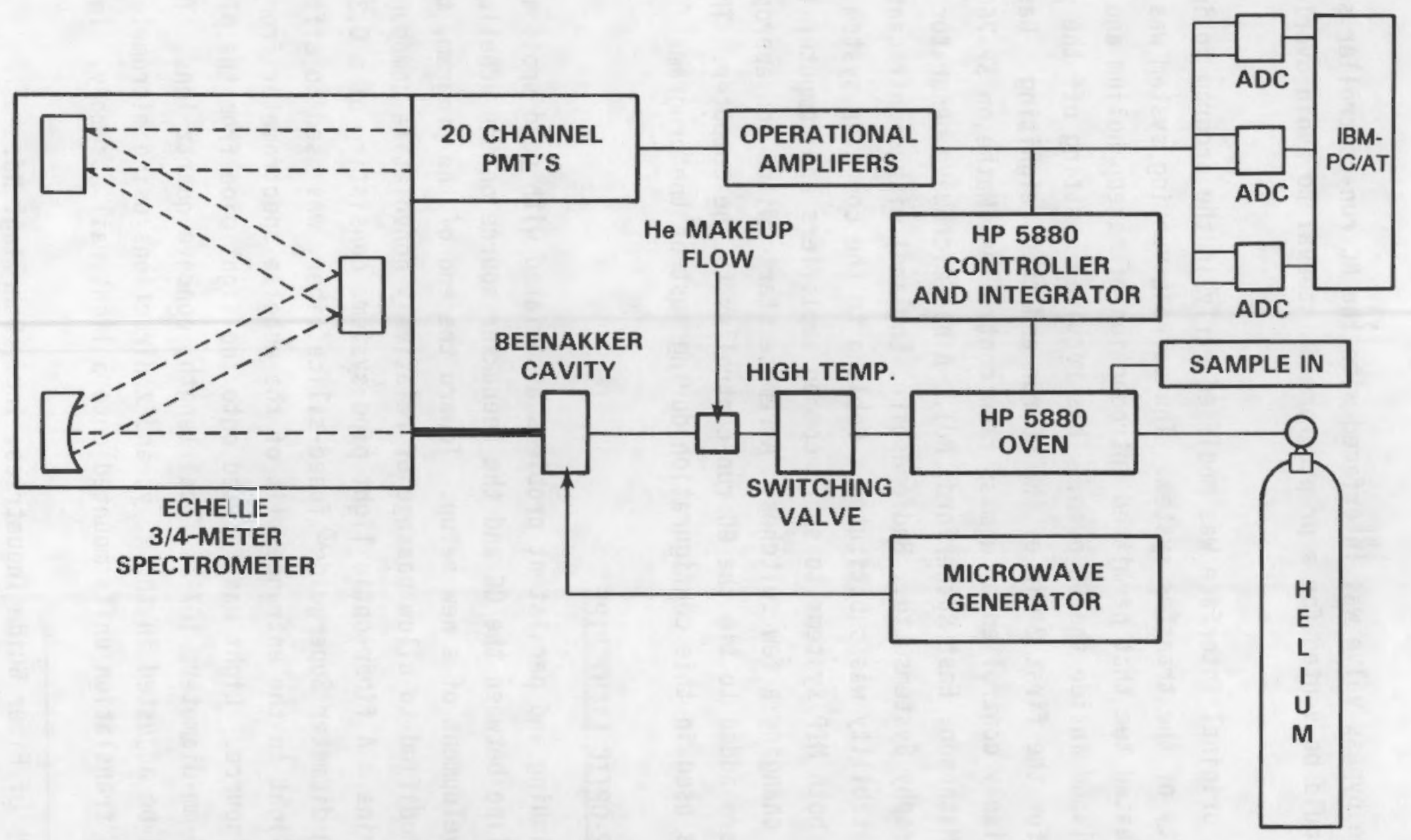

FIGURE 2. GC-MIP Echelle Schematic 
tube. The bypass valve was interfaced with the $\mathrm{GC}$ run-controller so that the solvent could be vented for a preprogrammed interval to avoid overloading the plasma.

This original interface was modified early in the program to improve the reliability of the transfer system. The solvent venting system was removed, and the heated tee that permitted introduction of makeup helium and scavenger gas was placed inside the GC oven. This required shutting off the plasma manually for the first 2 min of the GC run and then reigniting. Gas flows were precisely controlled by a mass flow controller (Matheson SP-760 DynaBlender, Matheson, East Rutherford, NJ). A new microwave generator (Applied Chromatography Systems Ltd., Bedfordshire, England) with significantly improved stability was substituted. Cabling to the computer system was added to enable both MIP systems to share common amplifiers and computer interfaces by simply changing a few switches. A remote start switch and appropriate cabling were added to tie the GC run-controller to the computer. The echelle system was used in this configuration during most of the program.

\subsection{FIBER-OPTIC LIGHT PIPE}

Continuing and persistent problems associated with cold spots in the transfer line between the GC and the Beenakker source on the echelle system led to development of a new setup. Toward the end of the program, the interface was modified to allow passage of relatively nonvolatile compounds such as porphyrins. A fiber-optic light pipe system, consisting of a $0.3-m-1$ ng by 1000 - $\mu \mathrm{m}$-diameter Superguide ${ }^{\circledR}$ fused-silica fiber, was used to efficiently transfer light to the entrance slit of the echelle spectrometer from the Beenakker source. Light was focused onto the light pipe from the plasma using a 25 -mm-diameter, $167-\mathrm{mm}$-focal length, concave quartz lens. The light pipe could be adjusted in the $x, y$, and $z$ directions using micrometer horizontal translation units mounted onto a light rail assembly. In this

(®) Trademark of Fiber Guide Industries, Inc., Sterling, NJ. 
configuration, the plasma tube jutted through a hole into the $\mathrm{GC}$ oven, thus allowing direct introduction of the transfer line into the plasma tube assembly without separate heating.

\subsection{MICROWAVE SOURCES}

The initial work done by PNL used the two sources that have been used for most of the work done in recent years--the low-pressure, Evenson-type 1/4-wave cavity (Dagnall et al. 1970) and the atmospheric-pressure Beenakker $\mathrm{TM}_{010}$ cavity (Beenakker 1976, 1977). Both sources had advantages and disadvantages. The low-pressure Evenson source provided optimal excitation energy, but the transverse viewing geometry had decreased sensitivity. Tube erosion and carbon buildup in the active region also caused degradation of long-term stability. The atmospheric-pressure Beenakker cavity provided a more efficient method for coupling microwave energy into the plasma and provided an axial geometry with inherently better light transmission. However, this source was prone to tube erosion with prolonged use, ignition difficulties, and slow stabilization after ignition.

A solution to this problem was to combine the most attractive features of both systems. To this end, a low-pressure version of a Beenakker source was constructed. An existing Beenakker cavity was modified by adding a tee to the end of the plasma tube with provision for a quartz window and a vacuum line connected at right angles to the axes of the plasma tube (Figure 3 ). In this manner, it was possible to view the plasma axially while maintaining an adequate differential pumping rate. Addition of a throttling valve on the vacuum pump further permitted variation of plasma pressure over a wide range. The prototype version of this source was initially mounted on the MPD-850 system to verify that it was fully operational as a chromatography detector. The system was then transferred to the echelle system. Helium and scavenge gas were supplied to the system by a mass flow controller capable of providing a stable flow rate over a wide operating range. The source stabilized very rapidly following ignition and operated stably from 3 to $700 \mathrm{~mm}$ pressure. Gas flows of 20 to $100 \mathrm{~mL} / \mathrm{min}$ were possible. At low pressures, the source operated over a very wide power range from 15 to at least $300 \mathrm{~W}$. This source configuration showed promise for providing the best overall 


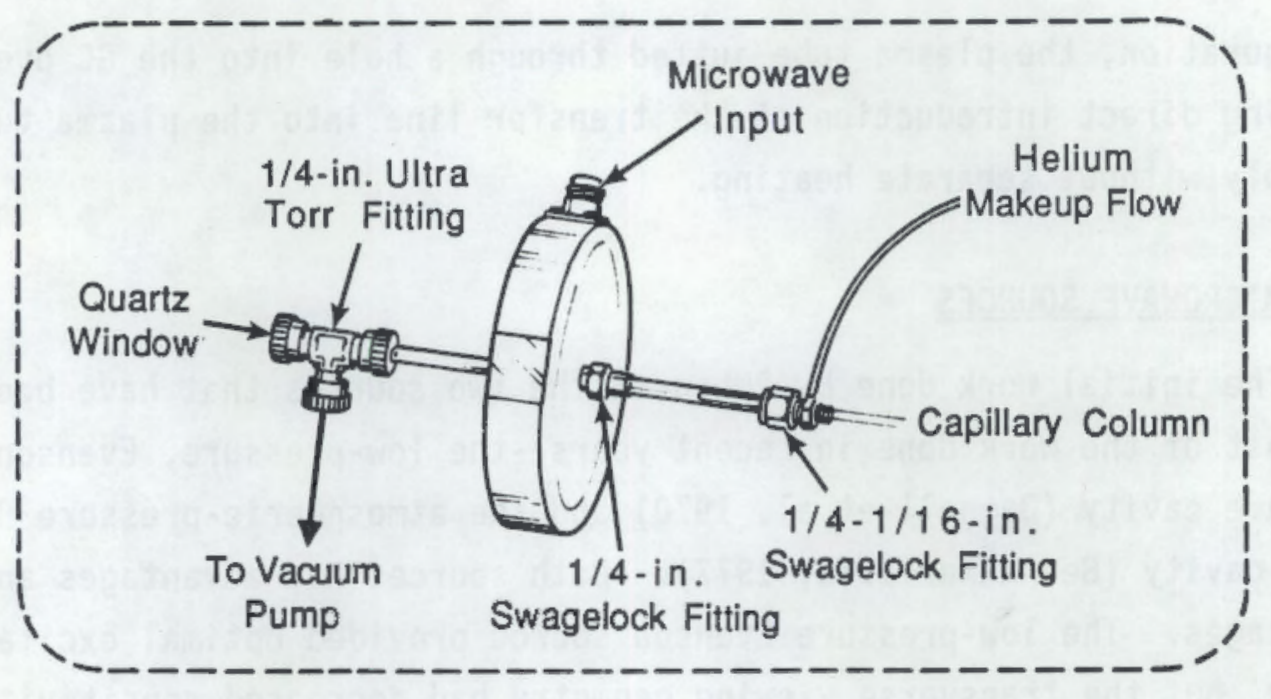

FIGURE 3. Low-Pressure Beenakker Source

characteristics for the needs of this program. Sensitivity and stability were good for carbon, hydrogen, and sulfur; however, sensitivity remained poor for nitrogen, apparently because of a continuing problem with high backgrounds from atmospheric contamination and wall effects (see Section 3.1).

\subsection{ALTERNATIVE METHODS}

\subsubsection{Radiofrequency-Induced Plasma Detection}

Radiofrequency-induced plasma (RFIP) detection represented an alternate method of element-specific chromatography effluent characterization using very similar methods to the MIP but with a somewhat different excitation mechanism. Helium metastables generated by an RFIP discharge react with the $\mathrm{GC}$ effluent to generate excited atomic species. The helium metastable can transfer up to $22 \mathrm{eV}$ of energy by Penning ionization or simple inelastic excitation to the analyte molecule. Studies by Rice, D'Silva, and Fassel (1985) demonstrated that the RFIP discharge could produce efficient excitation of nonmetallic analyte atoms with far less background light present (because of the absence of electron recombination), thus resulting in extremely favorable detection limits. In view of these positive results, we decided to compare the RFIP method with the MIP-type source. 
A low-frequency RF high-voltage power supply (Model HPG-2) capacitively coupled to a detector head was purchased from ENI Power Systems (Rochester, NY). It has a frequency range of $125-375 \mathrm{kHz}$ with a maximum forward power of $150 \mathrm{~W}$ at $10,000 \mathrm{~V}$ peak to peak. The source was constructed in-house according to the guidelines given by Rice, D'Silva, and Fassel (1985). The source was designed to operate at atmospheric and low pressure and be viewed along the axis of the quartz plasma tube. The capillary column was routed through the excitation region with the effluent exiting directly after the primary plasma excitation region. This arrangement eliminated the solvent-quenching effect found in microwave plasma sources and the consequent need for solvent venting. However, carbonization still occurred on the walls of the plasma tube when the solvent peak passed through the system.

The RFIP source was mounted on the echelle spectrometer and operated at either atmospheric pressure or $4-\mathrm{mm}-\mathrm{Hg}$ pressure. At atmospheric pressure, the RFIP system had similar detection limits for carbon and hydrogen as the MIP system. Compared to atmospheric pressure operation, the RFIP system at low pressure had approximately twice the sensitivity for hydrogen. However, the RFIP source, when operated at low or atmospheric pressure, demonstrated poor sensitivity for nitrogen, oxygen, or sulfur using the emission lines available on the echelle spectrometer. For example, the optimum line for sulfur is located at $182.0 \mathrm{~nm}$, in the vacuum UV (Rice, D'Silva, and Fassel 1985), which is outside the range of the spectrometers used in this program. As with the MIP system, a high oxygen background was found; its source could not be traced, though leaks were suspected. It did not appear to be related to carrier impurity or erosion of the quartz plasma tube. The RFIP source also appeared to be subject to quenching of the helium excitation caused by the presence of analyte molecules; this was not a problem for the MIP source. Consequently, the RFIP did not appear to be suitable for stoichiometric determinations and thus did not appear to offer any clear advantages over the MIP source.

\subsubsection{Alternate Sample Introduction}

Characterization of high molecular weight compounds, such as those present in heavy crude oils, by MIP detection is sometimes not feasible with 
GC. A different mode of sample introduction and compound separation may be required. Supercritical fluid chromatography (SFC) was considered to be the most promising approach. Other work done at PNL (Smith et al. 1987) demonstrated that supercritical fluid xenon exhibited solvent properties similar to those of supercritical $\mathrm{CO}_{2}$. Xenon was thought to provide the key to successful interfacing with plasma detection systems because it would not interfere with any elements of interest. Flow rates used in the capillary column system are relatively low $(3 \mathrm{~mL} / \mathrm{min})$, thus the use of xenon would not be prohibitively expensive. These low flows should also ease the problems of interfacing SFC with a helium-MIP detector because high concentrations of xenon in the helium (greater than about 1 mole\%) would destroy the helium excitation in the plasma. However, the effect of xenon on the plasma properties is largely unknown and is element dependent.

\subsubsection{Adaptations for Compounds with Higher Molecular Weights}

Most of the experiments in this program were done with compounds of intermediate molecular weight; that is, with carbon numbers ranging from 7 to 30. Compounds in this range had favorable chromatographic properties on standard capillary columns with typical elution times under $20 \mathrm{~min}$. To be applicable to the needs of this program, however, it was necessary to extend this range to the upper 1 imit feasible by GC. Several modifications were made to the gas chromatographs to achieve this goal. On-column injectors (Carlo Erba, Milan, Italy and J\&W Scientific, Rancho Cordova, CA) were purchased and installed on both HP 5880 gas chromatographs. Shorter columns with much thinner coatings were also used $(15-\mathrm{m} \times 0.25-\mathrm{mm}-\mathrm{i} . \mathrm{d}$., fused-silica capillary columns coated with $0.1-\mu$-thick DB-5), with increased helium flow rates and longer run times. Aluminum-coated capillary columns that can withstand oven temperatures as high as $400^{\circ} \mathrm{C}$ (Lipsky and Duffy 1986) were also employed. 


\subsection{OPTIMIZATION OF PARAMETERS}

\subsection{IDENTIFICATION OF BACKGROUND SOURCES}

As part of the optimization of the MPD-850, a careful evaluation was made of the gas-handling system because persistent nitrogen, oxygen, carbon, and hydrogen backgrounds were present in the instrument when operated according to the manufacturer's recommendations. If not corrected, this background problem would seriously affect system operation. Several factors contributed to this background problem that required system modifications. First, all sources of vacuum leaks were eliminated as much as possible using the instrument in a self leak-check mode by monitoring either the chlorine or hydrogen emission line (leak testing with freon or hydrogen, respectively). The helium was cryogenically scrubbed at the tank exit for further purification of air in ultra-high-purity helium. The remaining large $\mathrm{N}, \mathrm{O}, \mathrm{C}$, and $\mathrm{H}$ backgrounds were attributed to backstreaming from the vacuum pump. A cryogenic trapping system added to the pumping system eliminated the background almost entirely on a separate prototype system but was unsuccessful in eliminating the backgrounds on the full system because of continuing leakage. A bottom helium flow line and capillary restrictor were added to the plasma tube outlet to minimize the pressure drop across the tube. The remaining background was very sensitive to helium flow rate. A tee was added to the capillary column transfer line to provide a regulated flow of helium at the plasma inlet at a much higher rate than normally used. This resulted in almost complete elimination of the nitrogen background; however, the resulting dilution effect produced an unacceptably large decrease in sensitivity.

Because these initial modifications were unsuccessful in sufficiently eliminating background, a concerted effort was devoted to identifying additional sources of background. A system was assembled without a GC to isolate these sources. Air leakage was a primary source of nitrogen and oxygen background that could be greatly reduced by careful attention to vacuum seals. A vacuum gauge, improved vacuum pump, 0-ring sealed fittings, and cryotraps were added to the system to sustain a good-quality vacuum. This resulted in a marked decrease in background. 
The residual background appeared to originate from the quartz tubing, probably from entrained air in the quartz. Substitution of a silicon nitride plasma tube virtually eliminated the remaining nitrogen background. This appeared to be contradictory because a very high nitrogen background would be expected with a nitride-based tube. Apparently, the highly refractory nature of the ceramic material prevented any significant volatilization of the silicon nitride and subsequent excitation of nitrogen. The use of a silicon nitride tube was originally intended to remove the oxygen background. Paradoxically, a substantial oxygen background was present in the silicon nitride-based system even after most of the nitrogen signal disappeared. The remaining intensity of the oxygen signal was correlated with hydrogen and is presumed to be caused by traces of water from the walls of the gas inlet plumbing. Repeated heating of the tubing eventually minimized that effect, but it was difficult to eliminate entirely. Another source of nitrogen and oxygen background that was not successfully eliminated included swagelock fittings.

Carbon background is also a persistent feature. This appeared to be caused by traces of machine oil associated with any steel or copper tubing. Solvent cleaning of the tubing had little effect on the problem. Repeated baking with oxygen flow present was the best approach; however, carbon background was never completely eliminated because it appeared to be actually imbedded in the steel rather than to be simply a surface effect.

Once the GC was reintroduced to the system, additional sources of background that could not be eliminated included column bleed, bleeding of the polyimide coating on the column, and leakage from additional swagelock fittings.

The background may have been a minor source of element ratio variability at low levels for carbon and hydrogen. Background was a much more serious problem for detection of nitrogen and oxygen. Chemical reactions between carbon and hydrogen in analyte compounds with background oxygen resulted in a transient reduction in the atomic oxygen concentration in the plasma during peak passage. This resulted in the appearance of a negative peak if the analyte compound did not contain oxygen. If the analyte did contain oxygen 
at measurable levels, the negative peak was preceded by a positive inflection in the chromatogram. This effect was documented in several publications (Brenner 1978; Slatkavitz, Uden, and Barnes 1986) and was observed in our laboratory. Thus, we were not able to obtain sufficient background reduction for oxygen or nitrogen to enable use of the GC-MIP for these elements. However, derivatization of certain oxygen species (alcohols, phenols, acids) and possibly nitrogen species (amines) with elemental tags that are more favorable to MIP detection suggested the possibility that GC-MIP may be a useful indirect technique for measuring oxygen compounds. This is further explored in Section 5.2.

\subsection{INTERELEMENT INTERFERENCES}

An initial, limited study of interelement interferences consisted of monitoring the nitrogen, sulfur, and deuterium channels on the MPD-850 while injecting 1 to $2 \mu \mathrm{L}$ of an $\mathrm{n}$-alkene mixture standard containing individual components at relatively high concentrations ( 1 to $2 \mathrm{mg} / \mathrm{mL}$ ). The nitrogen channel was found to be free of interference. A large carbon interference was seen on the sulfur channel, and a small hydrogen interference was observed on the deuterium channel. The MPD-850 is equipped with an analog "ghosting" correction that applies a continuous correction from the carbon or hydrogen channel to the element of interest. This was applied successfully to the sulfur and deuterium channels.

A check of the elemental specificity was done using a three-component mixture. A 1- $\mu$ L injection of a solution of decadeuteronaphthalene $\left(C_{10} D_{18}\right)$, quinoline $\left(\mathrm{C}_{9} \mathrm{H}_{7} \mathrm{~N}\right)$, and dibenzothiophene $\left(\mathrm{C}_{12} \mathrm{H}_{8} \mathrm{~S}\right)$ at approximately $0.1 \mathrm{mg} / \mathrm{mL}$ concentrations was plotted from 5-15 min after injection to eliminate the solvent peak (Figure 4). The ghosting corrections described above were quite successfut because no detectable carbon interference was visible on the sulfur, nitrogen, or deuterium channels. No correction was made for the deuterium interference on hydrogen, and a significant overlap is evident. This correction posed some problems because the available deuterium compounds all contained some hydrogen. However, except for this deuterium problem, the 


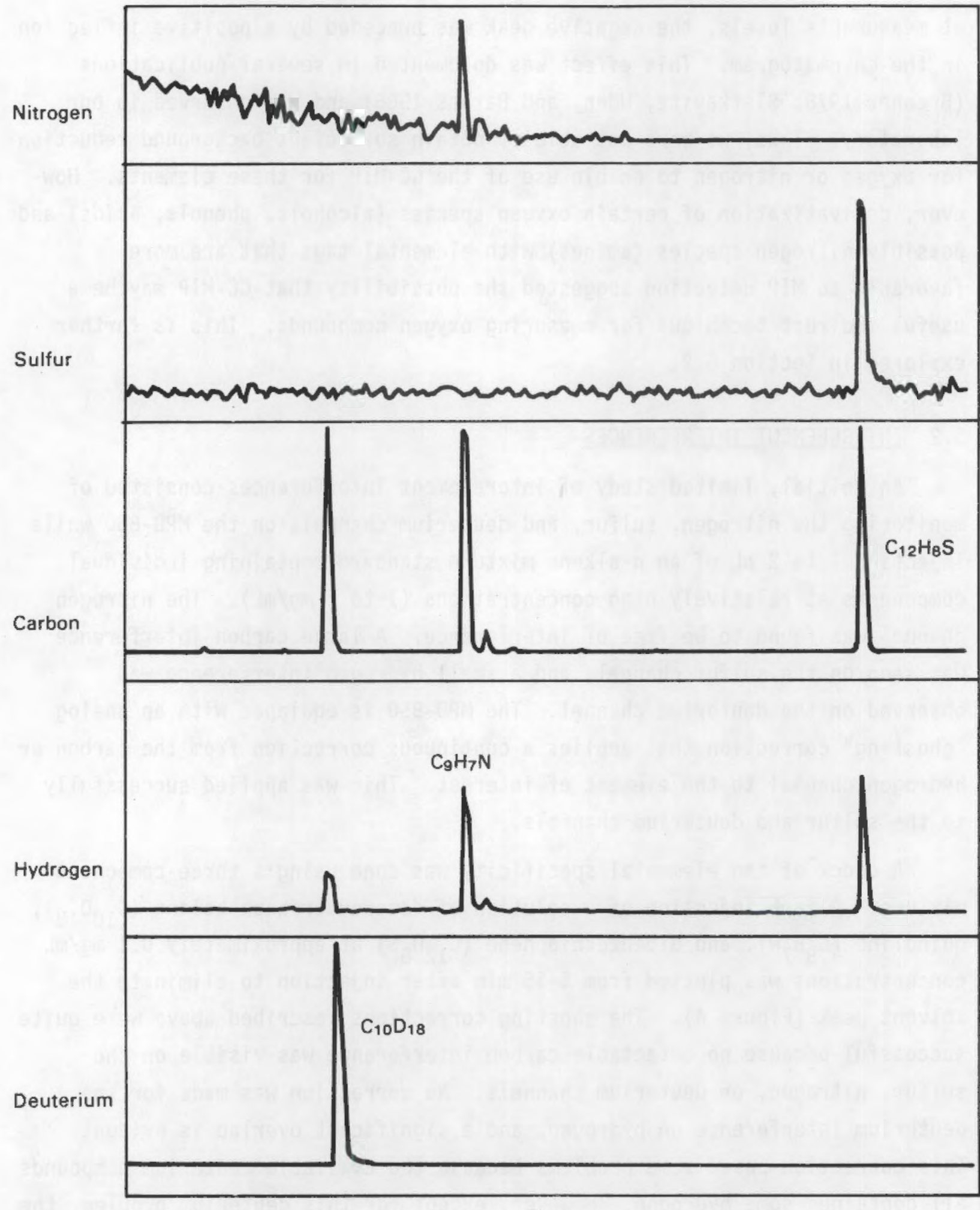

Time

FIGURE 4. Multichannel Capillary Column GC-MIP 
excellent elemental specificity attainable by this method was clearly demonstrated. The atmospheric-pressure Beenakker-echelle system was similarly evaluated with similar results.

\subsection{OPTIMIZATION OF LOW-PRESSURE BEENAKKER SOURCE}

Because this source configuration showed promise for providing the best overall characteristics for this program's needs, a major effort was undertaken to thoroughly characterize the optimum operational parameters of the source and to determine the corresponding expected physical limitations on empirical formulae determinations. This work was the subject of a paper by Evans, 01 sen, and Sklarew (1987) and is summarized here.

The characterization of the source included a determination of optimal settings for helium flow, scavenge gas flow, power level, and operating pressure. Elements monitored included $\mathrm{C}, \mathrm{H}, \mathrm{N}, \mathrm{S}, \mathrm{Cl}$, and He. Optimal parameters were chosen to minimize variation in elemental ratios resulting from instabilities in flow rates and power setting.

The first set of measurements were made by monitoring the $388.8-\mathrm{nm}$ helium line. The relative intensity of this line provided a measure of the excitation energy available in the plasma. Differing power levels had an effect on the helium line intensity (Figure 5). The plot was approximately linear with power up to about $40 \mathrm{~W}$, where it began to level out. Between 60 and $110 \mathrm{~W}$, the line intensity increased by only about $25 \%$ for a power increase of almost $100 \%$. Helium line intensity was found to be weakly dependent on flow rate, decreasing by about $50 \%$ in response to a factor of 10 increase in helium flow from 25 to $250 \mathrm{~mL} / \mathrm{min}$. By contrast, the helium line intensity was markedly affected by pressure, showing an approximately exponential falloff with increasing pressure approaching the normal operating range for Beenakker systems (i.e., atmospheric) (Figure 6). This appeared to confirm the belief that this low-pressure configuration should provide superior sensitivity for difficult-to-excite species such as nitrogen, sulfur, and oxygen. All subsequent work was done at a plasma pressure of 20 torr. 


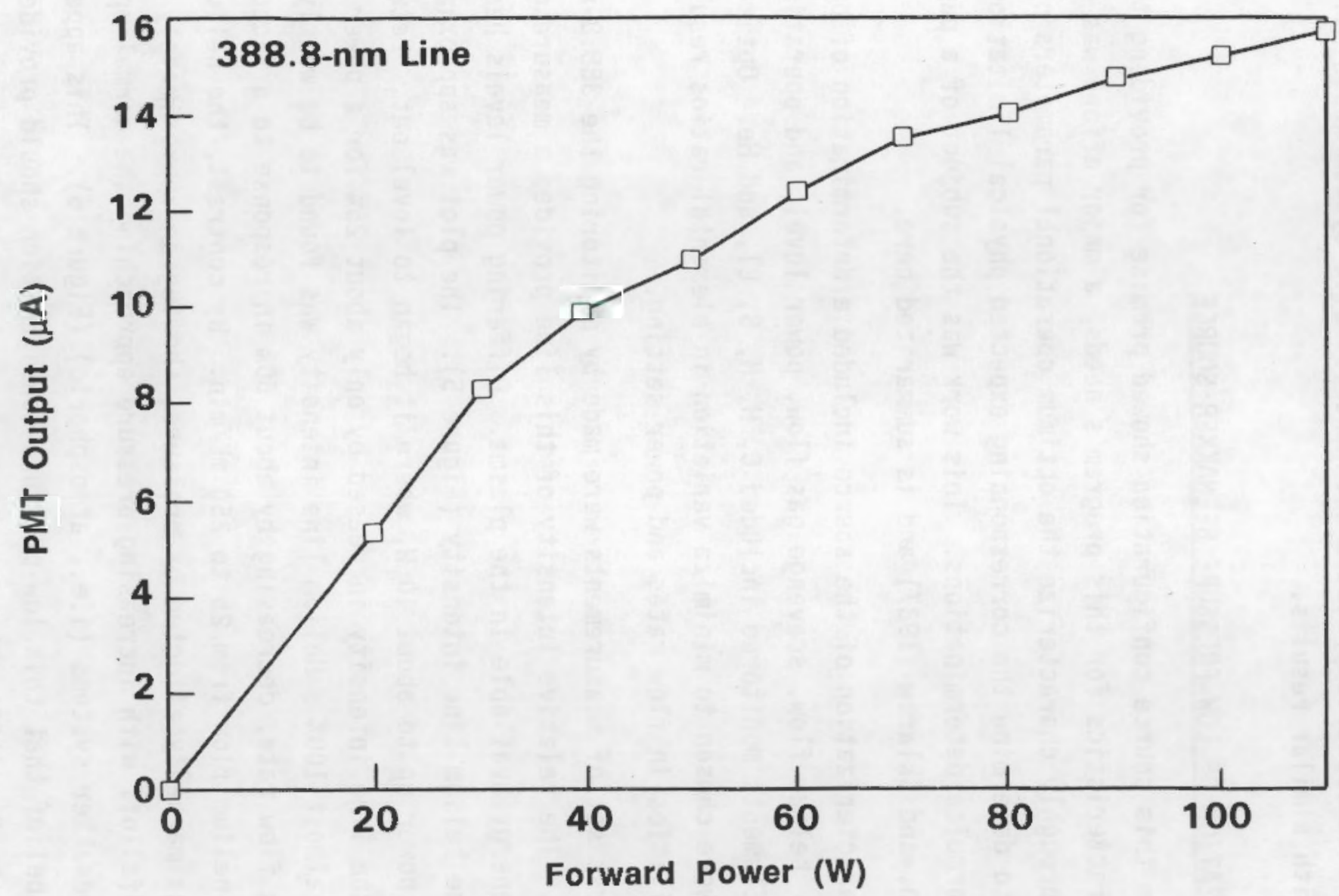

FIGURE 5. Helium Line Intensity Versus Forward Power Level: Low-Pressure Beenakker-Echelle 


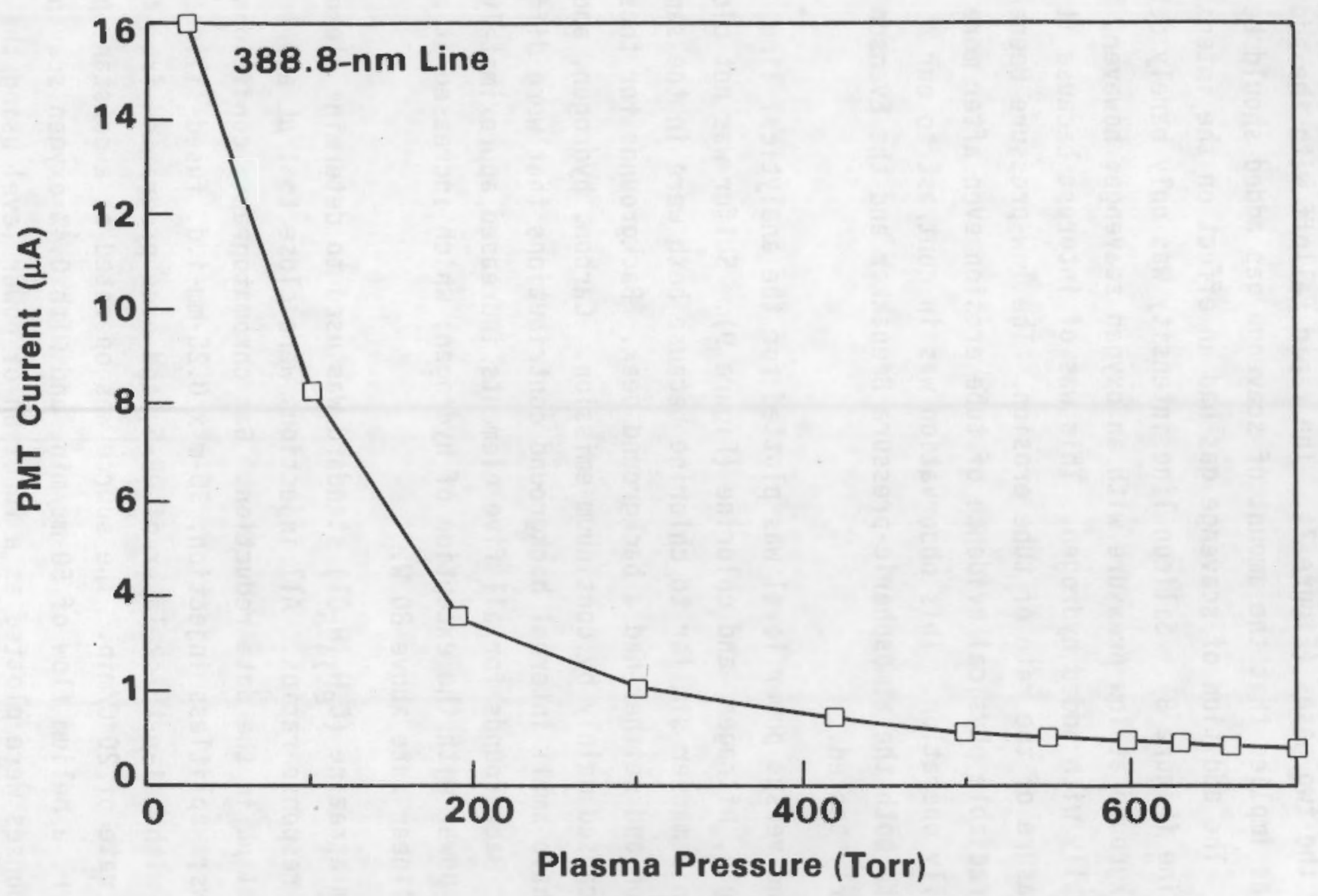

FIGURE 6. Helium Line Intensity Versus Pressure: LowPressure Beenakker-Echelle (75 W) 
In a plot of helium line intensity versus percentage of scavenge gas added to the carrier flow for both hydrogen and oxygen, very similar behavior was noted for the two gases (Figure 7 ). The rapid falloff with the addition of scavenge gas implied that the amount of scavenge gas added should be held to a minimum. The addition of scavenge gas had an effect on the intensity of the silicon line (Figure 8 ). Silicon line intensity was only barely detectable above background at low pressure with an oxygen scavenge; however, it did rise dramatically with added hydrogen. This was of interest because it provided a measure of the rate of tube erosion. The low-pressure Beenakker showed no appreciable physical evidence of tube erosion even after more than a month of daily operation. This observation was in contrast to our experience with both the atmospheric-pressure Beenakker and the Evenson sources formerly tested.

Background versus power level was plotted for the analytical lines of carbon, hydrogen, nitrogen, and chlorine (Figure 9). Sulfur was not plotted, but behaved in a manner similar to chlorine because both were in the same spectral region and neither had a background peak. Backgrounds for those regions were caused mainly by continuum emission. Carbon, hydrogen, and nitrogen did have small internal background contributions that were difficult to eliminate. Backgrounds for all five elements increased approximately linearly with power with the exception of hydrogen, which increased at a greater than linear rate above $80 \mathrm{~W}$.

A 400-ppm atrazine $\left(\mathrm{C}_{8} \mathrm{H}_{14} \mathrm{~N}_{5} \mathrm{Cl}\right)$ standard was used to determine elemental responses and response ratios. All injections were close to $1 \mu \mathrm{L}$ and were normalized to $1 \mu \mathrm{L}$ in the data reduction. Gas chromatography conditions were as follows: splitless injection, $30-\mathrm{m} \times 0.25-\mathrm{mm}-\mathrm{i} . \mathrm{d}$. fused-silica column coated with a $1-\mu$-thick layer of $\mathrm{DB}-5$, and oven programmed from $40^{\circ} \mathrm{C}$ to $300^{\circ} \mathrm{C}$ at a rate of $20^{\circ} \mathrm{C} / \mathrm{min}$. The source was operated at a constant pressure of 20 torr, a helium flow of $50 \mathrm{~mL} / \mathrm{min}$, and with $0.4 \%$ oxygen scavenge. Elemental responses were plotted as a function of power level using the areas computed by the Nelson system (Figure 10). The behavior was complex at low power with an approximately linear response above $40 \mathrm{~W}$, except for hydrogen, which showed a dip above $80 \mathrm{~W}$. The reason for the dip was unknown. This behavior was better illustrated in Figure 11, which plots the same data as 


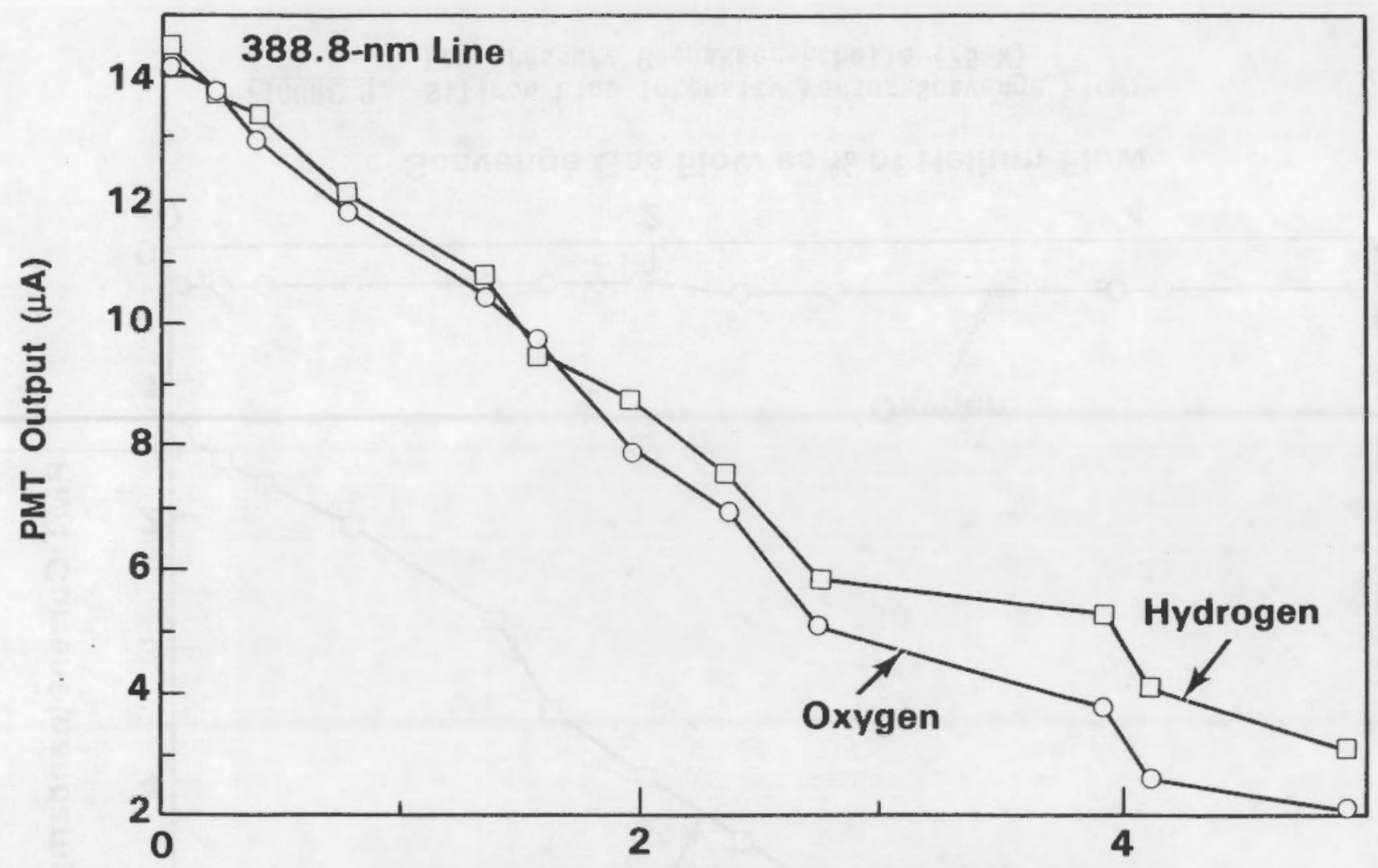

Scavenge Gas Flow as \% of Helium Flow

FIGURE 7. Helium Line Intensity Versus Scavenge Flow: Low-Pressure Beenakker-Echelle (75 W) 


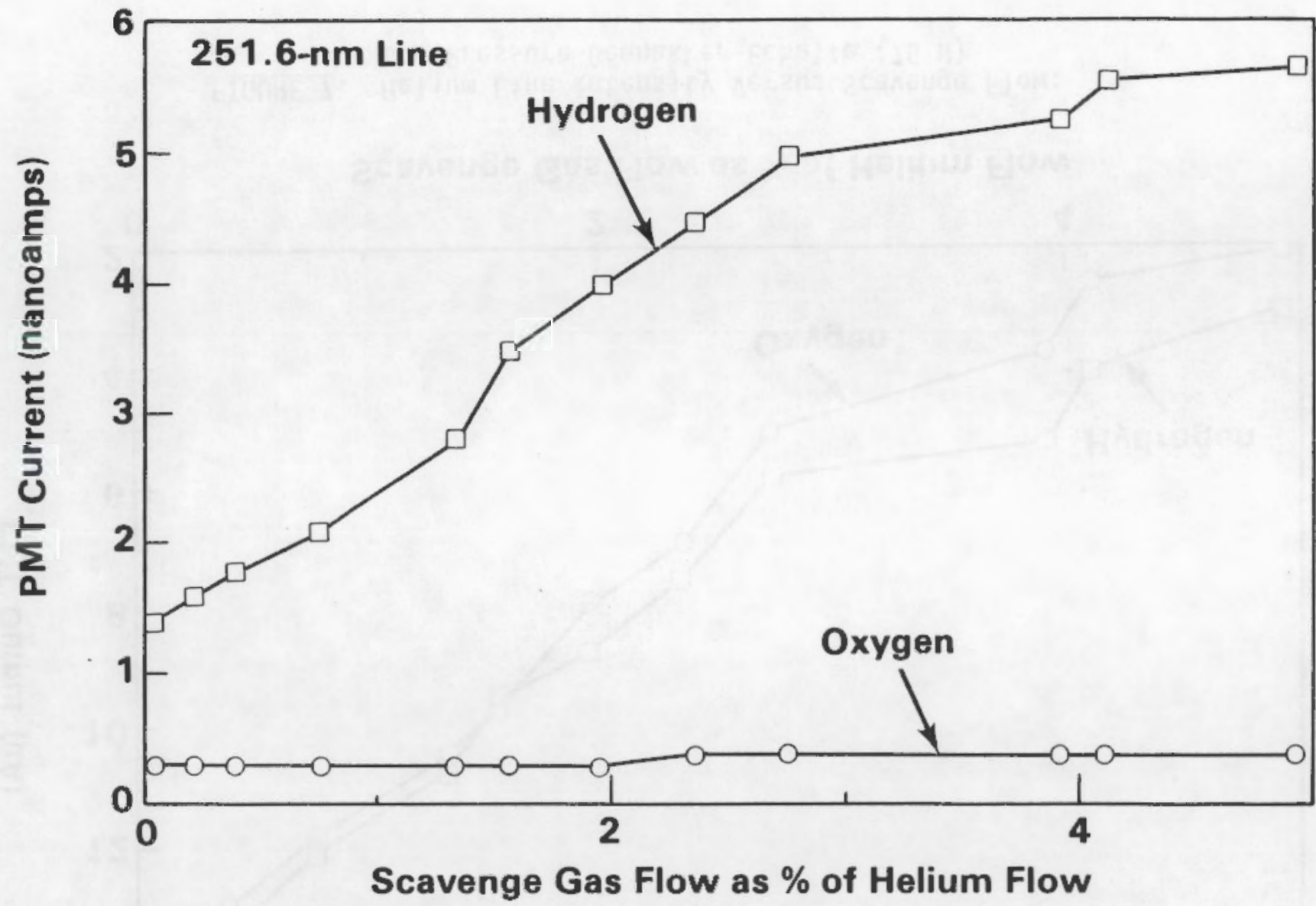

FIGURE 8. Silicon Line Intensity Versus Scavenge Flow: Low-Pressure Beenakker-Echelle (75 W) 


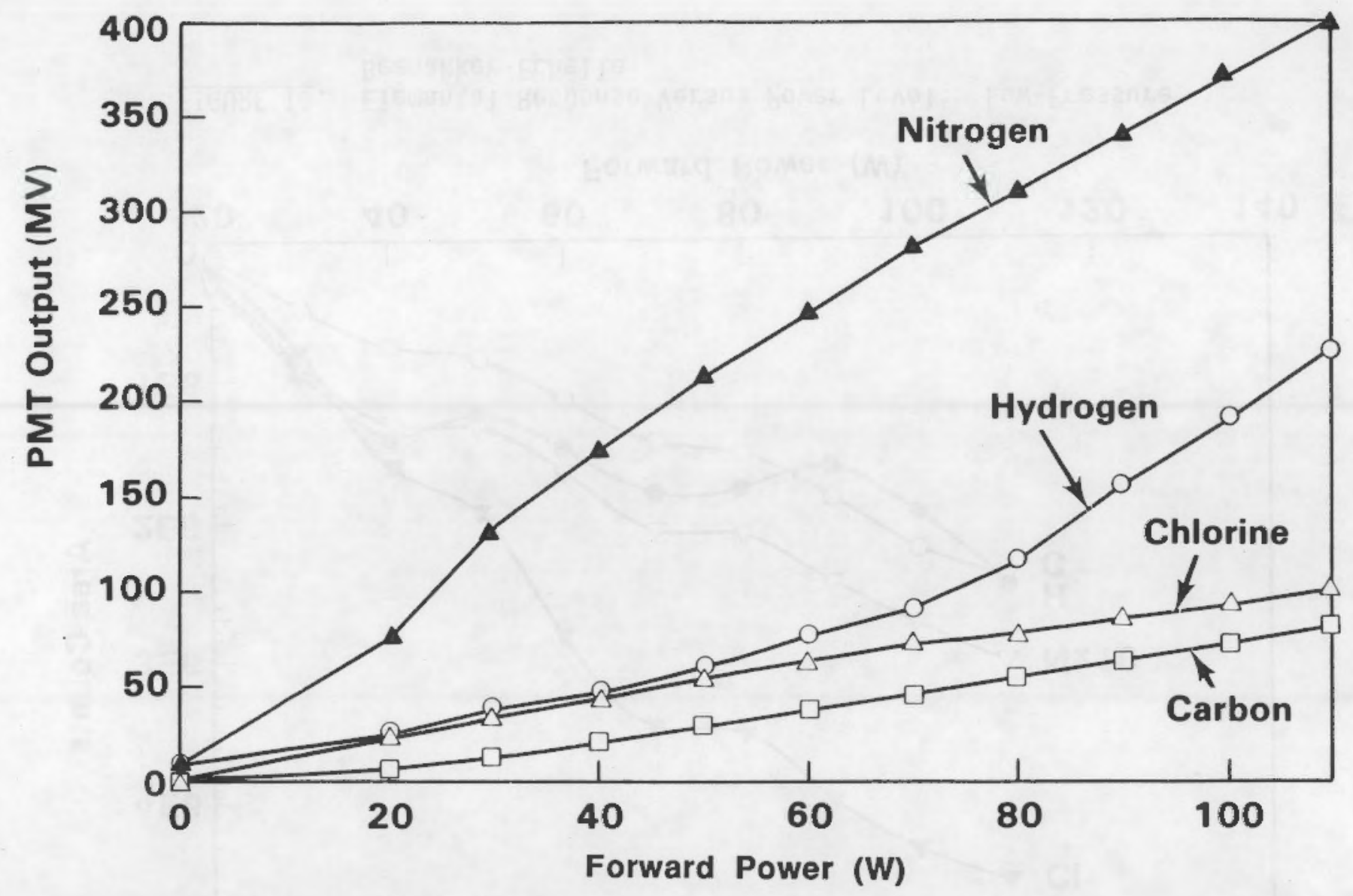

FIGURE 9. Background Versus Power Level: Low-Pressure Beenakker-Echelle 


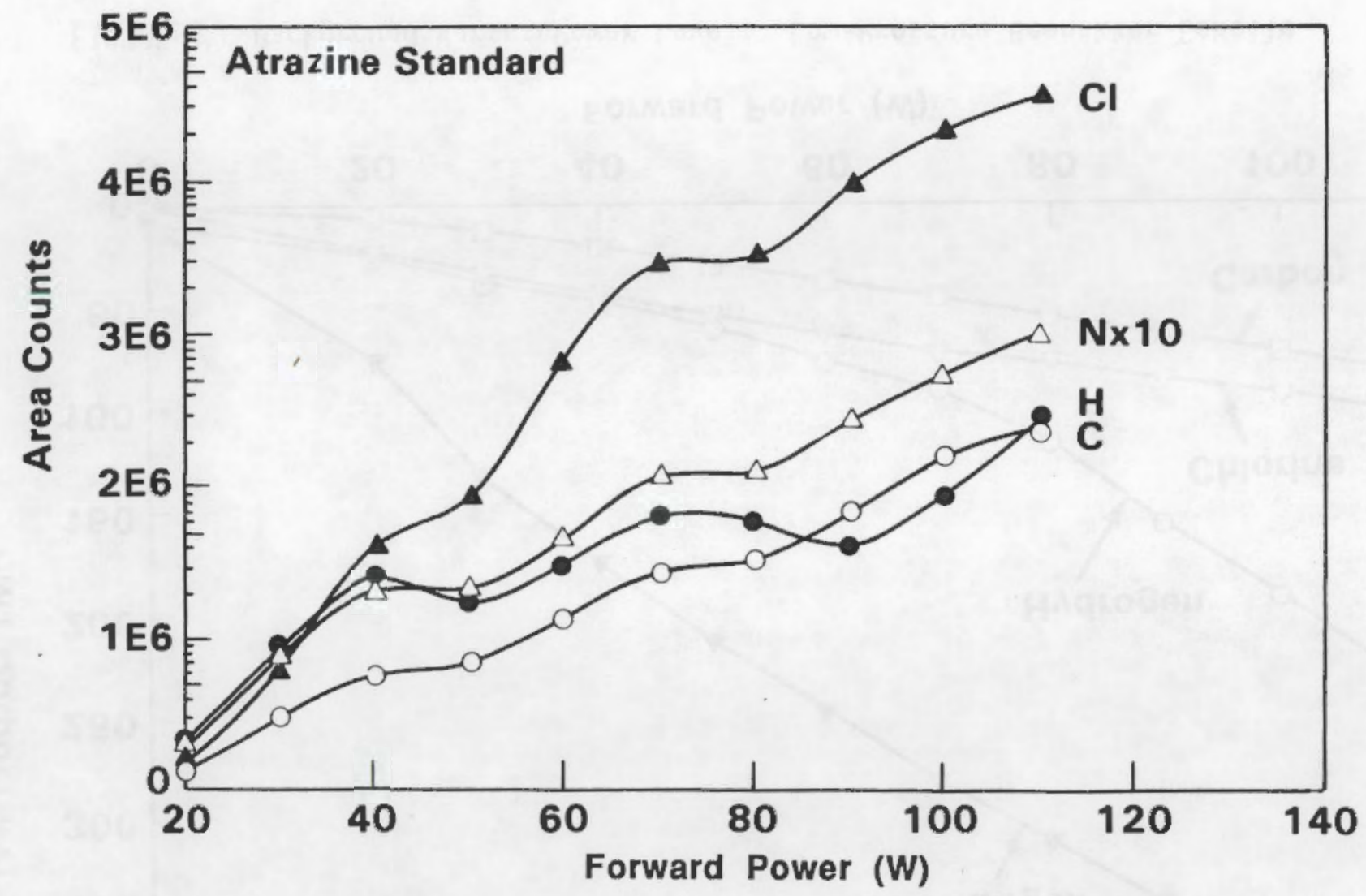

FIGURE 10. Elemental Response Versus Power Level: Low-Pressure Beenakker-Echelle 


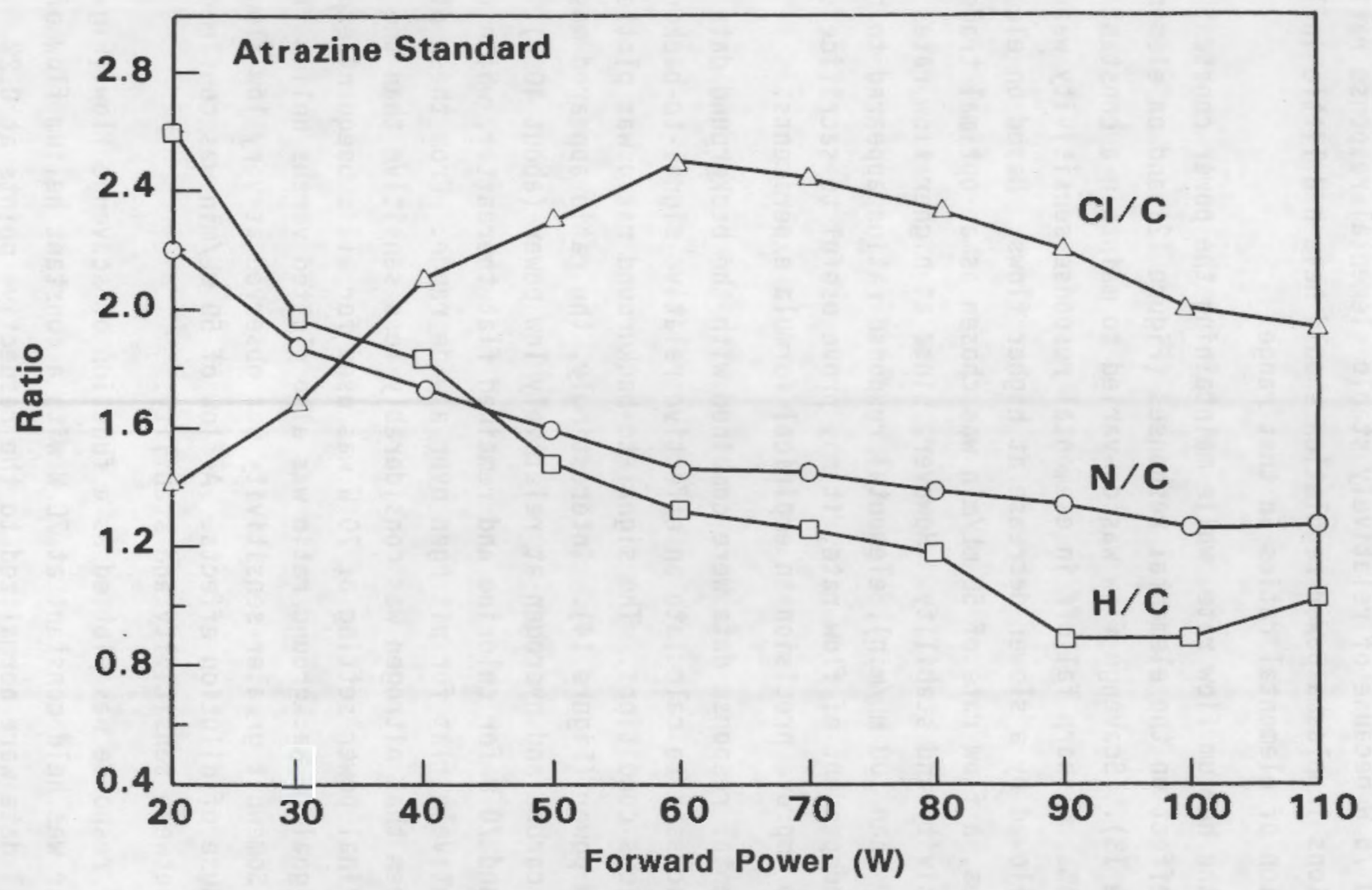

FIGURE 11. Elemental Response Ratio Versus Power Level: Low-Pressure Beenakker-Echelle 
elemental ratios with a sharp dip in the hydrogen to carbon ratio above $80 \mathrm{~W}$. From these data, it appeared that the most favorable operating power was between 60 and $75 \mathrm{~W}$ because of relatively stable elemental response ratios. Slight variations in plasma power regulation should have had little influence. on the precision of elemental ratios in that range.

Varying the helium flow rate, while maintaining the power constant at $75 \mathrm{~W}$, had an effect on the elemental responses (Figure 12) and on elemental ratios (Figure 13). Scavenge flow was co-varied to maintain a constant percentage of $0.4 \%$. A sharp falloff in elemental response sensitivity was seen initially, followed by a slower decrease at higher flows. Based on elemental response ratios, a flow rate of $50 \mathrm{~mL} / \mathrm{min}$ was chosen as an optimal tradeoff between sensitivity and stability. However, since at higher flow rates (i.e., greater than $100 \mathrm{~mL} / \mathrm{min}$ ), elemental response ratios appeared to be essentially independent of flow rate, it may prove useful to sacrifice some sensitivity to improve precision in empirical formula experiments.

The elemental response data were combined with the background data previously discussed to calculate an effective relative signal-to-background ratio for various conditions. The signal-to-background ratio was plotted versus forward power (Figure 14). Interestingly, the ratio appeared most favorable for carbon and hydrogen at relatively low power (about $40 \mathrm{~W}$ ). It peaked at around $70 \mathrm{~W}$ for chlorine and remained flat thereafter, while the ratio was relatively flat for nitrogen over a wide range. From these plots it could be seen that nitrogen was considerably less sensitive than the other elements. A final power setting of $70 \mathrm{~W}$ was used for all subsequent experiments. The signal-to-background ratio was also plotted versus helium flow (Figure 15). Somewhat greater sensitivity was observed at very low flows, as expected, because of dilution effects. A flow of $50 \mathrm{~mL} / \mathrm{min}$ was confirmed as a compromise between sensitivity and stability.

Elemental response was plotted as a function of scavenge flow (Figure 16). Power was held constant at $70 \mathrm{~W}$ with a constant helium flow of $50 \mathrm{~mL} / \mathrm{min}$. All data were normalized to the respective points at $0.2 \%$. Sulfur and nitrogen sensitivities showed little effect; the chlorine response showed considerable sensitivity to scavenge flow rate with a decreased 


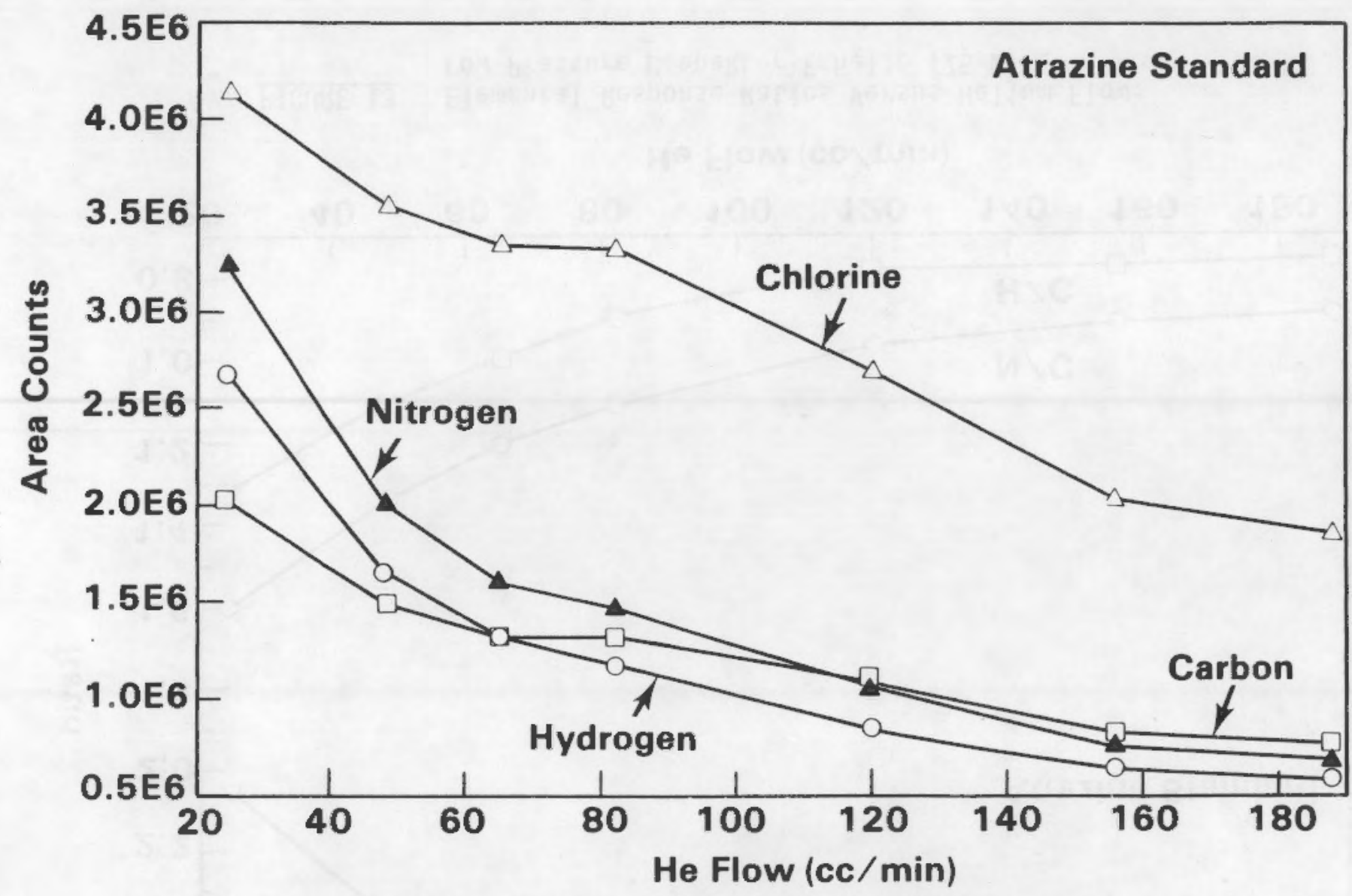

FIGURE 12. Elemental Response Versus Helium Flow:

Low-Pressure Beenakker-Echelle (75 W) 


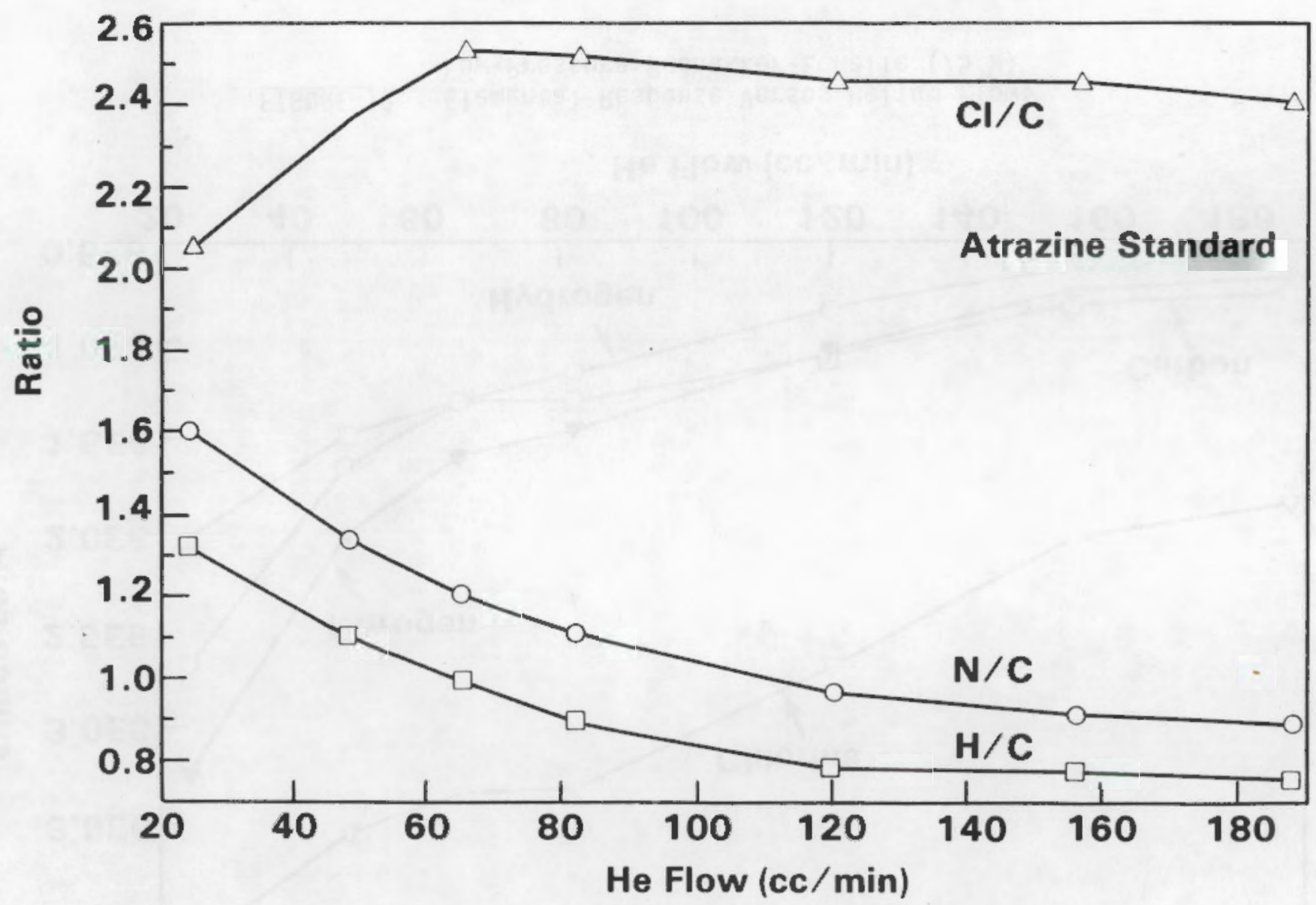

FIGURE 13. Elemental Response Ratios Versus Helium Flow: Low-Pressure Beenakker-Echelle (75 W) 


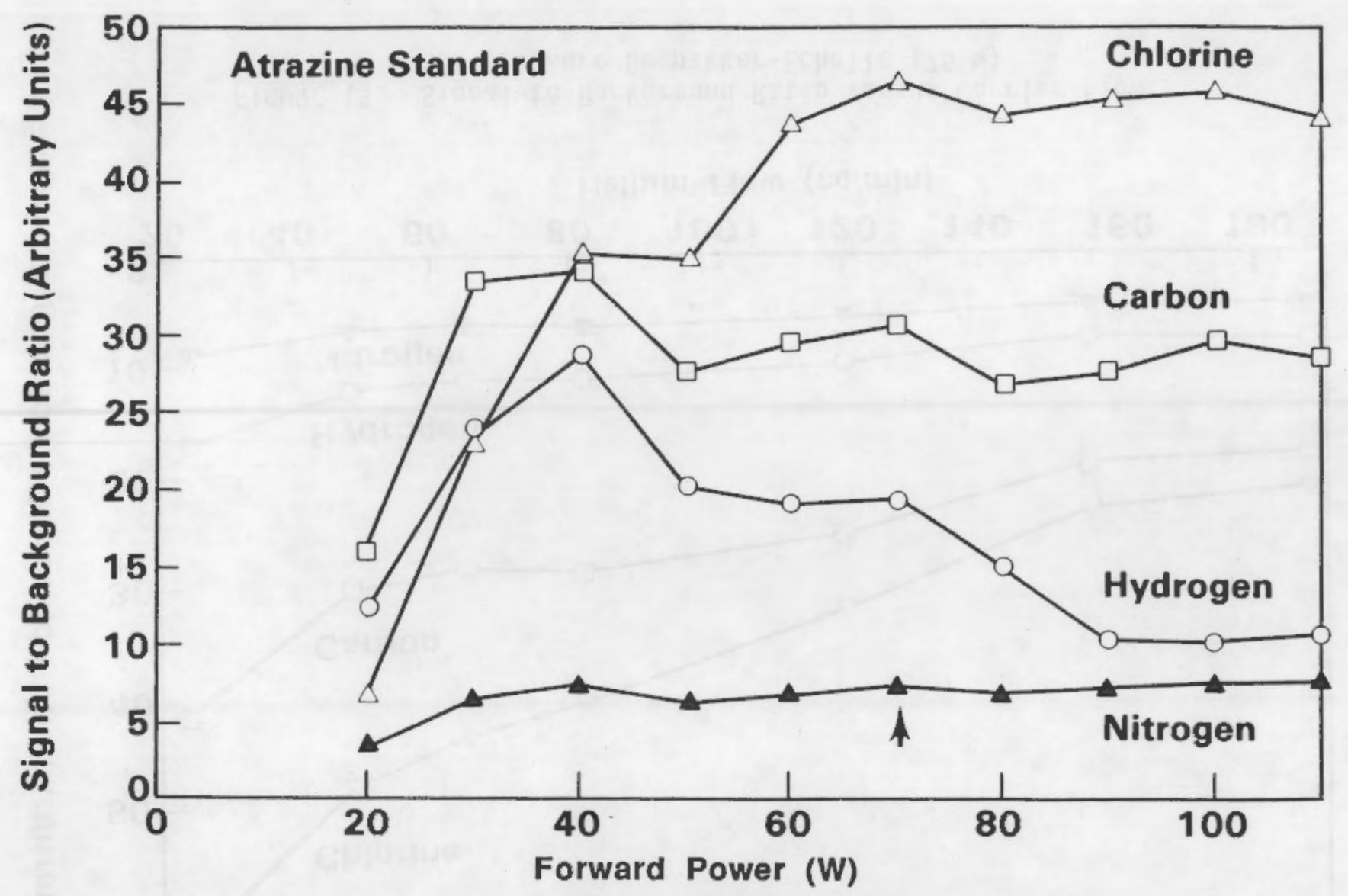

FIGURE 14. Signal-to-Background Ratio Versus Plasma Power: Low-Pressure Beenakker-Echelle 


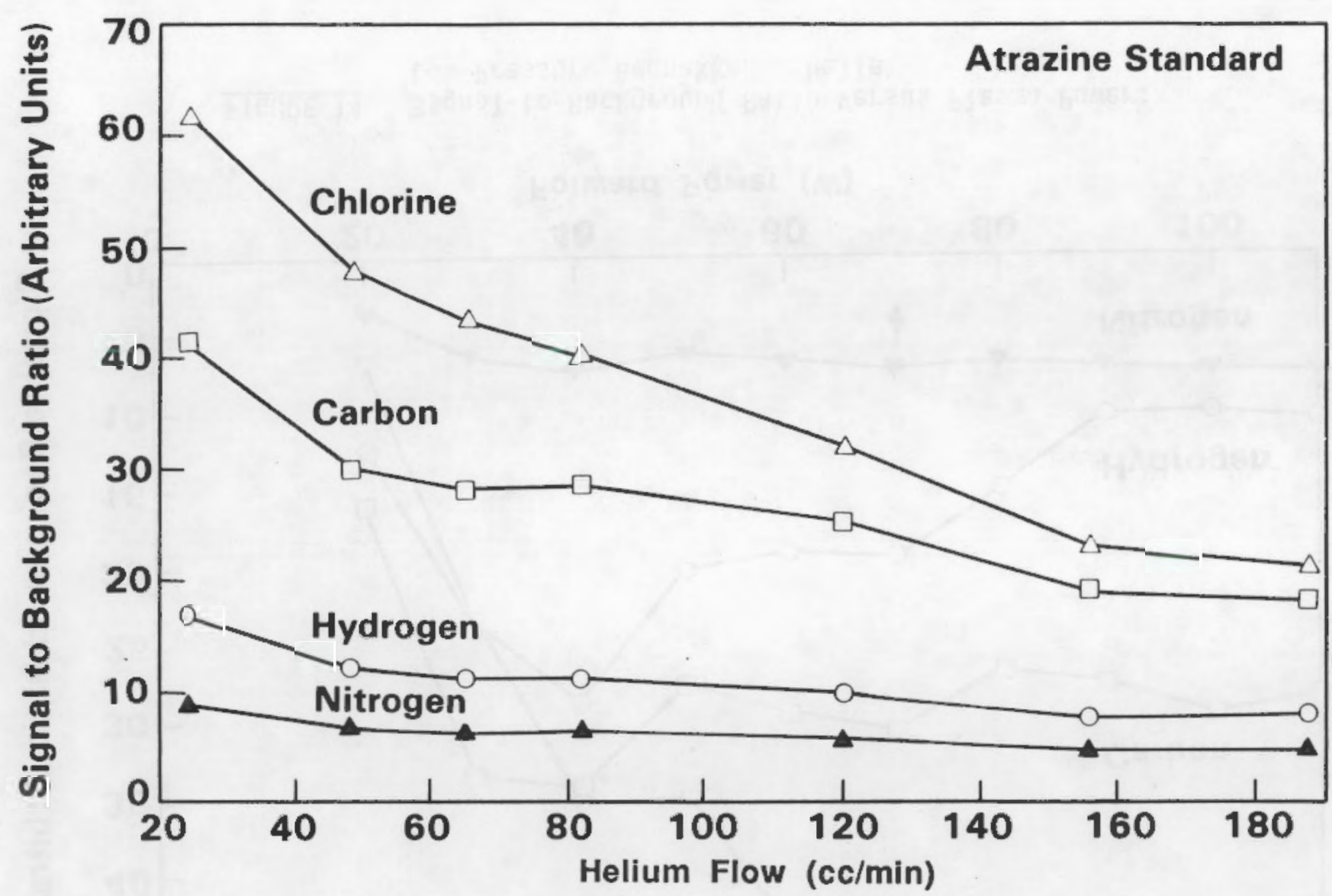

FIGURE 15. Signal-to-Background Ratio Versus Carrier Flow: Low-Pressure Beenakker-Echelle (75 W) 


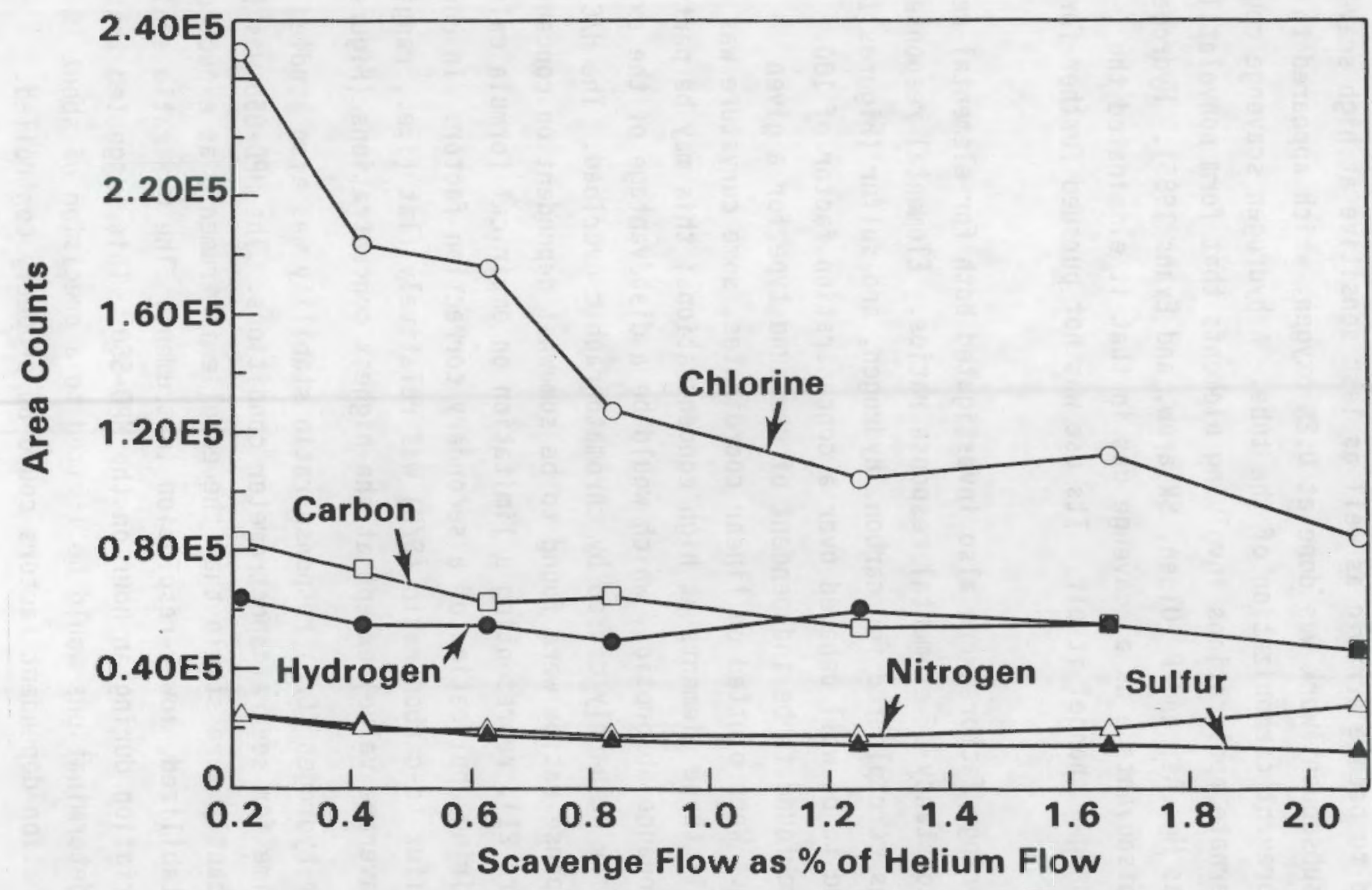

FIGURE 16. Elemental Response Versus Scavenge Flow: Low-Pressure Beenakker-Echelle (70 W) 
response at increased flow rate. Elemental response ratios were plotted as a function of scavenge flow (Figure 17$)$. The hydrogen-to-carbon $(\mathrm{H} / \mathrm{C})$ ratio data appeared to become erratic as well as less sensitive at high scavenge flows. All subsequent work was done at $0.2 \%$ oxygen, which appeared to be adequate to prevent carbonization of the tube. A hydrogen scavenge could be used for alternate applications involving elements that form nonvolatile oxides such as $\mathrm{Hg}, \mathrm{As}$, and $\mathrm{P}$ (01 sen, Sklarew, and Evans 1985). Hydrogen had the obvious disadvantage as a scavenge gas in that it eliminated the important hydrogen channel itself. Its use was not pursued further for this project.

Dynamic range factors were also investigated both for elemental response factors and constancy of elemental response ratios. Elemental response calibration curves were plotted for carbon, hydrogen, and sulfur (Figures 18-20) and were found to be well behaved over a concentration factor of 100 . Responses were found to be independent of compound type for a given concentration. When plotted on linear coordinates, some curvature was evident for all three elements at high concentrations; this may be partly a result of resonance absorption, which would be a disadvantage of the axial geometry, or may be partly caused by chromatographic overload. The H/C elemental response ratios were found to be somewhat dependent on concentration (Figure 21), representing a limitation on empirical formula calculation and requiring application of a secondary correction factor. In contrast, the sulfur-to-carbon ratio $(\mathrm{S} / \mathrm{C})$ was relatively flat (i.e., ranging $\pm 6 \%$ from the average value) except at the highest concentrations (Figure 22).

Carbon-to-hydrogen $(\mathrm{C} / \mathrm{H})$ response ratio stability was also studied as a function of time for several spectrometer conditions. The MPD-850 was found to be significantly more stable than the echelle instrument, as expected for a thermally stabilized, lower-resolution instrument. The $\mathrm{C} / \mathrm{H}$ ratio exhibited a $0.6 \%$ RMS variation during an hour on the MPD-850. This suggested that elemental ratio determinations would be limited to a precision of about $1 \%$ if other concentration-dependent factors could be properly controlled. 


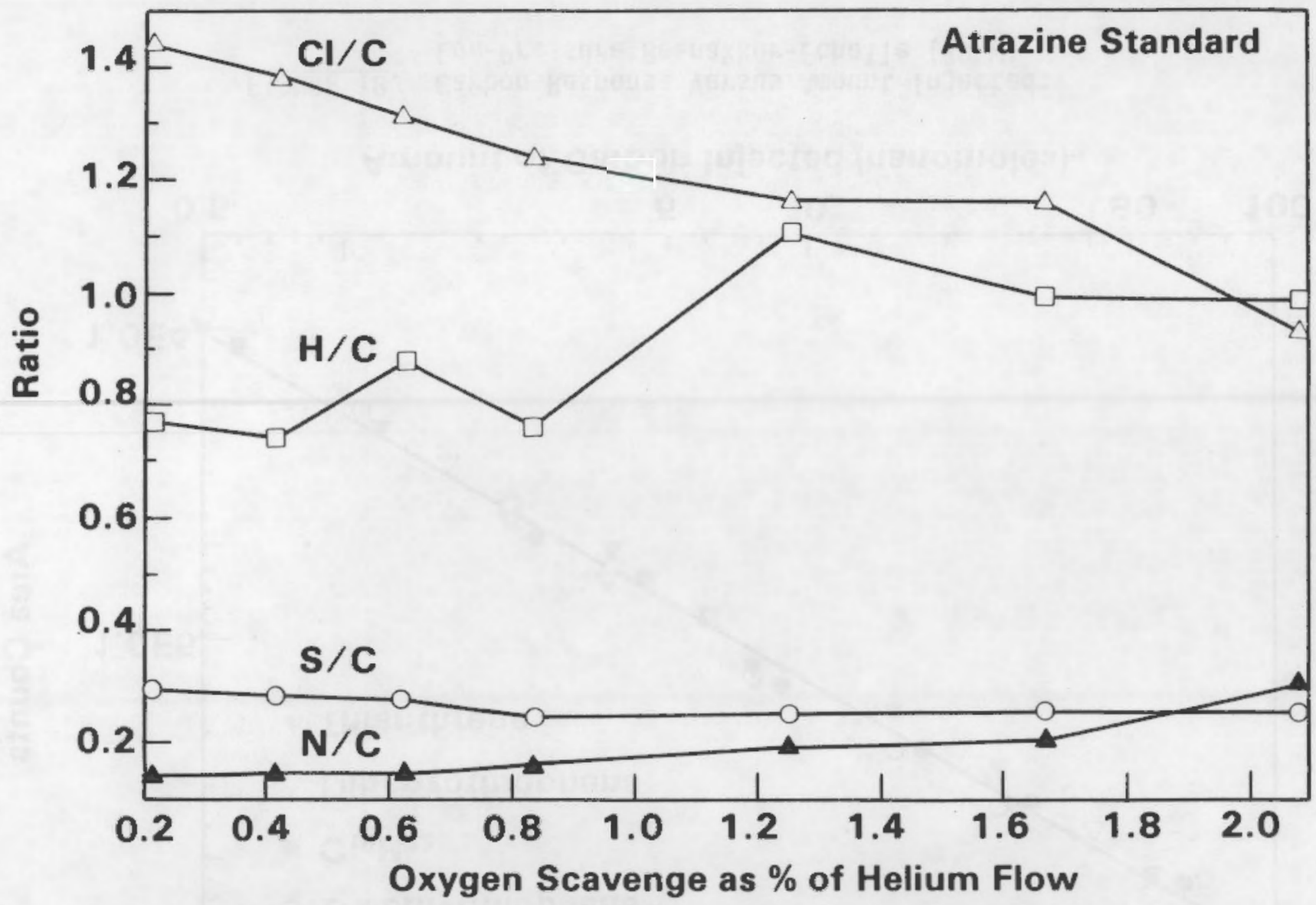

FIGURE 17. Elemental Response Ratios Versus Scavenge Flow: Low-Pressure Beenakker-Echelle (70 W) 


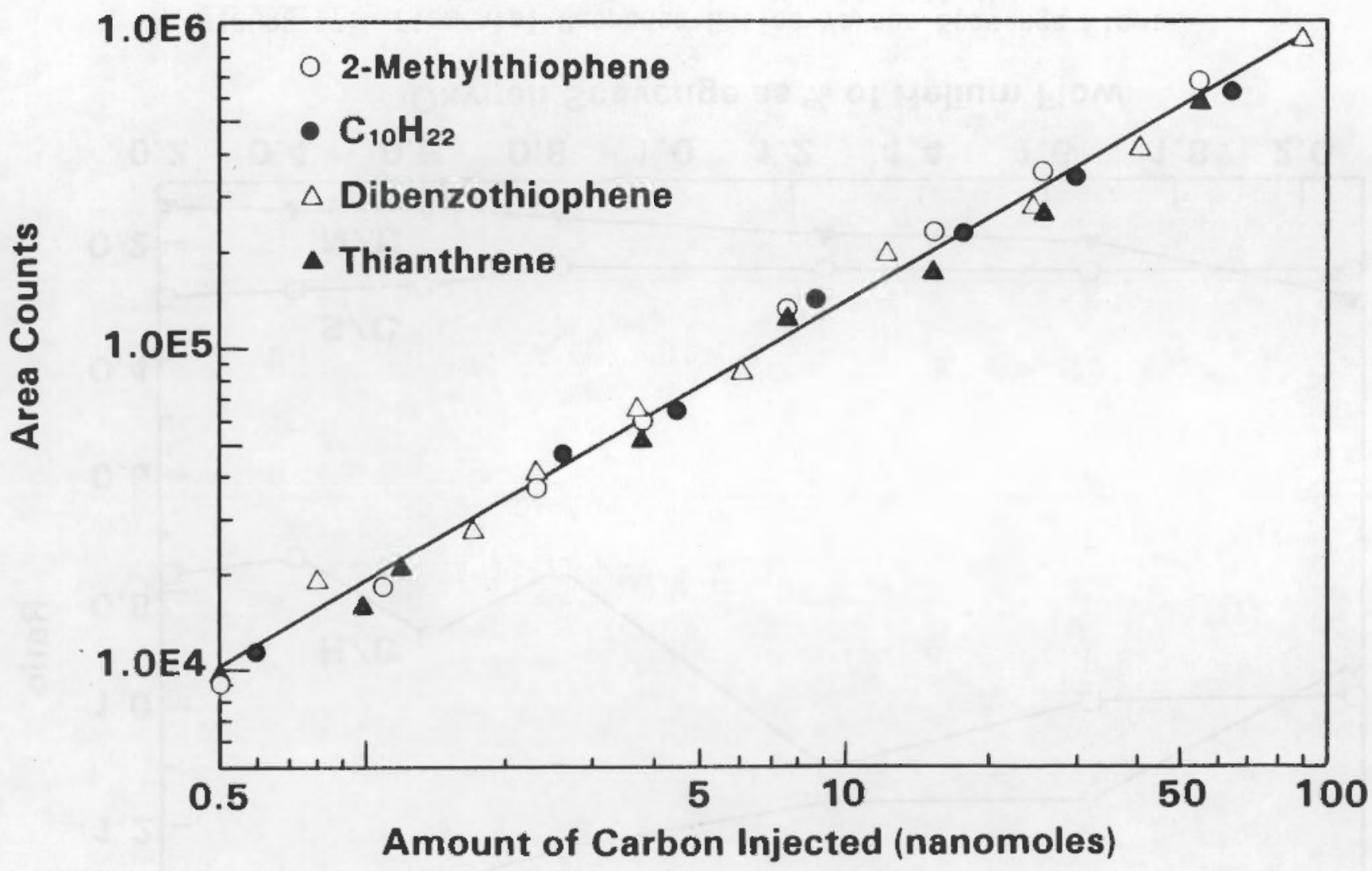

FIGURE 18. Carbon Response Versus Amount Injected: Low-Pressure Beenakker-Echelle (70 W) 


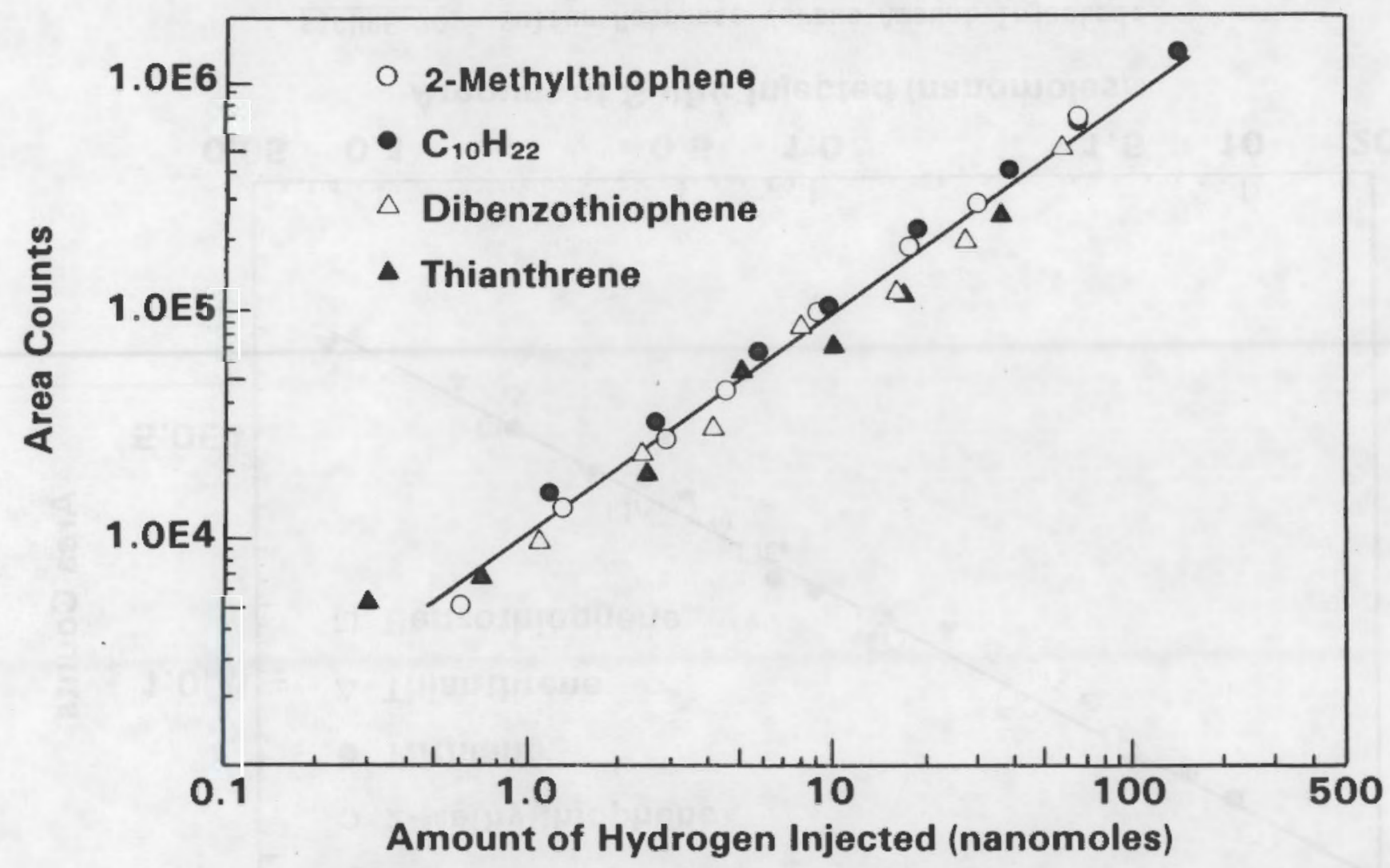

FIGURE 19. Hydrogen Response Versus Amount Injected: Low-Pressure Beenakker-Echelle (70 W) 


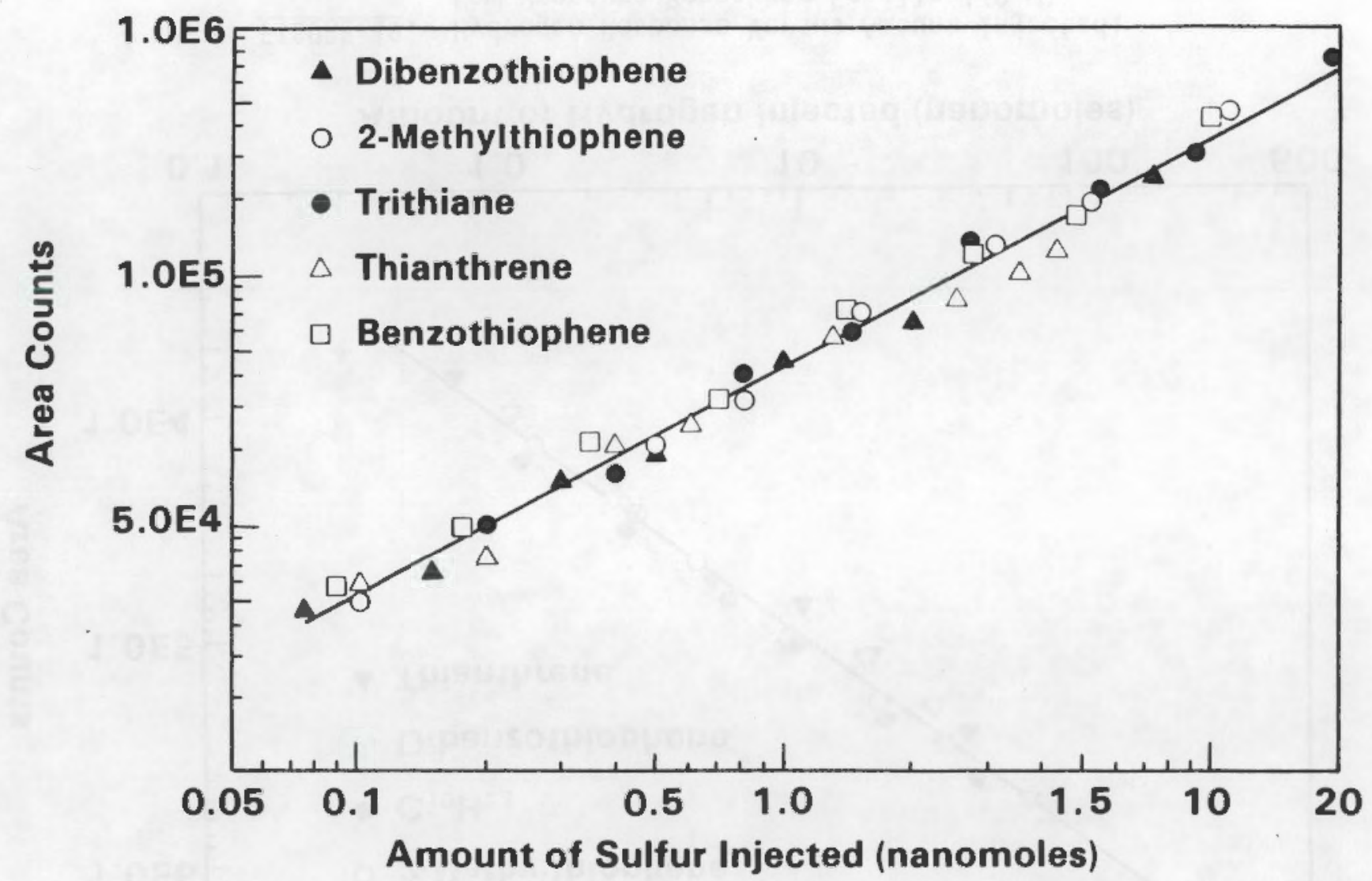

FIGURE 20. Sulfur Response Versus Amount Injected: Low-Pressure Beenakker-Echelle (70 W) 


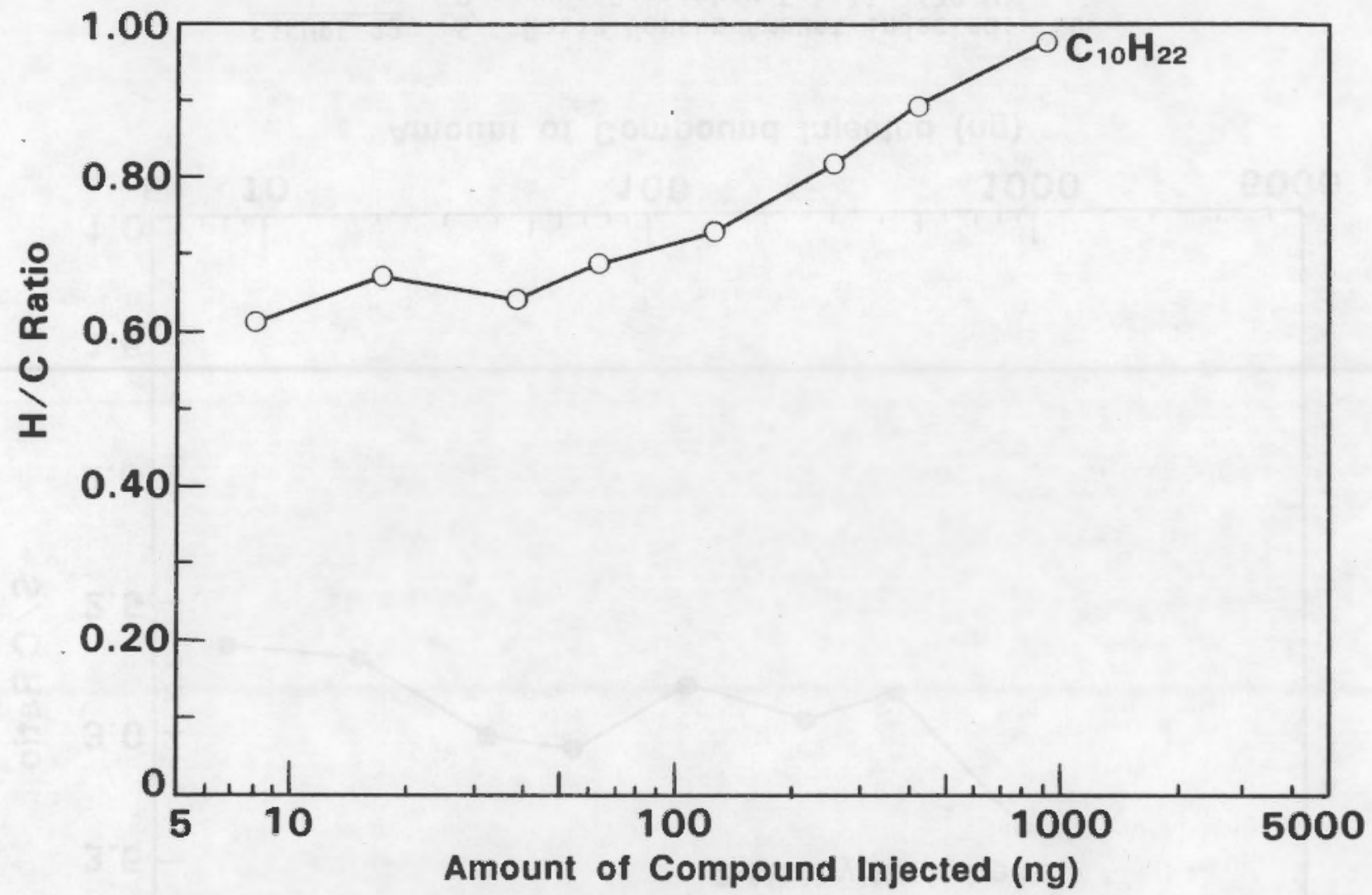

FIGURE 21. H/C Ratio Versus Amount Injected: Low-Pressure Beenakker-Echelle (70 W) 


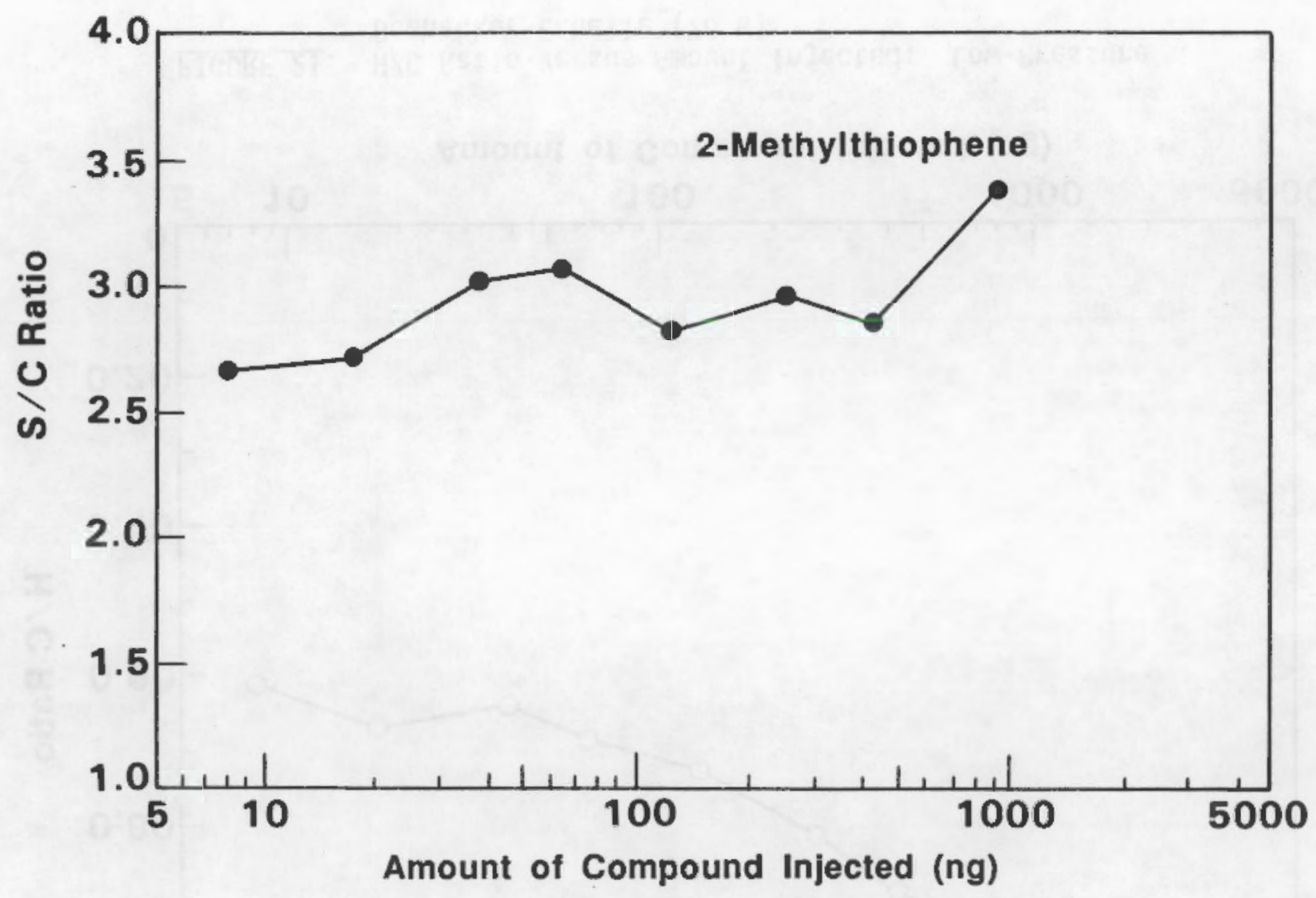

FIGURE 22. S/C Ratio Versus Amount Injected: LowPressure Beenakker-Echelle (70 W) 


\subsection{EMPIRICAL FORMULA DETERMINATION FOR SIMPLE MIXTURES}

\subsection{SOURCES OF UNCERTAINTY}

Sources of uncertainty in elemental ratios include plasma stability, compound class, multiple injections, spectral interelement interferences, molecular weight, analyte quantity, signal-to-noise ratio, and chromatogram integration accuracy, including chromatographic performance in complex mixtures. The experiments conducted above indicated that some of these effects may be of minimal concern. For example, plasma stability appeared to have little effect on elemental response ratios, provided the instrument was set up and maintained in a steady-state condition with respect to gas flow rate and power level. No significant dependence on compound class was evident although this was not fully investigated. Accuracy of injection should not have affected elemental response factor ratios; the data was normalized to carbon to eliminate this uncertainty. Spectral interelement corrections (ghosting) appeared to be controllable either by using a high-resolution spectrometer (echelle) and/or through an analog correction (available on the MPD 850 and echelle systems). In the relatively limited molecular weight range studied, elemental response ratios appeared to be independent of molecular weight. However, at higher molecular weights (i.e., carbon number greater than 30), compounds may be incompletely disassociated by the plasma. It was shown in Section 3.3 that the quantity of analyte entering the plasma could affect the elemental response ratios for carbon, hydrogen, and sulfur thus requiring a correction factor. The largest single factor affecting empirical formula accuracy was integration accuracy under a wide variety of conditions. Several factors were involved, including analog-to-digital conversion sampling rate, signal-to-noise ratio, and chromatographic resolution. A major effort was devoted to quantifying these effects (see Sections 4.2 and 4.3 ).

The experiments conducted above (see Section 3.3) as well as previous literature references (see Section 1.0) suggested that empirical formula calculations should be feasible at least for simple mixtures at relatively high concentrations, provided some simple calibration and correction factors 
were considered. Initial empirical formula studies in this program used simple hydrocarbon mixtures. Further studies extended the work to include simple mixtures of sulfur- and nitrogen-containing compounds. In Section 5.1, extension of empirical formula calculations to complex mixtures will be discussed.

\subsection{SIMPLE HYDROCARBON MIXTURES USING THE MPD-850 WITH EVENSON SOURCE}

Initial empirical formula studies were conducted on mixtures of alkane, alkene, and aromatic hydrocarbons (A17tech Associates, Deerfield, IL; Chem Service, West Chester, PA) and employed the Evenson 1/4-wave cavity on the MPD-850 system. The instrumental conditions used are given in Table 3 . Stock solutions of $1 \mathrm{mg} / \mathrm{mL}$ were prepared in chloroform and diluted serially to factors of 10 and 100 . Alkane mixtures contained normal alkanes at carbon numbers $10,14,18,22,26,30$, and 36 , with the $C_{22}$ compound included at double the concentration to act as a marker. Alkene mixtures contained normal 1-al kenes at carbon numbers $10,12,14,16,18$, and 20 , with the $C_{16}$ compound at double concentration. The three aromatic compounds used-naphthalene, anthracene, and $n$-hexyl-benzene--were prepared as separate, single-compound solutions.

The $\mathrm{C} / \mathrm{H}$ ratios were plotted for the most dilute alkane mixture as a function of carbon number (Figure 23). The ratios were corrected for the known number of carbon and hydrogen atoms per molecule in each compound. The ratio plotted was thus the true relative response for carbon versus hydrogen. Expressed in this way, it was possible to intercompare different compound types in a common fashion. The line on the plot was the average of all measurements for three runs during a 3-day period. The precision of the ratio measurement was from 3 to $5 \%$ and appeared to be limited primarily by integration accuracy with no trend with carbon number or time evident.

Similar plots were made for tenfold and hundredfold higher concentrations (Figures 24 and 25). There was considerably greater precision in the $\mathrm{C} / \mathrm{H}$ response ratios than was found in the most dilute mixture because of the significantly improved signal-to-noise ratio. The overall average $\mathrm{C} / \mathrm{H}$ response was, however, reduced by about $20 \%$ at the intermediate 
TABLE 3. GC and Plasma Detector Conditions

A. Gas Chromatography

Instrument:

Hewlett-Packard $5880 \mathrm{~A}$

Column:

$30-m \times 0.25-m m-i . d$. fused-silica capillary column coated with DB-5 (1 $\mu \mathrm{m}$ film thickness)

Temperature program: $\quad$ Initial Temperature $=40^{\circ} \mathrm{C}$

Initial Hold $=1 \mathrm{~min}$

Program Rate $=20^{\circ} \mathrm{C} / \mathrm{min}$

Final Temperature $=300^{\circ} \mathrm{C}$

Final Hold $=6-30 \mathrm{~min}$

Injector temperature: $250^{\circ} \mathrm{C}$

Injection:

Splitless mode, $1 \mu$, 1.0-min purge time

Carrier gas:

Helium

B. Helium Plasma Detector

Instrument:

Applied Chromatography Systems MPD-850

Cavity:

Evenson 1/4-wave

Plasma pressure:

2.5 torr

Forward power:

$80 \mathrm{~W}$

Reflected power:

$0.15 \mathrm{~W}$

Scavenge gas:

Oxygen $(0.2 \%)$

Analytical lines:

Carbon, $247.8 \mathrm{~nm}$ (2nd order) Hydrogen, $486.1 \mathrm{~nm}$

concentration and further suppressed by an additional $30 \%$ for $C_{10}$ to $C_{22}$ at the highest concentration compared to the low-concentration $\mathrm{C} / \mathrm{H}$ response. This effect appeared to be caused by perturbation of the excitation properties of the plasma by the analyte, with a somewhat greater effect on carbon relative to hydrogen. The $C_{26}$ and $C_{30}$ peaks did not show the same suppression at the highest concentration, possibly because the concentration of the analyte in the plasma at any given time decreased because of peak broadening. 


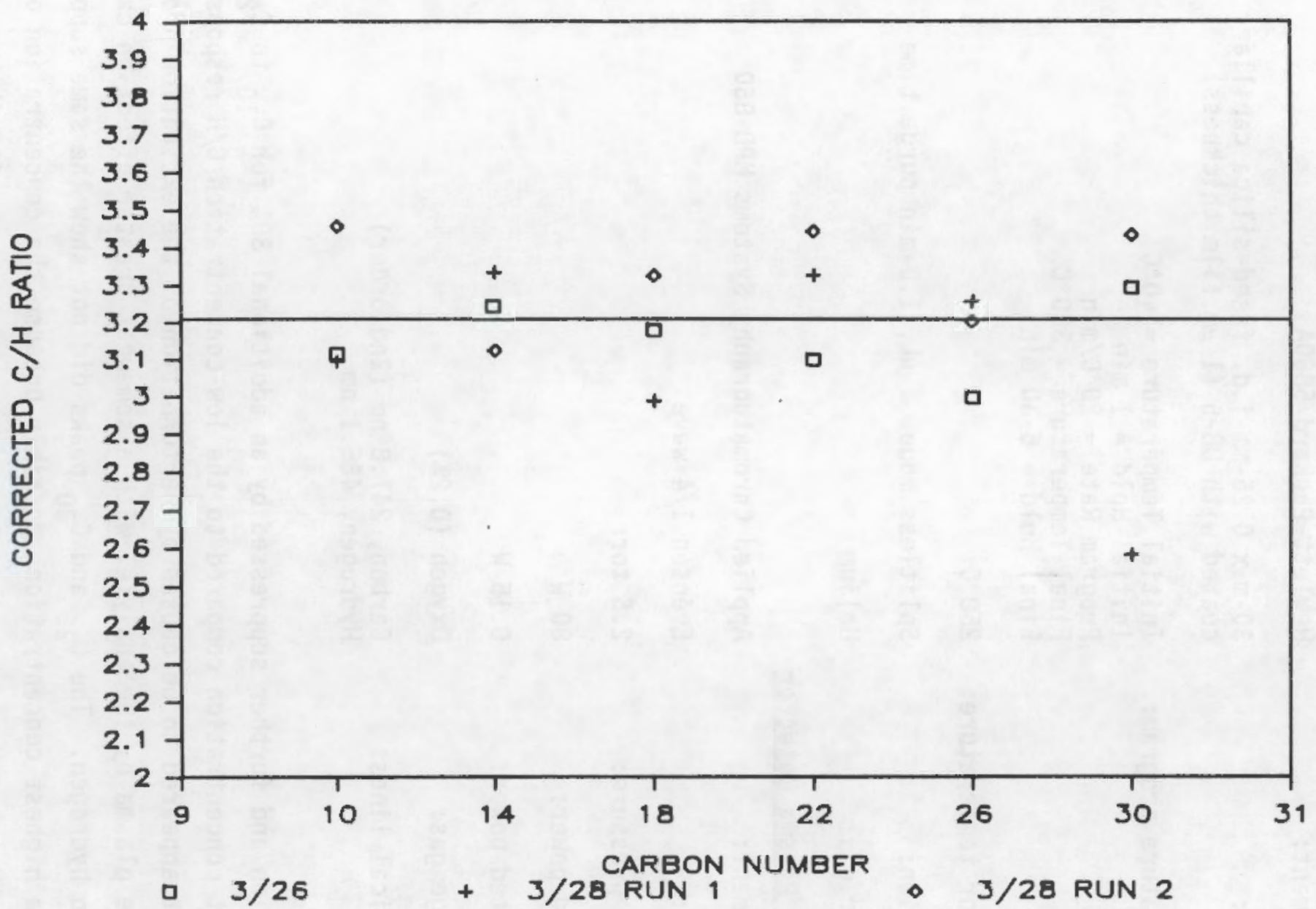

FIGURE 23. C/H Response Ratio of $\mathrm{n}-\mathrm{Alk}$ anes at $0.01-0.02 \mathrm{mg} / \mathrm{mL}$. Concentration: Evenson-MPD 850 


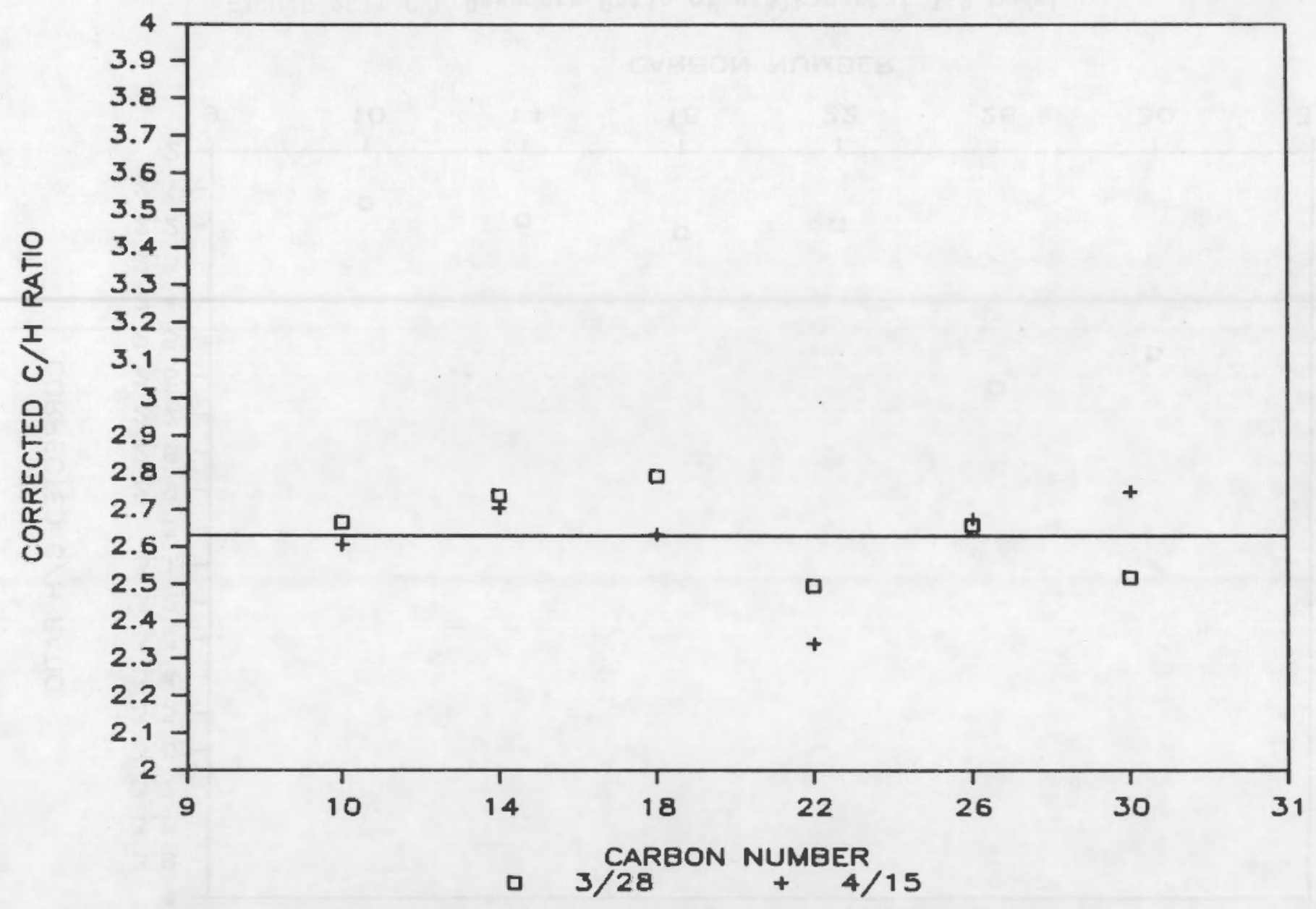

FIGURE 24. C/H Response Ratio of n-Alkanes at $0.1-0.2 \mathrm{mg} / \mathrm{mL}$ Concentration: Evenson-MPD 850 


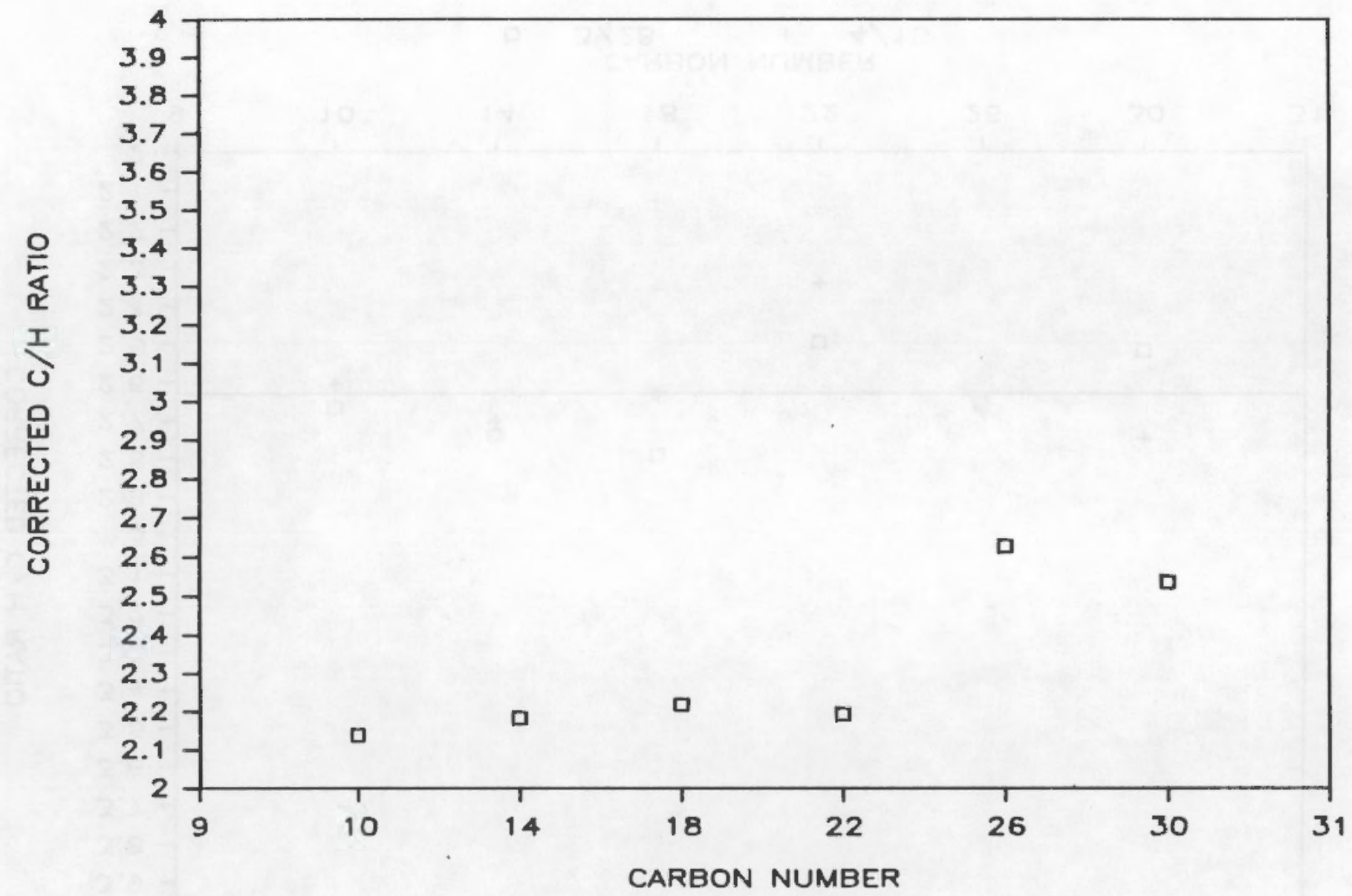

FIGURE 25. C/H Response Ratio of n-Alkanes at $1-2 \mathrm{mg} / \mathrm{mL}$ Concentration: Evenson-MPD 850 
These observations could be explained in terms of known plasma properties, but it was clear that such effects must be considered to obtain accurate element ratios on unknown compounds.

The effect of analyte concentration on the corrected $\mathrm{C} / \mathrm{H}$ ratio was further illustrated in Figure 26, which summarized the results for all of the measurements on a common scale plotted versus nanograms of carbon injected. All three compound classes were included, because compound class did not appear to have any discernible effect on the corrected ratio for comparable concentrations. This was shown as a $\log$ plot because it was a slowly changing effect.

The $\mathrm{C} / \mathrm{H}$ ratio was plotted versus carbon number for the combined alkane, alkene, and aromatic data at a common concentration $(0.1 \mathrm{mg} / \mathrm{mL}$ ) (Figure 27$)$. This plot showed little spread (less than $5 \%$ ) considering that these data were pooled from five different runs carried out on different days for three compound $\mathrm{classes}$ differing in true $\mathrm{C} / \mathrm{H}$ ratio by up to a factor of three. The same runs were also used to calculate absolute detector response per nanogram of carbon injected (Figure 28). Up to $C_{22}$, a relatively constant response (within 6\%) was obtained independent of either carbon number or compound class. The spread in the data is entirely consistent with imprecision in weighing and injection. Above $\mathrm{C}_{22}$ the response dropped off because of chromatographic factors, as discussed previously. Exploration of this region would require a different temperature program.

By using the $\mathrm{nC}_{14}$-alkene as a standard with a measured $\mathrm{H} / \mathrm{C}$ response factor of 2.69, the $\mathrm{H} / \mathrm{C}$ ratios of the other hydrocarbons, considered as pseudo-unknowns, were calculated and compared with their true values (Table 4). From this type of information alone, it was not possible to determine the empirical formula of the compounds explicitly, but the compound classes could be resolved to some extent. The difference between alkane and alkene was a bit marginal, but larger differences were readily resolvable with some information about carbon number inferable from retention time or matching GC/MS data. Hydrocarbons were actually the least favorable case for empirical formula determination because there are only two elements present. 


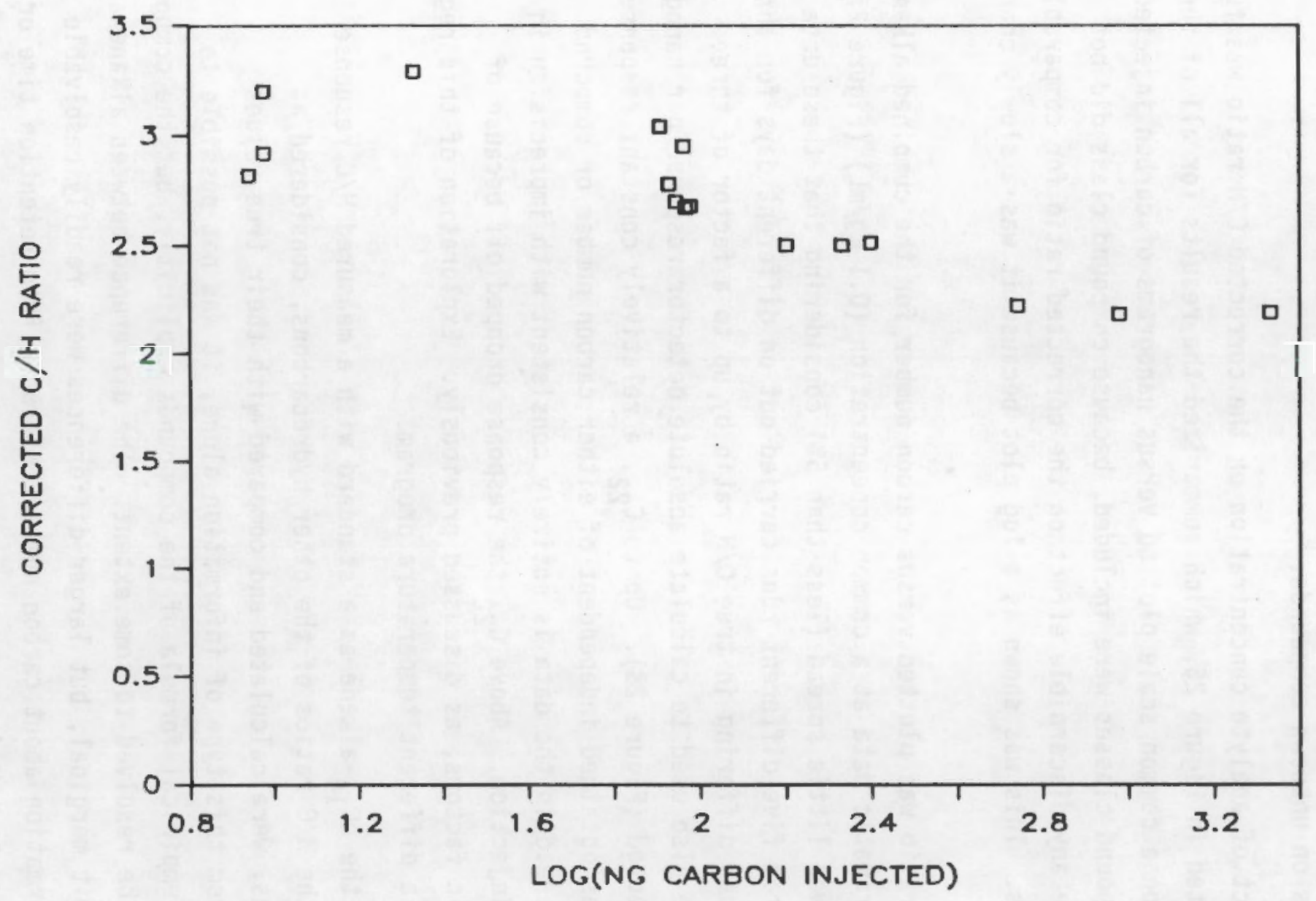

FIGURE 26. C/H Response Versus Carbon Injected for Alkanes, Alkenes, and Aromatics: Evenson-MPD 850 


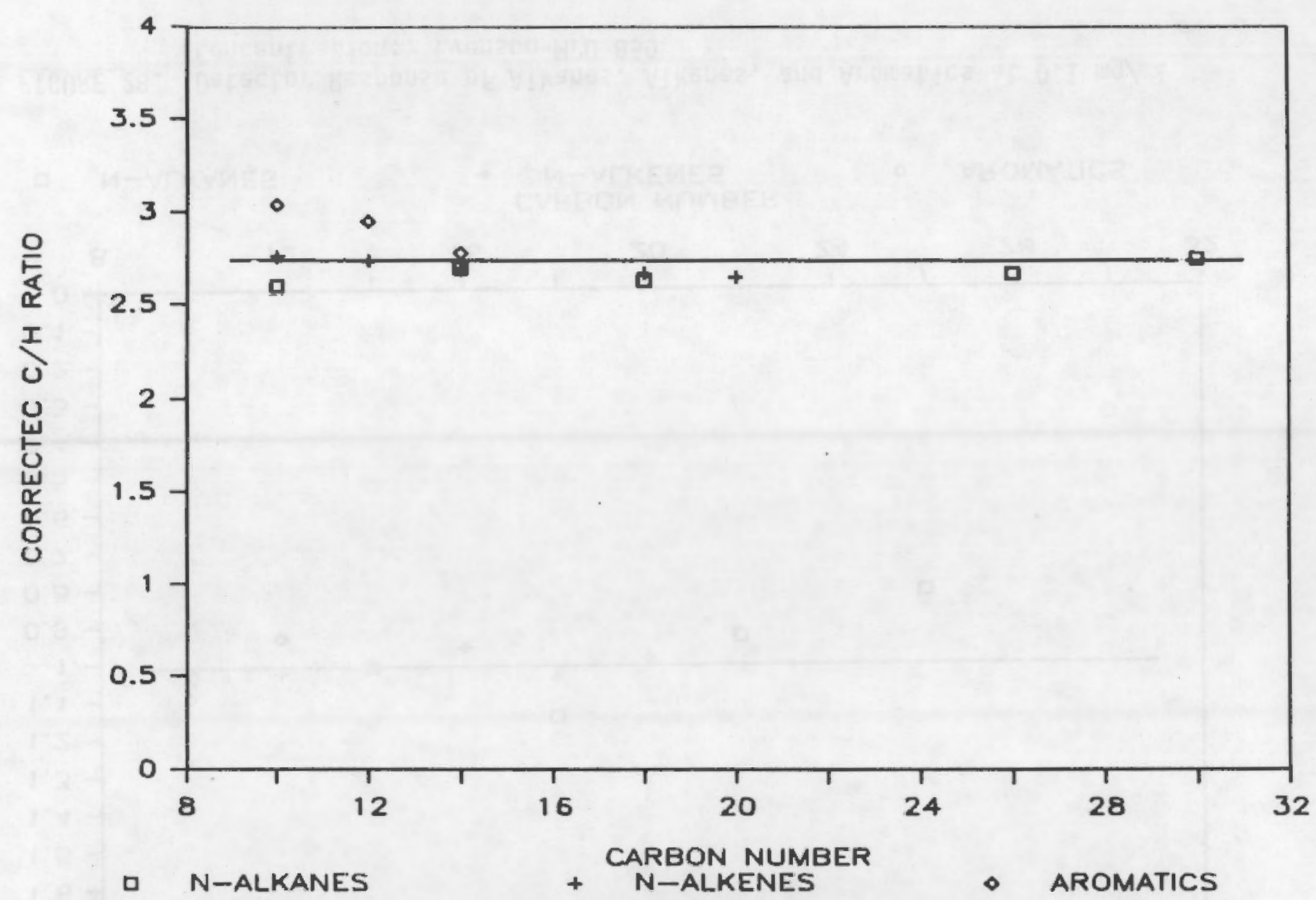

FIGURE 27. C/H Response Ratio for Alkanes, Alkenes, and Aromatics at $0.1 \mathrm{mg} / \mathrm{mL}$. Concentration: Evenson-MPD 850 


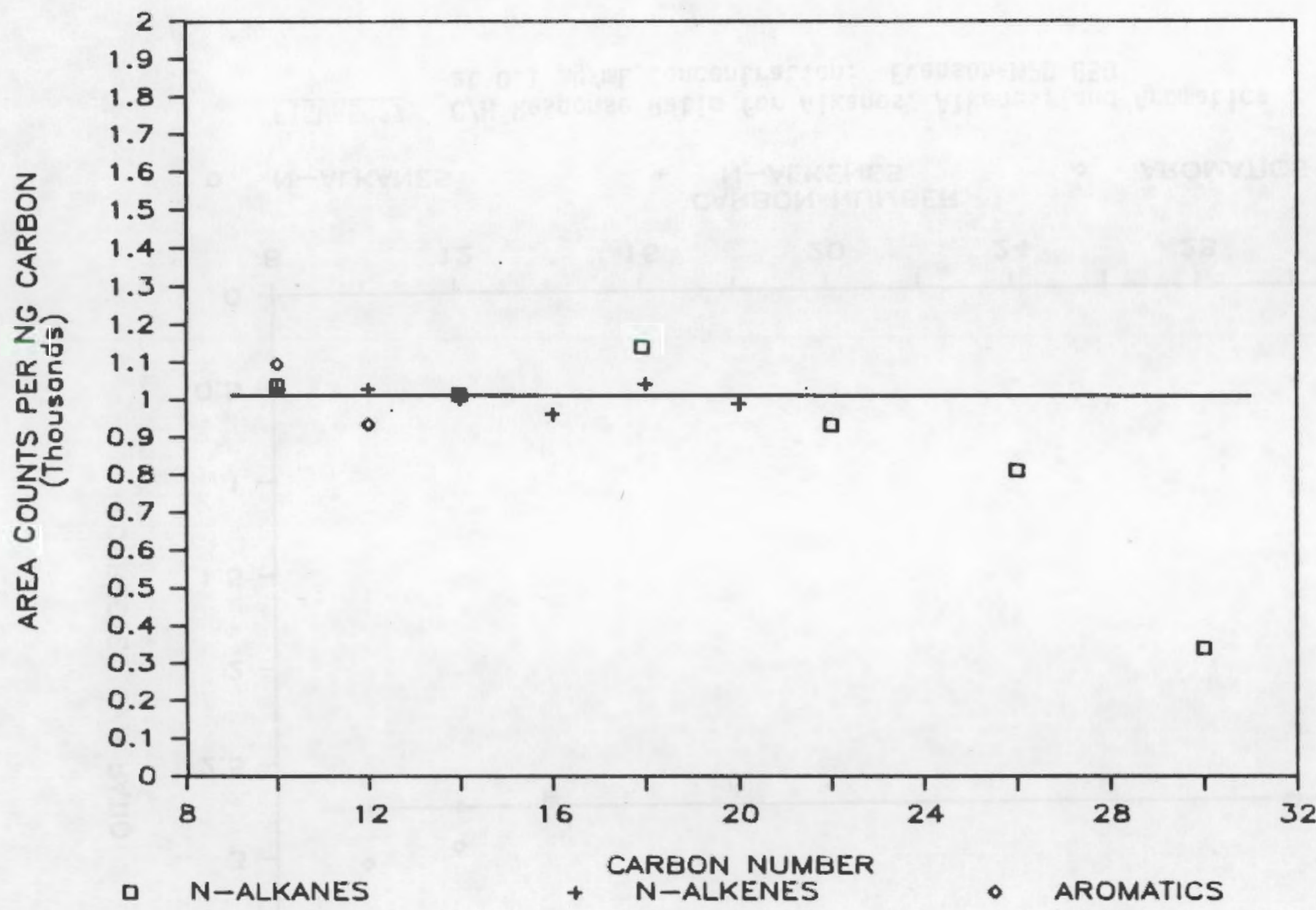

FIGURE 28. Detector Response of Alkanes, Alkenes, and Aromatics at $0.1 \mathrm{mg} / \mathrm{mL}$ Concentration: Evenson-MPD 850 
TABLE 4. H/C Ratio Determination $(0.1 \mathrm{mg} / \mathrm{mL})$

\begin{tabular}{|c|c|c|c|c|}
\hline & & & $H / C R_{i}$ & \\
\hline Class & Formula & Measured & Irue & \% Deviation \\
\hline Aromatic & $\mathrm{C}_{14} \mathrm{H}_{10}$ & 0.69 & 0.70 & 2.8 \\
\hline Aromatic & $\mathrm{C}_{10} \mathrm{H}_{8}$ & 0.71 & 0.80 & 11.2 \\
\hline Aromatic & $\mathrm{C}_{12} \mathrm{H}_{18}$ & 1.37 & 1.50 & 8.6 \\
\hline$n$-alkene & $\mathrm{C}_{10} \mathrm{H}_{20}$ & 1.95 & 2.00 & 2.5 \\
\hline n-alkene & $\mathrm{C}_{12} \mathrm{H}_{24}$ & 1.97 & 2.00 & 1.5 \\
\hline n-alkene & $\mathrm{C}_{14} \mathrm{H}_{28}$ & Standard & 2.00 & -- \\
\hline n-alkene & $\mathrm{C}_{16} \mathrm{H}_{32}$ & 2.15 & 2.00 & 7.5 \\
\hline$n$-alkene & $\mathrm{C}_{18} \mathrm{H}_{36}$ & 2.29 & 2.00 & 14.3 \\
\hline$n$-alkene & $\mathrm{C}_{20} \mathrm{H}_{40}$ & 2.03 & 2.00 & 1.5 \\
\hline n-alkane & $\mathrm{C}_{10} \mathrm{H}_{22}$ & 2.22 & 2.20 & 1.0 \\
\hline n-alkane & $\mathrm{C}_{14} \mathrm{H}_{30}$ & 2.13 & 2.14 & 0.5 \\
\hline n-alkane & $\mathrm{C}_{18} \mathrm{H}_{38}$ & 2.03 & 2.11 & 3.8 \\
\hline n-alkane & $\mathrm{C}_{22} \mathrm{H}_{46}$ & 2.25 & 2.09 & 7.7 \\
\hline n-alkane & $\mathrm{C}_{26} \mathrm{H}_{54}$ & 2.10 & 2.08 & 1.0 \\
\hline n-alkane & $\mathrm{C}_{30} \mathrm{H}_{62}$ & 2.21 & 2.07 & 6.8 \\
\hline
\end{tabular}

For compounds containing heteroatoms, additional information on carbon number could be obtained by setting measured element ratios to integral numbers.

\subsection{SIMPLE MIXTURES OF SULFUR- AND NITROGEN-CONTAINING COMPOUNDS USING THE MPD-850 WITH EVENSON SOURCE}

Further empirical formula measurements were conducted on simple mixtures of compounds containing nitrogen and sulfur and used the Evenson cavity on the MPD-850. Some deuterated compounds were also included to test their value as internal standards. The instrumental conditions were the same as in Table 3 except that the pressure was held at 4 torr, forward power was $90 \mathrm{~W}$, and reflected power was $0.35 \mathrm{~W}$; wavelengths for $\mathrm{C}, \mathrm{H}, \mathrm{N}, \mathrm{S}$, and $\mathrm{D}$ were as given in Table 1. Compounds used included 2-methylthiophene, 
dibenzothiophene (Aldrich, Milwaukee, WI); indole, 2-methylbenzothiazole, 2-mercaptobenzothiazole, quinoline, phenothiazine (Chem Service, West Chester, PA); and decadeuteronaphthalene, pentadeuteroaniline (Sigma Chemical Co., St. Louis, M0). All compounds were first chromatographed in concentrated form as single-compound solutions to determine their individual properties and impurities. A number of other compounds investigated were found unsatisfactory because of limited solubility, conflicting retention times, or poor thermal stability, as evidenced by poor throughput from splitiess injection.

A mixture of decadeuteronaphthalene, quinoline, and dibenzothiophene (standard 1) was used to determine elemental molar response factors to be used for comparison with a first pseudo-unknown consisting of a mixture of the other compounds listed above. All compounds in both mixtures were present at levels ranging from 0.090 to $0.14 \mathrm{mg} / \mathrm{mL}$ in chloroform. The concentrations were kept relatively constant to minimize variations in molar response factors caused by the effect of analyte quenching of the plasma. Injections of approximately $1 \mu \mathrm{L}$ were made, and results were all normalized to $1 \mu \mathrm{L}$. A second pseudo-unknown, consisting of 2-methylthiophene, benzenethiol, quinoline, indole, dibenzothiophene, and phenothiazine, was run using 2-methylbenzothiazole as a standard (standard 2) for elemental molar response factors. The latter was chosen because it contained all four elements $(\mathrm{C}, \mathrm{H}, \mathrm{N}$, and $\mathrm{S})$ and had an intermediate retention time $(8.88 \mathrm{~min})$.

Response factors for the elements of interest, expressed as integrator counts per nanomole of injected element, were calculated for standards 1 and 2 in Table 5. These numbers were, of course, dependent on the integrator used, in this case, the Nelson Analytical data reduction method. In most cases, the default integration was found to be satisfactory. In the case of nitrogen, some manual baseline selection was needed because of the rather noisy baseline. The molar response factors had a precision of better than $8 \%$ both within a single chromatogram and between standards 1 and 2 . This supported the expectation that a single standard could be used for the determination of these quantities at least over the limited retention time range studied. When expressed on a molar rather than weight basis, carbon and sulfur had approximately equal response factors, nitrogen was a factor of 


\section{TABLE 5. Integrator Counts per Nanomole Injected}

\begin{tabular}{|c|c|c|c|c|c|}
\hline \multirow[b]{2}{*}{ Formula } & \multicolumn{5}{|c|}{ Analytical Channel } \\
\hline & Carbon & Hydrogen & Nitrogen & Sulfur & Deuterium \\
\hline \multicolumn{6}{|c|}{ Standard-1 } \\
\hline $\mathrm{C}_{10} \mathrm{D}_{18}$ & 113860 & -- & -- & -- & 21233 \\
\hline $\mathrm{C}_{9} \mathrm{H}_{7} \mathrm{~N}$ & 99259 & 24094 & 48440 & -- & -- \\
\hline $\mathrm{C}_{12} \mathrm{H}_{8} \mathrm{~S}$ & 113840 & 26993 & - & 115124 & -- \\
\hline Average & 108886 & 25543 & 48440 & 115124 & 21233 \\
\hline \multicolumn{6}{|c|}{ Standard-2 } \\
\hline $\mathrm{C}_{8} \mathrm{H}_{7} \mathrm{SN}$ & 95524 & 25688 & 47930 & 119564 & -- \\
\hline
\end{tabular}

two less responsive, and hydrogen and deuterium were another factor of two less responsive. Deuterium and hydrogen had approximately equal response factors; deuterium was considerably more sensitive because of its lower background.

The molar response factors were used to calculate empirical formulae for pseudo-unknowns 1 and 2 (Table 6 ). The integrated results were first divided by the number of microliters injected and the elemental molar response factors given in Table 5 to yield the number of nanomoles per microliter of each element. The numbers given in Table 6 were then computed by dividing by the carbon content (in nanomoles) thus determined and multiplying by an appropriate integer factor to obtain the best fit to integral numbers. For illustration purposes, the integer chosen was the known carbon number for each compound. In most cases, this did in fact give the best fit; however, for true unknowns, this would only be accurate to \pm 1 carbon number. Some additional information such as a matching GC/MS parent ion peak would be needed to verify this. Most of the calculated formulae in Table 6 showed very good agreement with the known compound formulae, with typical deviations of $5-10 \%$. The one notable exception was the deuterated aniline compound, in which the larger deviation may have been caused by the ghosting correction in a compound that contained both hydrogen and deuterium. These results demonstrated that the MPD-850 was capable of empirical formula determination at least for simple mixtures over a limited concentration range. 
TABLE 6. Empirical Formulae (normalized to carbon)

Formula

Analytical Channel
Carbon Hydrogen Nitrogen Sulfur Deuterium

Pseudo-Unknown-1

$\begin{array}{lcccccc}\mathrm{C}_{5} \mathrm{H}_{6} \mathrm{~S} & 5 & 6.00(\mathrm{a})(6)(\mathrm{b}) & -- & 1.20(1) & -- \\ \mathrm{C}_{6} \mathrm{D}_{5} \mathrm{NH}_{2} & & 6 & -- & 0.86(1) & -- & 3.95(5) \\ \mathrm{C}_{8} \mathrm{H}_{7} \mathrm{~N} & 8 & 6.95(7) & 0.93(1) & -- & -- \\ \mathrm{C}_{8} \mathrm{H}_{7} \mathrm{SN} & 8 & 7.4(7) & 1.02(1) & 1.08(1) & -- \\ \mathrm{C}_{12} \mathrm{H}_{9} \mathrm{SN} & 12 & 8.88(9) & 1.05(1) & 1.13(1) & --\end{array}$

Pseudo-Unknown-2

$\begin{array}{lclccc}\mathrm{C}_{5} \mathrm{H}_{6} \mathrm{~S} & 5 & 6.4(6) & - & 1.20(1) & - \\ \mathrm{C}_{6} \mathrm{H}_{5} \mathrm{SH} & 6 & 5.94(6) & - & 1.02(1) & - \\ \mathrm{C}_{9} \mathrm{H}_{7} \mathrm{~N} & 9 & 7.02(7) & 1.04(1) & - & - \\ \mathrm{C}_{8} \mathrm{H}_{7} \mathrm{~N} & 8 & 7.04(7) & 1.09(1) & -- & - \\ \mathrm{C}_{12} \mathrm{H}_{8} \mathrm{~S} & 12 & 7.68(8) & -- & 0.996(1) & - \\ \mathrm{C}_{12} \mathrm{H}_{9} \mathrm{SN} & 12 & 8.89(9) & 0.888(1) & 0.965(1) & -\end{array}$

(a) Computed value.
(b) Actual value.

\subsection{SIMPLE MIXTURES OF HYDROCARBONS AND NITROGEN-, SULFUR-, AND CHLORINE-CONTAINING COMPOUNDS USING THE ECHELLE SYSTEM WITH ATMOSPHERIC-PRESSURE BEENAKKER SOURCE}

Empirical formula measurements were also conducted on simple mixtures of compounds that included $\mathrm{C}, \mathrm{H}, \mathrm{N}, \mathrm{S}$, and/or $\mathrm{Cl}$. These experiments used the atmospheric-pressure Beenakker source on the echelle system. The instrumental conditions are given in Table 7 . Compounds in the first mixture included 2-methylthiophene, benzenethiol, naphthalene, quinoline, n-tetradecane, atrazine, dibenzothiophene, aldrin, and phenothiazine at a 10:1 dilution of a $1-\mathrm{mg} / \mathrm{mL}$ stock solution. The second mixture, containing 2-methylbenzothiazole and lindane, was used as an elemental response standard. 


\section{IABLE 7. GC and Plasma Detector Conditions}

A. Gas Chromatography

Instrument:

Column:

Temperature program:

Injector temperature:

Injection:

Carrier gas:

B. Helium Plasma Detector

Spectrometer:

Cavity:

Plasma pressure:

Forward power:

Reflected power:

Helium flow:

Scavenge gas:

Analytical lines:
Hewlett-Packard $5880 \mathrm{~A}$

$30-\mathrm{m} \times 0.25-\mathrm{mm}-i . d$. fused-silica capillary coated with DB-5 (0.25 $\mu$ m thickness)

Initial Temperature $=40^{\circ} \mathrm{C}$

Initial Hold $=1 \mathrm{~min}$

Program Rate $=20^{\circ} \mathrm{C} / \mathrm{min}$

Final Temperature $=300^{\circ} \mathrm{C}$

Final Hold $=6$ min

$250^{\circ} \mathrm{C}$

Splitless mode, $1 \mu \mathrm{L}, 1.0$-min purge time

Hel ium
Spectraspan IIIB, multielement

Beenakker TM 010

Atmospheric

$75 \mathrm{~W}$

$0.3 \mathrm{~W}$

$300 \mathrm{~mL} / \mathrm{min}$

Oxygen, $0.2 \mathrm{~mL} / \mathrm{min}$

Hydrogen, $656.2 \mathrm{~nm}$

Carbon, $241.8 \mathrm{~nm}$

Sulfur, $545.3 \mathrm{~nm}$

Nitrogen, $746.8 \mathrm{~nm}$

Chlorine, $479.4 \mathrm{~nm}$

A typical multielement chromatogram showed that interelement interferences were of negligible importance with this system, demonstrating the greater resolving power of the echelle spectrometer (Figure 29). Sulfur showed no measurable interference with carbon whereas with the MPD-850 system, a large analog ghosting correction was needed for sulfur using the 


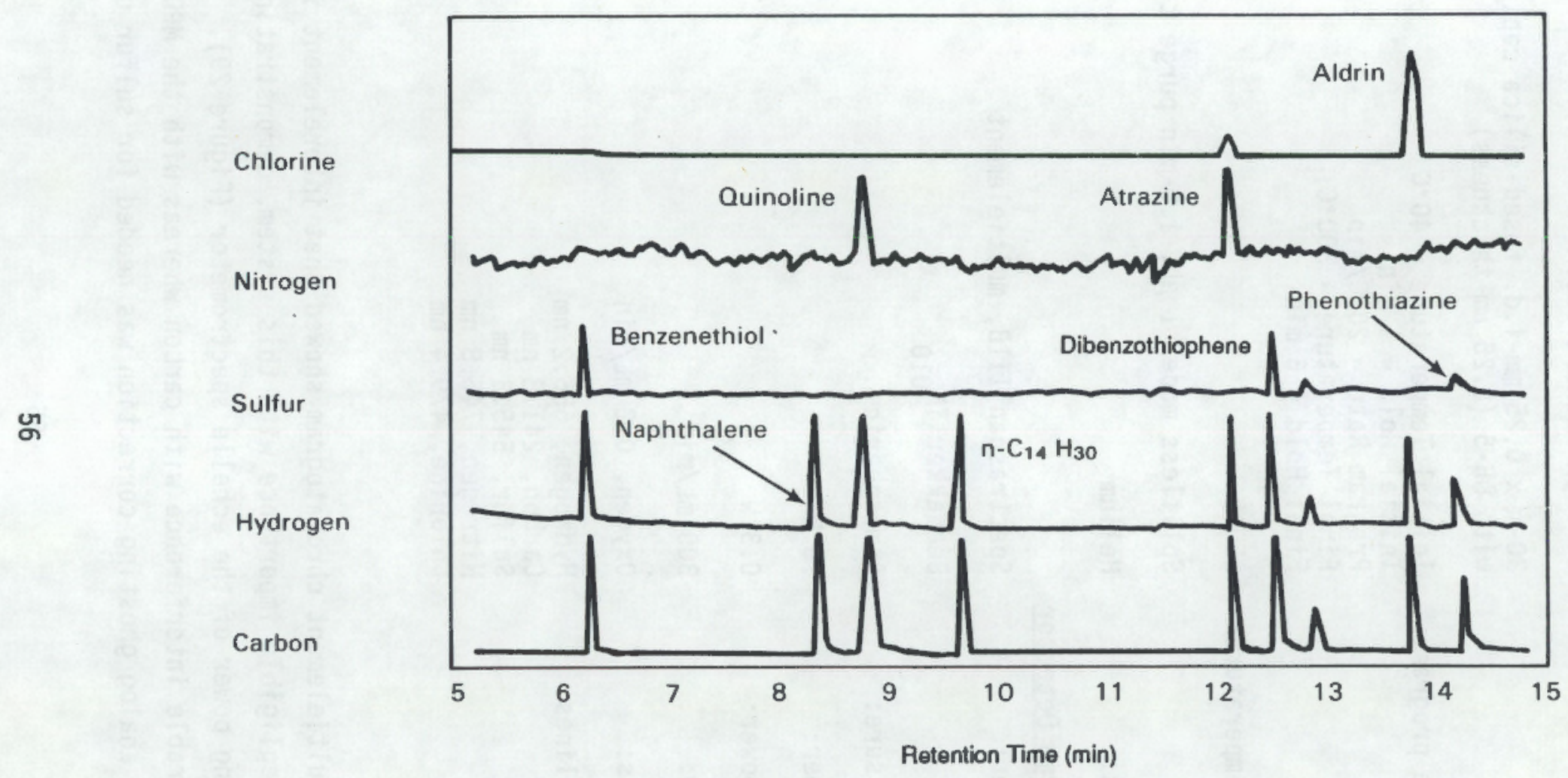

FIGURE 29. Multielement Chromatogram $(0.1 \mathrm{mg} / \mathrm{mL})$ : AtmosphericPressure Beenakker-Echelle (75 W) 
same analytical line. Sensitivity of $\mathrm{H}, \mathrm{C}, \mathrm{S}$, and $\mathrm{Cl}$ was similar to or slightly increased from that observed with the Evenson source, though nitrogen was about a factor of 10 less sensitive. The carbon response factor (Figure 30), corrected for known amounts of carbon injected, did not demonstrate the relatively smooth behavior seen with the Evenson source. However, this may have been caused by chromatographic factors and may be improved with the use of simple hydrocarbon mixtures.

The $\mathrm{C} / \mathrm{H}$ and $\mathrm{C} / \mathrm{S}$ response factors were plotted as a function of retention time (Figures 31 and 32 , respectively). The response ratios were reasonably constant (within $\pm 0.25 \mathrm{C} / \mathrm{H}$ ratio units) across several diverse compound types. The amount of scatter was similar to that observed with the Evenson source. A similar constancy was observed for chlorine as well.

Empirical formulae were calculated from these data using elemental response factors from the 2-methylbenzothiazole and 1 indane mixture and known carbon numbers for the compounds of interest (Table 8 ). The results deviated from the correct formulae by 5 to $10 \%$ for hydrogen, sulfur, and chlorine. The nitrogen data were considerably worse (as high as $40 \%$ deviation), probably because of problems with integration accuracy resulting from the poor detection sensitivity for that element.

The results for the Beenakker source were rather similar to those with the Evenson source for carbon, hydrogen, and sulfur (Table 9). The Beenakker source was more sensitive for chlorine and 10 times less sensitive for nitrogen.

\subsection{SIMPLE MIXTURES OF HYDROCARBONS AND SULFUR-CONTAINING COMPOUNDS USING THE LOW-PRESSURE BEENAKKER SOURCE WITH THE MPD-850 AND ECHELLE SYSTEMS}

Empirical formula studies with the low-pressure Beenakker source concentrated on sulfur-containing compounds and hydrocarbons in simple multicomponent mixtures of known composition. Compound types included aliphatic and aromatic hydrocarbons, sulfur heterocycles, and aliphatic mercaptans. Considerations in selecting standards included purity, stability, chromatographic separation from other compounds, and diversity of compound types. 


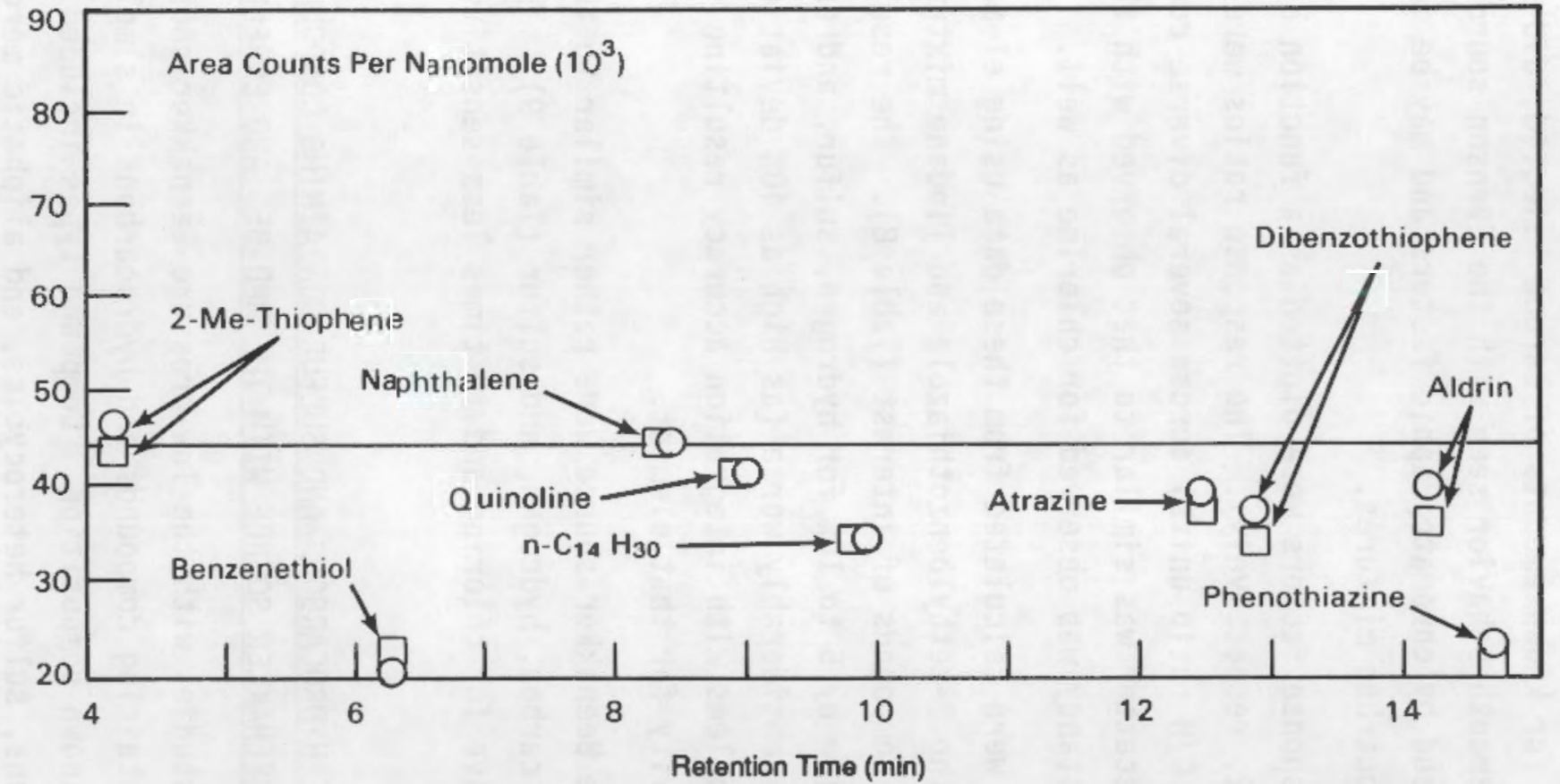

FIGURE 30. Carbon Response Factor $(0.1 \mathrm{mg} / \mathrm{mL})$ : Atmospheric-Pressure Beenakker-Echelle $(75 \mathrm{~W})$. Results of two determinations. 


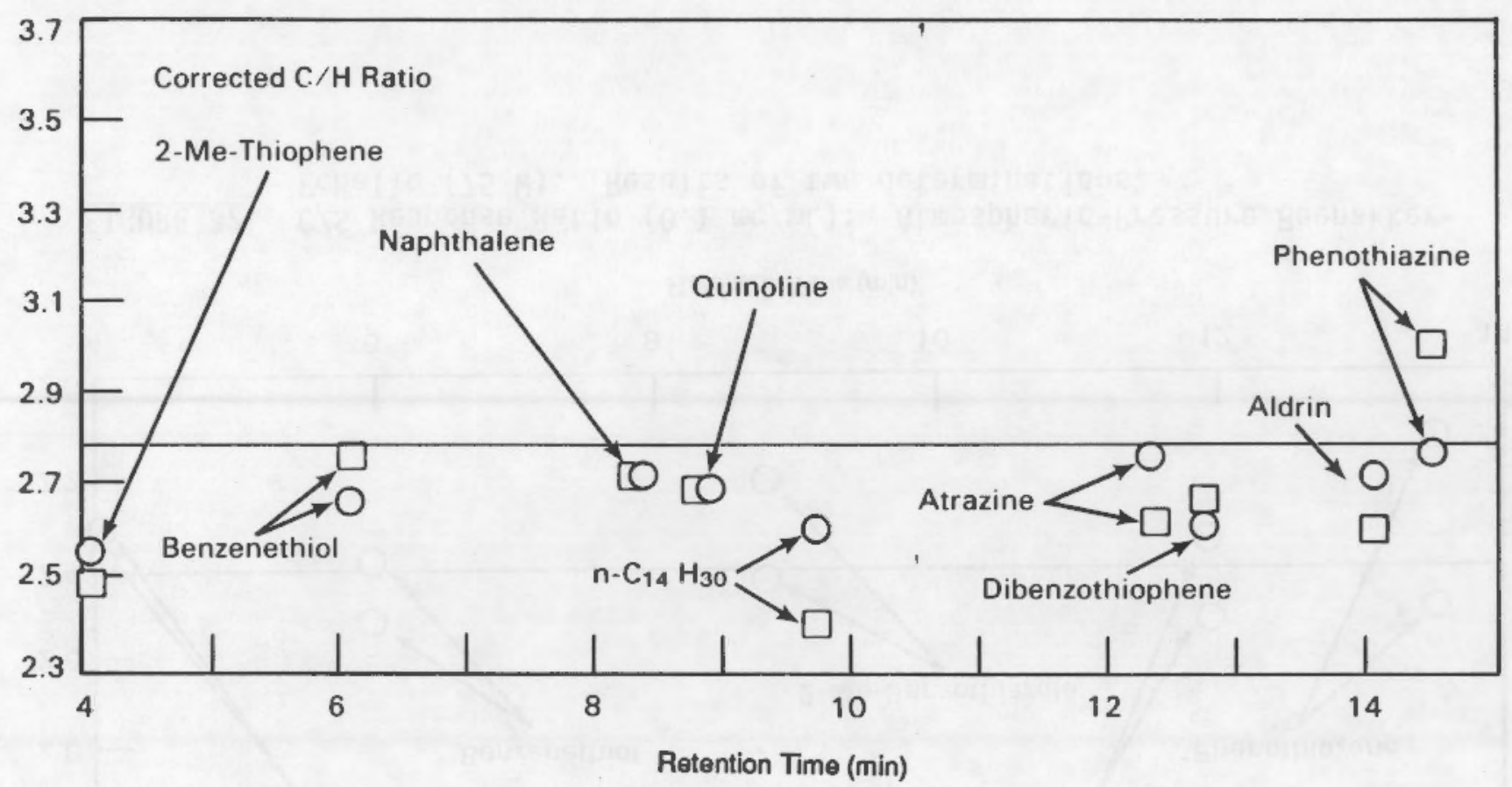
FIGURE 31. C/H Response Ratio $(0.1 \mathrm{mg} / \mathrm{mL})$ : Atmospheric-Pressure Beenakker-Echelle (75 W)
Results of two determinations. 


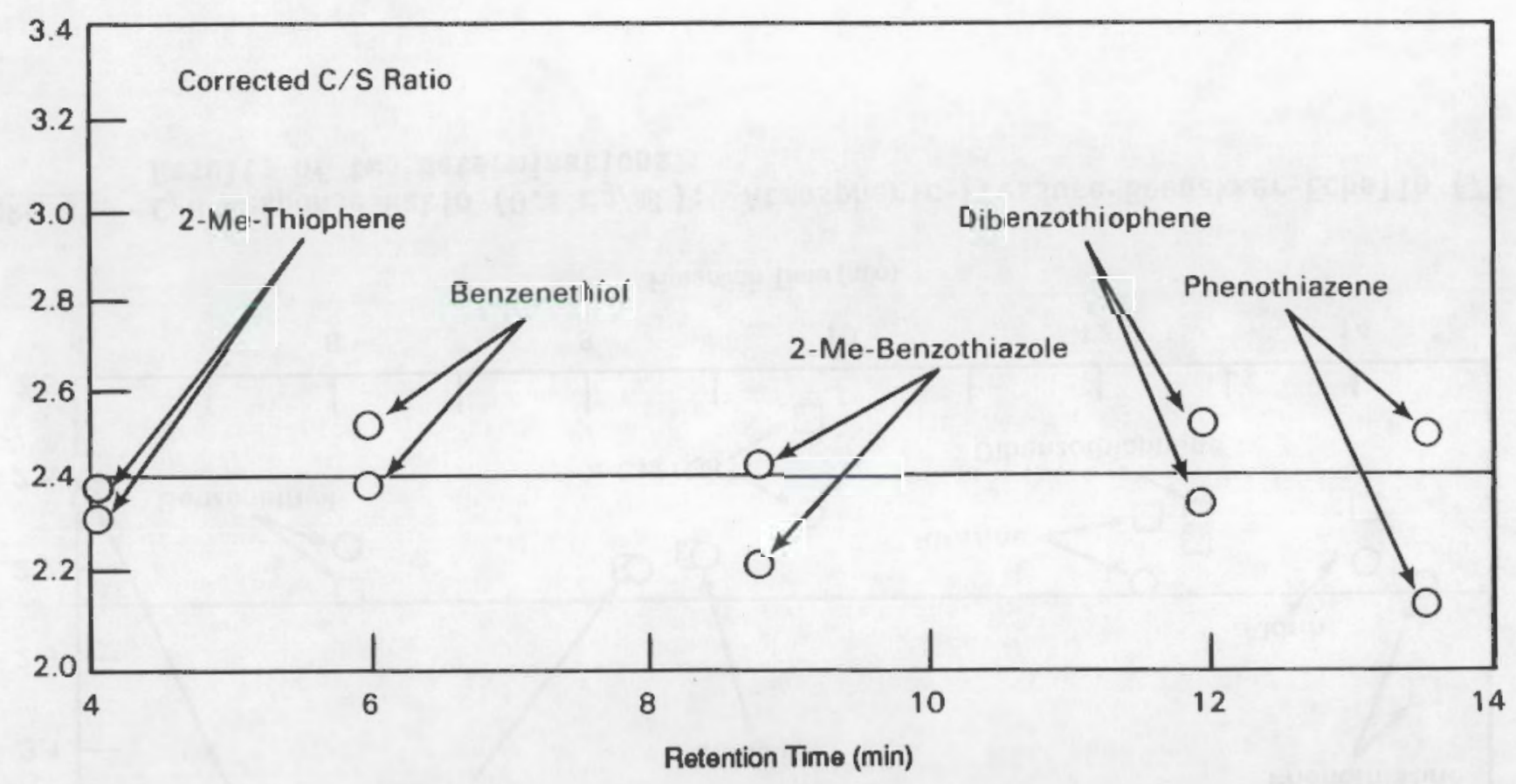

FIGURE 32. C/S Response Ratio $(0.1 \mathrm{mg} / \mathrm{mL})$ : Atmospheric-Pressure BeenakkerEchelle $(75 \mathrm{~W})$. Results of two determinations. 
TABLE 8. Empirical Formulae (normalized to carbon; 2-methylbenzothiazole, lindane standard)

\begin{tabular}{|c|c|c|c|c|}
\hline Compound & $\mathrm{H}$ & $\mathrm{N}$ & $s$ & $\mathrm{Cl}$ \\
\hline $\mathrm{C}_{5} \mathrm{H}_{6} \mathrm{~S}$ & $\begin{array}{l}6.54 \\
6.70\end{array}$ & $=$ & $\begin{array}{l}1.15 \\
1.12\end{array}$ & $\begin{array}{l}-- \\
--\end{array}$ \\
\hline $\mathrm{C}_{6} \mathrm{H}_{6} \mathrm{~S}$ & $\begin{array}{l}6.25 \\
6.05\end{array}$ & $\begin{array}{l}-- \\
--\end{array}$ & $\begin{array}{l}1.06 \\
1.12\end{array}$ & $\begin{array}{l}-- \\
--\end{array}$ \\
\hline $\mathrm{C}_{10} \mathrm{H}_{8}$ & $\begin{array}{l}8.16 \\
8.16\end{array}$ & $=$ & $\begin{array}{l}-- \\
--\end{array}$ & $\because$ \\
\hline $\mathrm{C}_{9} \mathrm{H}_{7} \mathrm{~N}$ & $\begin{array}{l}7.25 \\
7.20\end{array}$ & $\begin{array}{l}0.62 \\
0.59\end{array}$ & $\begin{array}{l}-- \\
--\end{array}$ & $\begin{array}{l}-- \\
--\end{array}$ \\
\hline $\mathrm{C}_{14} \mathrm{H}_{30}$ & $\begin{array}{l}32.00 \\
34.90\end{array}$ & -- & $\begin{array}{l}-- \\
--\end{array}$ & -- \\
\hline $\mathrm{C}_{8} \mathrm{H}_{14} \mathrm{ClN}_{5}$ & $\begin{array}{l}14.40 \\
14.80\end{array}$ & $\begin{array}{l}3.60 \\
3.00\end{array}$ & -- & $\begin{array}{l}0.90 \\
0.90\end{array}$ \\
\hline $\mathrm{C}_{12} \mathrm{H}_{8} \mathrm{~S}$ & $\begin{array}{l}8.48 \\
8.30\end{array}$ & -- & $\begin{array}{l}1.13 \\
1.06\end{array}$ & -- \\
\hline $\mathrm{C}_{12} \mathrm{H}_{8} \mathrm{Cl}_{6}$ & $\begin{array}{l}8.20 \\
8.51\end{array}$ & -- & -- & $\begin{array}{l}5.56 \\
5.77\end{array}$ \\
\hline
\end{tabular}

TABLE 9. Relative Molar Response

$\begin{array}{lccc} & \text { Evenson } & & \text { Beenakker } \\ & \mathrm{H} / \mathrm{C} & 0.2 & 0.4 \\ \mathrm{~N} / \mathrm{C} & 0.4 & 0.05 \\ \mathrm{~S} / \mathrm{C} & 1.0 & 0.4 \\ \mathrm{Cl} / \mathrm{C} & -- & 4.4\end{array}$

A fivefold dilution of the approximately $1 \mathrm{mg} / \mathrm{mL}$ stock solution containing 13 components was chromatographed to determine retention times and to confirm elemental selectivity (Figure 33, chromatographic conditions as in Table 3 ). The broad hump in the hydrogen chromatogram baseline could be minimized but not eliminated by repeated baking of the system at $300^{\circ} \mathrm{C}$. Because the hump 

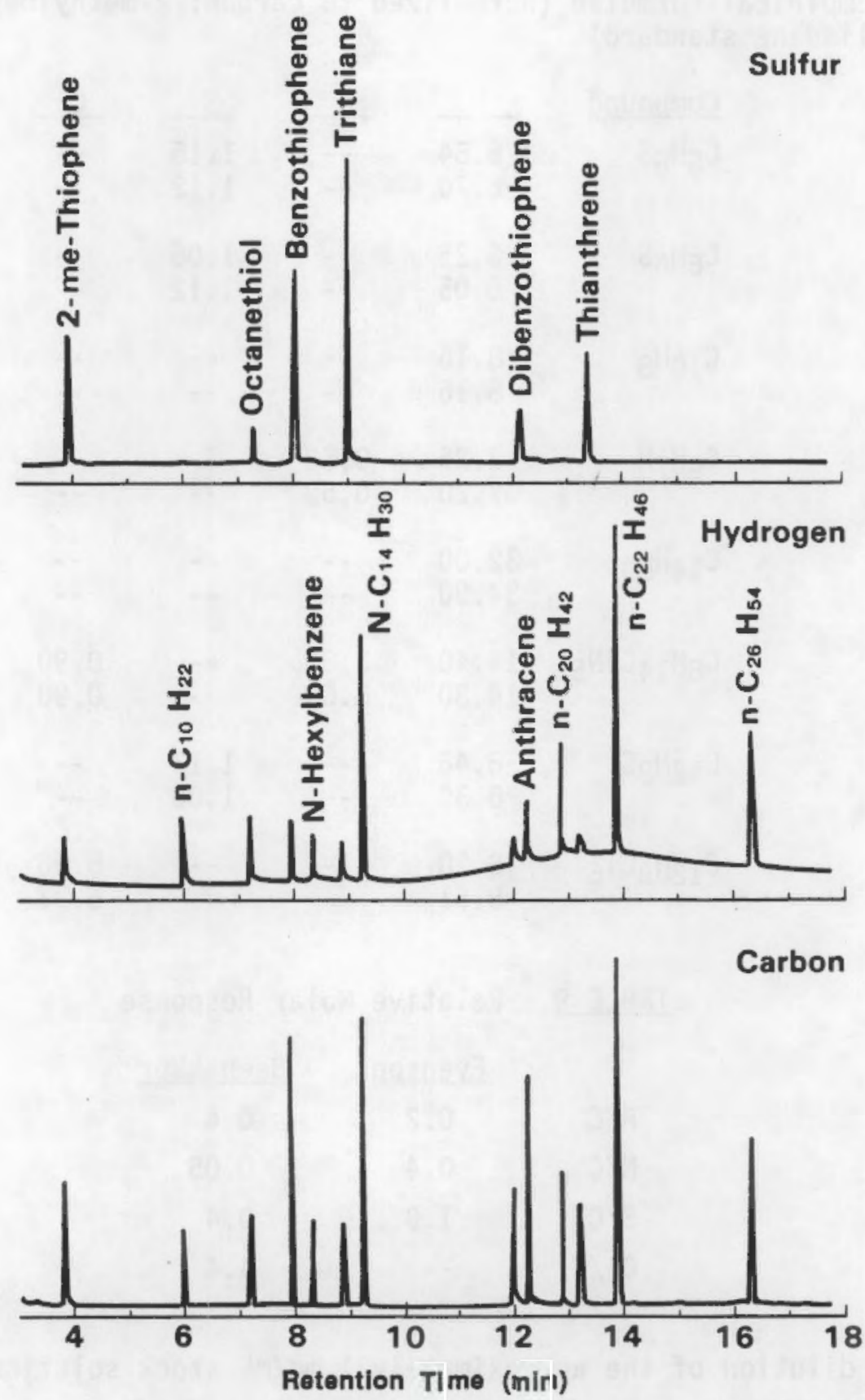

FIGURE 33. Multielement Chromatogram for Carbon, Hydrogen, and Sulfur Channels (DB-5, $1 \mu \mathrm{m}, 20^{\circ} \mathrm{C} / \mathrm{min}$ to $300^{\circ} \mathrm{C}$ ): Low-Pressure Beenakker-Eche1le (70 W). 
was not present in the carbon channel, it was apparently caused by water. This behavior was essentially absent on the MPD-850 system after prolonged conditioning at $325^{\circ} \mathrm{C}$.

The reproducibility of empirical formula calculations was determined for both the MPD-850 and echelle systems by four repeated injections in each system of the standard mixture chromatographed in Figure 33. Approximately $200 \mathrm{ng}$ per compound were injected, representing a compromise between signal strength and differential analyte concentration effects described in Section 3.3. The instrumental conditions are given in Table 10. To improve chromatographic resolution and resulting integration accuracy, the temperature program rate was decreased to $10^{\circ} \mathrm{C} / \mathrm{min}$. Under these conditions, baseline resolution was obtained for all peaks. To minimize instability caused by optical drift in the echelle system, the inlet slit was increased from its normal setting of 50 to $200 \mu \mathrm{m}$. This did indeed appear to improve the precision of the measurement at the expense of some loss in elemental selectivity.

Element-to-carbon ratios, $\mathrm{R}$, were computed for each peak according to the expression

$$
R=\left(E_{u} / C_{u}\right)\left(C_{r} / E_{r}\right)\left(n_{E} / n_{C}\right)
$$

where $E$ and $C$ are the responses for the element of interest (sulfur or hydrogen) and carbon, respectively, $u$ and $r$ represent unknown and reference, respectively, and $n$ is the number of atoms in the reference compound. Both peak heights and peak areas were tested, but peak areas gave better precision. Tetradecane was used as the internal reference for the hydrocarbons and 2-methylthiophene was used as the reference for the sulfur compounds for calculation of empirical formulae. All other compounds were treated as unknowns. For the sulfur compounds, the carbon number was calculated by assuming the sulfur number was an integer. The hydrogen number was then calculated by multiplying the experimentally determined $\mathrm{H} / \mathrm{C}$ ratio by the calculated carbon number. In most cases, the molecular formulae were inferred from the empirical formulae by reference to the peak retention time, thus allowing differentiation between, for example, a $C_{6}$ and a $C_{12}$ compound. 
TABLE 10. GC and Plasma Detector Conditions

A. Gas Chromatography

Instrument:

Hewlett-Packard 5880A

Column :

30-m $\times 0.25-\mathrm{mm}-\mathrm{i} . \mathrm{d}$. fused-silica capillary coated with DB-5 ( $1 \mu \mathrm{m}$ thickness)

Temperature program:

Initial Temperature $=40^{\circ} \mathrm{C}$

Initial Hold $=1 \mathrm{~min}$

Program Rate $=20^{\circ} \mathrm{C} / \mathrm{min}$

Final Temperature $=280^{\circ} \mathrm{C}$

Final Hold $=5$ min

Injector temperature: $\quad 250^{\circ} \mathrm{C}$

Injection: $\quad$ Splitless mode, $1 \mu \mathrm{L}, 1.0$-min purge time

Carrier gas: Helium

B. Helium Plasma Detector

Instruments :

Applied Chromatography Systems MPD- 850

Spectraspan IIIB, multielement

Cavity:

Low-Pressure Beenakker

Plasma pressure:

20 torr

Forward power:

$70 \mathrm{~W}$

Helium flow:

$50 \mathrm{~mL} / \mathrm{min}$

Oxygen flow:

$0.1 \mathrm{~mL} / \mathrm{min}$

Analytical lines:

Carbon, $247.9 \mathrm{~nm}$

Hydrogen, $656.1 \mathrm{~nm}$

Sulfur, $545.4 \mathrm{~nm}$

This procedure broke down for trithiane because the $S / C$ ratio was unity. For the hydrocarbons and trithiane, it was assumed that the carbon number was known for the calculation of the hydrogen number.

Results for the MPD-850 system were slightly more accurate for the sulfur compounds than those for the echelle system (Table 11). For the MPD-850 $S / C$ data, four of the compounds plotted within one standard deviation of the true normalized value while the trithiane was out by about $1 \sigma$. For the 
TABLE 11. Empirical Formulae Using the Low-Pressure Beenakker Source on the Eche1le and MPD-850 Systems

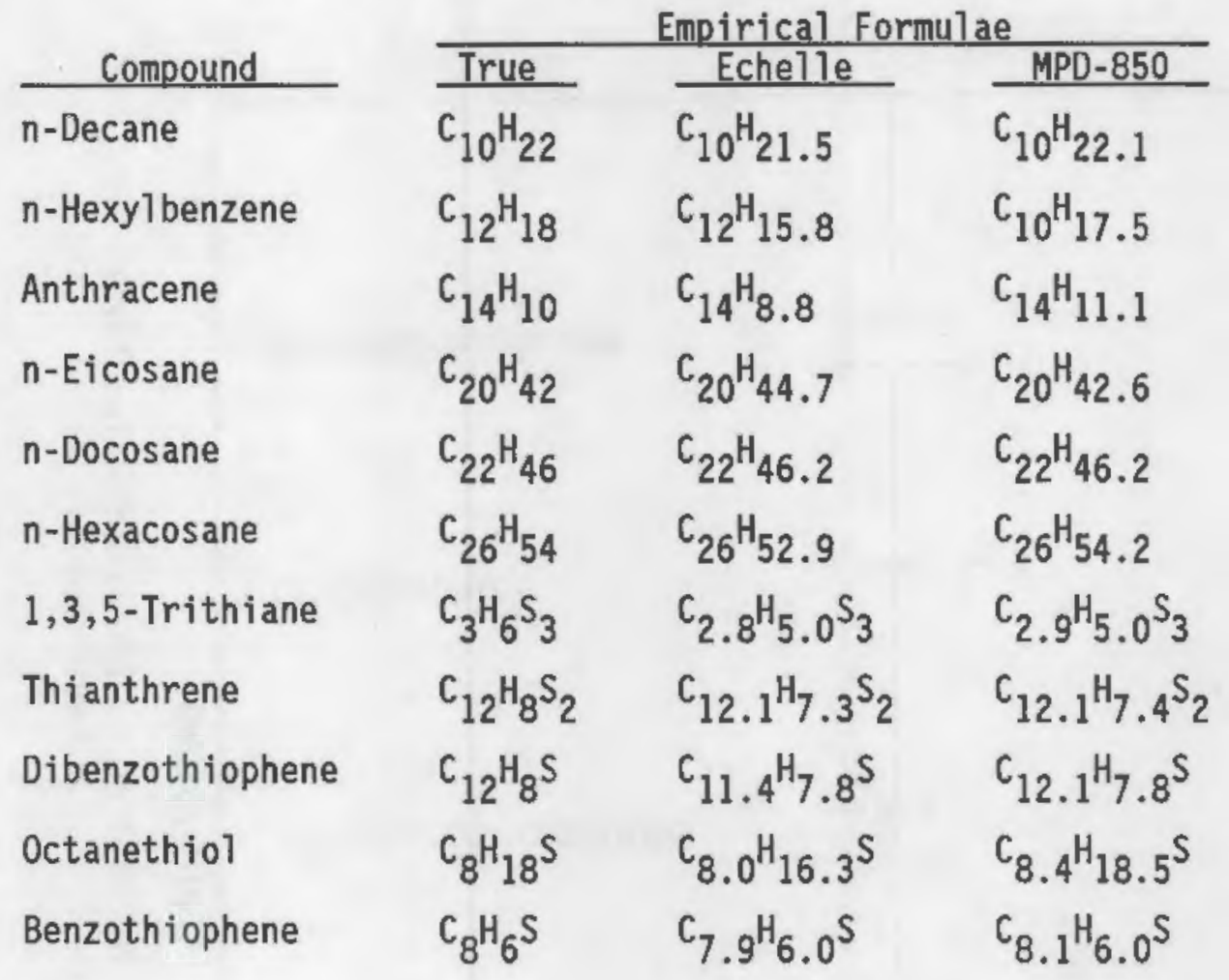

hydrocarbon data, agreement was excellent (typically within 2.8\%) for the MPD-850 system but only fair (0.4-12.2\%) for the echelle system. Precision was somewhat worse than expected for both sets of data, ranging from 1 to $5 \%$ for the MPD-850 (Figures 34-36). The $\mathrm{H} / \mathrm{C}$ ratios for the sulfur compounds were somewhat less precise than those for the pure hydrocarbons, possibly reflecting subtle compound specific effects that may have affected the accuracy of the elemental ratios.

Better precision, on the order of $1 \%$, would be desirable for empirical formula calculations. That level of precision was attained for a homologous series of hydrocarbons by Uden et al. (1986) and would be adequate to distinguish between alkanes and alkenes. Precision and accuracy were less favorable for $\mathrm{Cl} / \mathrm{C}$ ratios measured by the same authors. By contrast, Hagen, Marhevka, and Haddad (1985) were able to obtain a precision for $\mathrm{Cl} / \mathrm{C}$ ratios in the range of 0.1 to $2 \%$, using an MPD-850 equipped with an Evenson source, but relatively poor precision for $\mathrm{H} / \mathrm{C}$ ratios. 
ภ

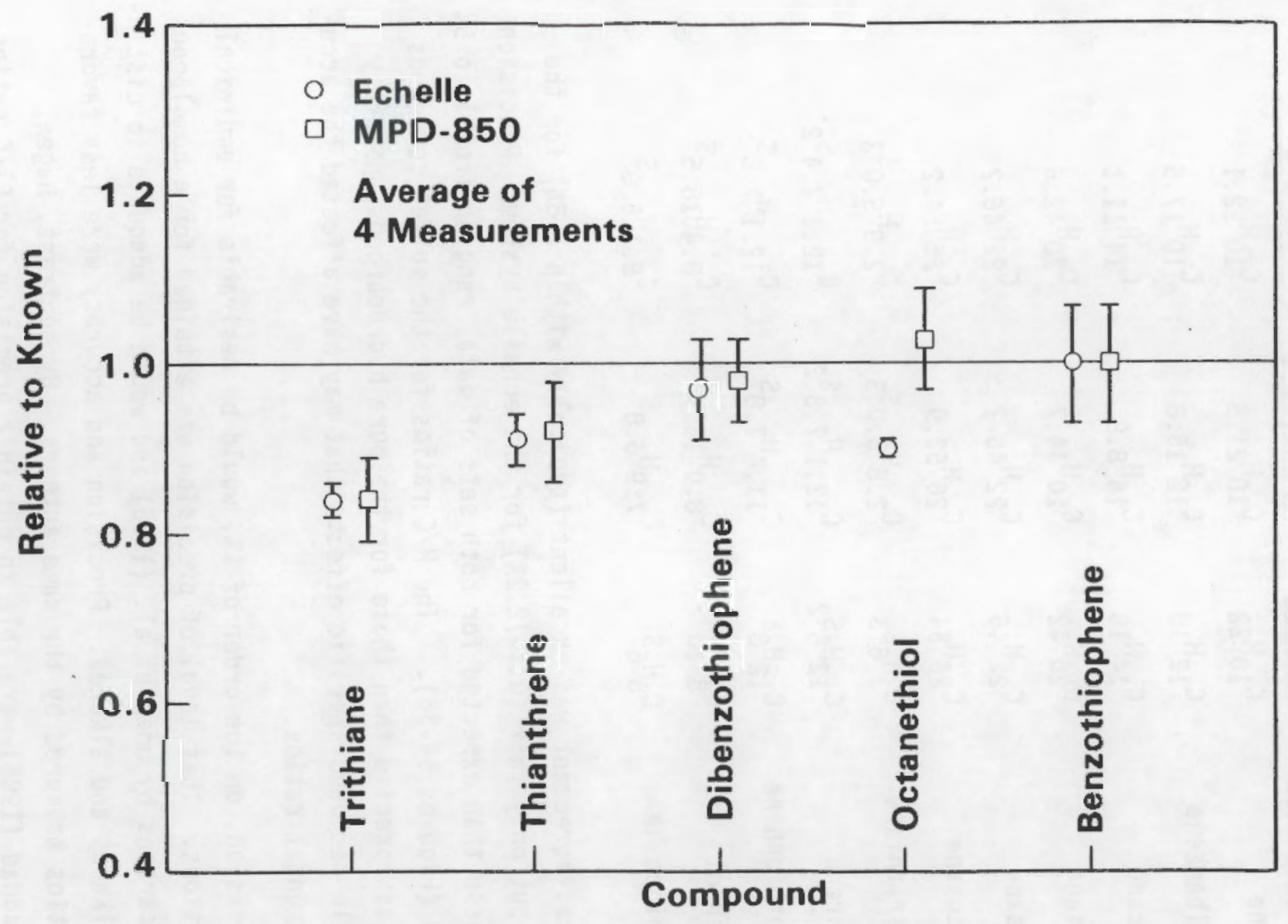

FIGURE 34. Measured S/C Ratios Normalized to the Known Value for Each Sulfur Compound: Low-Pressure Beenakker (70 W) 


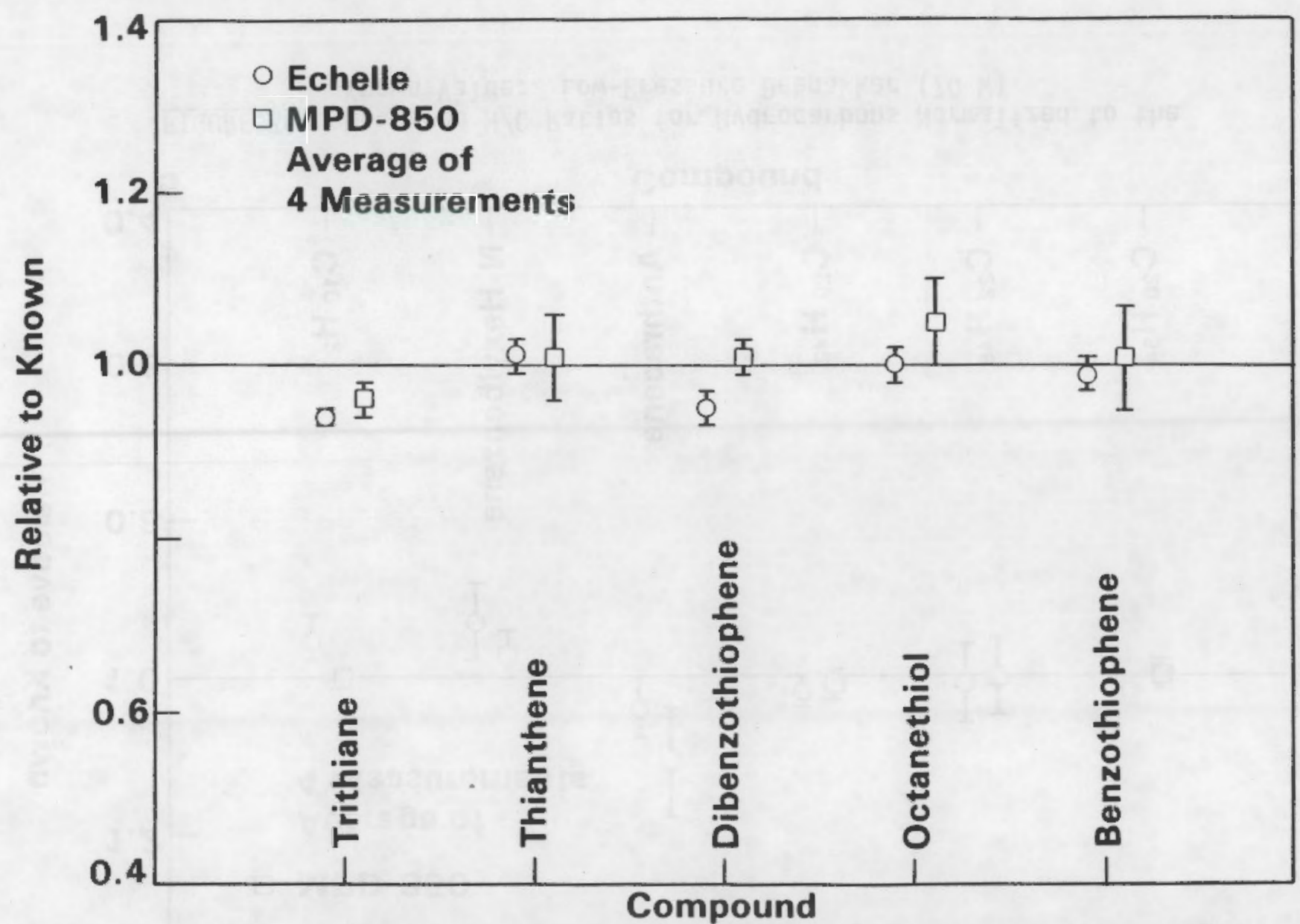

FIGURE 35. Measured H/C Ratios for Sulfur Compounds Normalized to the Known Value: Low-Pressure Beenakker (70 W) 


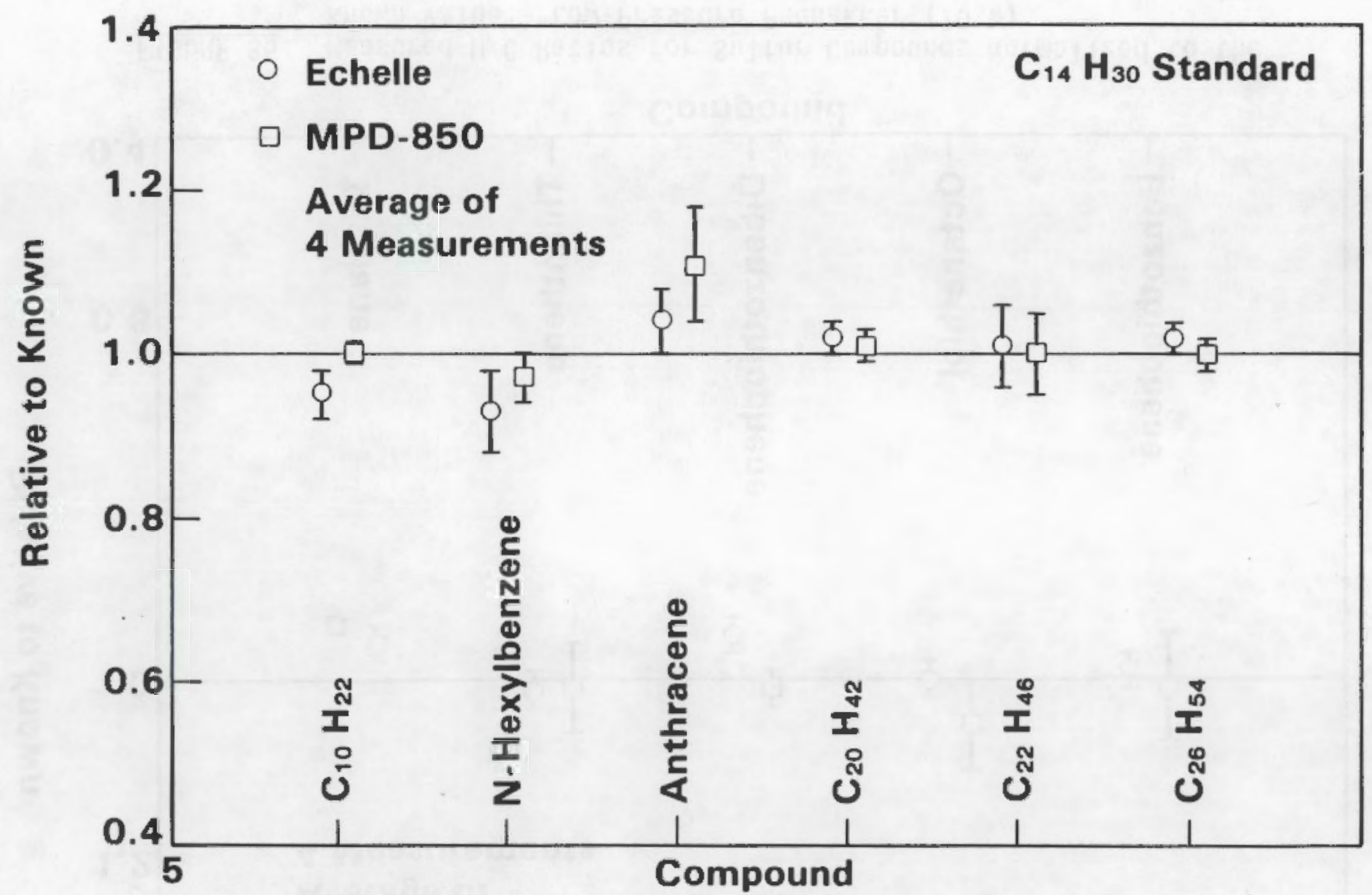

FIGURE 36. Measured H/C Ratios for Hydrocarbons Normalized to the Known Value: Low-Pressure Beenakker (70 W) 
To further examine the issue of precision in empirical formula calculations, an 11-component sulfur standard was prepared, with concentrations varying over the relatively narrow range of 0.1 to $0.24 \mathrm{mg} / \mathrm{mL}$. Instrumental conditions were similar to those in Table 10 except that a $0.25-\mu \mathrm{m}-\mathrm{film}$ thickness column was used and the temperature program was increased to $20^{\circ} \mathrm{C} /$ min after the oven temperature reached $180^{\circ} \mathrm{C}$. Empirical formulae were calculated as described above with n-propylthiophene used as the internal reference standard. The results were based on the average of six individual determinations (Table 12). Elemental accuracy remained a problem with deviations averaging about $\pm 6 \%$ for the carbon number and $\pm 8 \%$ for the hydrogen number. Precision on individual compounds was considerably better, ranging from 1 to $3 \%$. The deviations thus appeared to be systematic and apparently unrelated to compound type. The dominant effect appeared to be a concentration dependence in elemental ratio which resulted in an accuracy problem even for a limited dynamic range.

A direct inlet experiment was set up to test the element ratio precision of the systems in the absence of chromatographic effects (i.e., sloping base1 ines, integration accuracy, etc.). For this purpose, a mixture of proportional counting gas consisting of $1.3 \%$ isobutane and $98.7 \%$ helium was introduced into the carrier gas 7 ine through a needle valve teed in after the mass flow controller. All other conditions were unaffected except that the transfer line and GC were at room temperature. Outputs from the carbon and hydrogen channels were monitored with digital voltmeters (DVMs) to assure that the system was not saturated. Sample flow was adjusted accordingly. The signals from the echelle system were then recorded for up to $1 \mathrm{~h}$ with the Nelson Analytical system, using a sampling rate of 10 points per second. It was evident from the behavior of the system on the DVMs and graphical display that the ratio was very sensitive to very minor changes in the optical alignment of the system. This was to some extent true even at the 200- $\mu \mathrm{m} \mathrm{s}$ slit settings used for the data presented above. The principal source of spectrometer instability was drift in the optics caused by thermal expansion and contraction of the aluminum base used as the spectrometer support mounting. This could be minimized by the addition of thermal insulation, which would require major modifications to the echelle spectrometer. The 
TABLE 12. Empirical Formulae Using the Low-Pressure Beenakker Source on the MPD-850

\begin{tabular}{|c|c|c|c|c|}
\hline Compound & $\begin{array}{c}\text { Known } \\
\text { Carbon \# }\end{array}$ & $\begin{array}{c}\text { Known } \\
\text { Hydrogen \# }\end{array}$ & $\begin{array}{c}\text { Calculated } \\
\text { Carbon \# }\end{array}$ & $\begin{array}{l}\text { Calculated } \\
\text { Hydrogen \# }\end{array}$ \\
\hline 2-Methyl thiophene & 5 & 6 & $4.52 \pm 0.12$ & $6.06 \pm 0.09$ \\
\hline 3-Methyl thiophene & 5 & 6 & $4.73 \pm 0.07$ & $5.86 \pm 0.32$ \\
\hline 2,5-Dimethyl thiophene & 6 & 8 & $6.28 \pm 0.18$ & $7.59 \pm 0.20$ \\
\hline Benzenethiol & 6 & 5 & $6.77 \pm 0.15$ & $5.80 \pm 0.12$ \\
\hline Octanethiol & 8 & 18 & $8.41 \pm 0.30$ & $16.77 \pm 0.32$ \\
\hline Benzothiophene & 8 & 6 & $8.38 \pm 0.13$ & $5.38 \pm 0.05$ \\
\hline 2-Methylbenzothiazole & 8 & 7 & $8.20 \pm 0.15$ & $6.36 \pm 0.07$ \\
\hline Dibenzothiophene & 12 & 8 & $12.17 \pm 0.49$ & $7.34 \pm 0.19$ \\
\hline Thi anthrene & 12 & 8 & $12.38 \pm 0.27$ & $7.55 \pm 0.25$ \\
\hline Phenothiazine & 12 & 9 & $12.03 \pm 0.30$ & $8.50 \pm 0.16$ \\
\hline
\end{tabular}

experiment was repeated with the MPD-850 system, using a sampling rate of 1 point per second, which allowed commercial software to be used for data reduction. That analysis showed that the low-pressure Beenakker-MPD-850 system could maintain a $\mathrm{H} / \mathrm{C}$ ratio precision on the order of $0.6 \%$ averaged over $10 \mathrm{~min}$. The principal source of the $\mathrm{H} / \mathrm{C}$ instability was in the hydrogen channel, which showed a noise level of about $1 \%$ during the same time interval.

An experiment was also performed to determine the feasibility of obtaining compound formulae from partially resolved chromatographic peaks by the use of time-resolved elemental ratios. This was done using a mixture of naphthalene and benzothiophene at approximately equal levels $(0.1 \mathrm{mg} / \mathrm{mL})$. Preliminary results indicated that the idea may have merit; however, software development would be needed to do a more detailed analysis of the data. 


\subsection{FOSSIL FUEL APPLICATIONS}

The final goal of this program consisted of exploring the extension of the GC-MIP technique to the analysis of the complex mixtures found in fossil fuels. As one application, identification of specific element-containing compounds in fossil fuels was attempted. Once a specific element was identified in a fossil fuel component, the next question was whether its empirical formula could be determined.

Three different types of fossil fuels were used in exploring these applications: shale oil and offgas from a Western 0 il shale retorted in the PNL 6-kg bench-scale retort (01sen et al. 1984), hydrotreated coal (H-Coal), and Cerro Negro and Boscan crude oils, the latter of which contains approximately $140 \mathrm{ppm}$ nickel. The shale oil was fractionated into 14 fractions on a silica gel (60/200 mesh, activated) column using solvents of increasing polarity (hexane, toluene, methylene chloride, ethyl acetate, and methanol) (01sen et al. 1985). The H-Coal sample was a $700-750^{\circ} \mathrm{F}$ blended distillate that had previously been fractionated on an alumina column into four fractions of increasing polarity: aliphatic hydrocarbons, neutral polycyclic aromatic hydrocarbons (PAH), nitrogen-containing PAH, and hydroxy-PAH (Wilson et al. 1985). The asphaltene fractions from the two crude oils were further fractionated first on silica gel and then on alumina following the procedure of 01 sen et al. (1981).

The oil shale retort offgas was analyzed for sulfur-containing compounds and empirical formula measurements were attempted. The shale oil and $\mathrm{H}$-Coal fractions were analyzed for sulfur-containing compounds and were derivatized in an attempt to characterize oxygen-containing compounds. The two crude oils were analyzed for $\mathrm{Ni}$-porphyrins. The rest of this section describes the preliminary work with standards as well as the sample analyses.

\subsection{SULFUR SPECIES IN AN OIL SHALE RETORT OFFGAS-- EMPIRICAL FORMULA DETERMINATIONS}

A sample of offgas condensate, collected at $-77^{\circ} \mathrm{C}$ and dissolved in methylene chloride, was analyzed using the GC-10w-pressure Beenakker-echelle 
system. Conditions were similar to those described in Table 10 (Section 4.5); however, because of the low boiling nature of the sample, the temperature program of the GC oven was modified. The oven temperature was held at $40^{\circ} \mathrm{C}$ for $1 \mathrm{~min}$, then programmed at $1^{\circ} \mathrm{C} / \mathrm{min}$ to $60^{\circ} \mathrm{C}$, then at $5^{\circ} \mathrm{C} / \mathrm{min}$ to $100^{\circ} \mathrm{C}$, and at $20^{\circ} \mathrm{C} / \mathrm{min}$ to $300^{\circ} \mathrm{C}$, where it was held for $6 \mathrm{~min}$. The experimental protocol was described in greater detail in a paper to be published in Chromatographia. (a)

This sample provided a good demonstration of the selectivity of the GC-MIP for sulfur against a very large hydrocarbon background. The carbon and hydrogen chromatograms were quite complex. By contrast, all peaks were clearly resolved on the sulfur chromatogram and could be identified on the basis of retention time as a series of thiophenes plus dimethyl disulfide (Figure 37). Peaks 1 and 2 in Figure 37 were presumed to be two other dimethylthiophene isomers. The detection limit for the methylthiophenes was approximately $2 \mathrm{ng}$ injected onto the GC, whereas for the ethylthiophene it was close to $8 \mathrm{ng}$ (Figure 38 ).

The sulfur species were quantitated based on calibration curves for the standards in the sulfur mode (Figure 39). The sulfur species were present in the undiluted offgas in concentrations ranging from 1.5 to $10.7 \mathrm{~mol} \mathrm{ppm}$ (Table 13). In all cases, the amounts present in the chromatograms fell within the linear range of the curves. The possibility of interference in the quantitation of the sulfur species by complex hydrocarbon matrices similar to those present in the retort gas condensate was considered. To provide such a complex matrix, the nonpolar fraction of a shale oil (which consisted predominantly of hydrocarbons and no sulfur compounds) was coinjected in a 1:1 ratio with dibenzothiophene $(0.1 \mathrm{mg} / \mathrm{mL})$ onto the GC-MIP. The temperature was ramped rapidly to maximize overlap of the dibenzothiophene with the hydrocarbon peaks. The area of the dibenzothiophene peak on the sulfur channel was essentially identical (within $1 \%$ ) to the dibenzothiophene peak when injected alone.

(a) Sklarew, D. S., K. B. 01 sen, and J. C. Evans. 1988. Detection of Thiophenes in the offass Condensate of an 0 il Shale Retort by a GCMicrowave-Induced Helium Plasma Detector. PNL-SA-16190, Pacific Northwest Laboratory, Richland, Washington. 


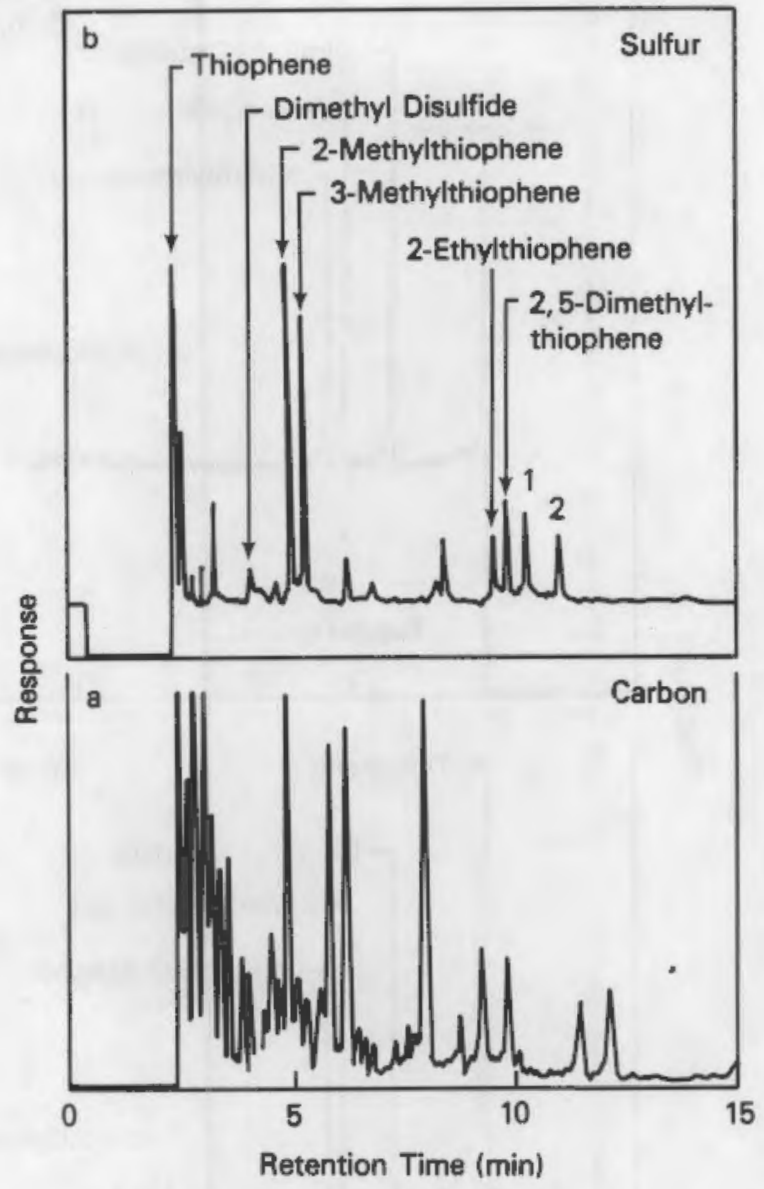

FIGURE 37. GC-MIP Analysis of Condensed Retort Offgas from a 6-kg 0 il Shale Retort

The possibility of using the GC-MIP to calculate the empirical formulae of unknowns was first addressed using a simple mixture of low molecular weight sulfur compounds (Table 14). 2-Methylthiophene was treated as the reference compound, and the other standards were considered unknowns. The agreement of the calculated values with the true values was good for carbon (within \pm 0.5 carbon number) and fair for hydrogen (within \pm 1 hydrogen number).

Extension of this powerful identification technique to a complex mixture depended on obtaining well-resolved peaks (i.e., those that could be accurately integrated) in each of the elemental chromatograms. The degree of complexity of the offgas made this difficult for the carbon and hydrogen 


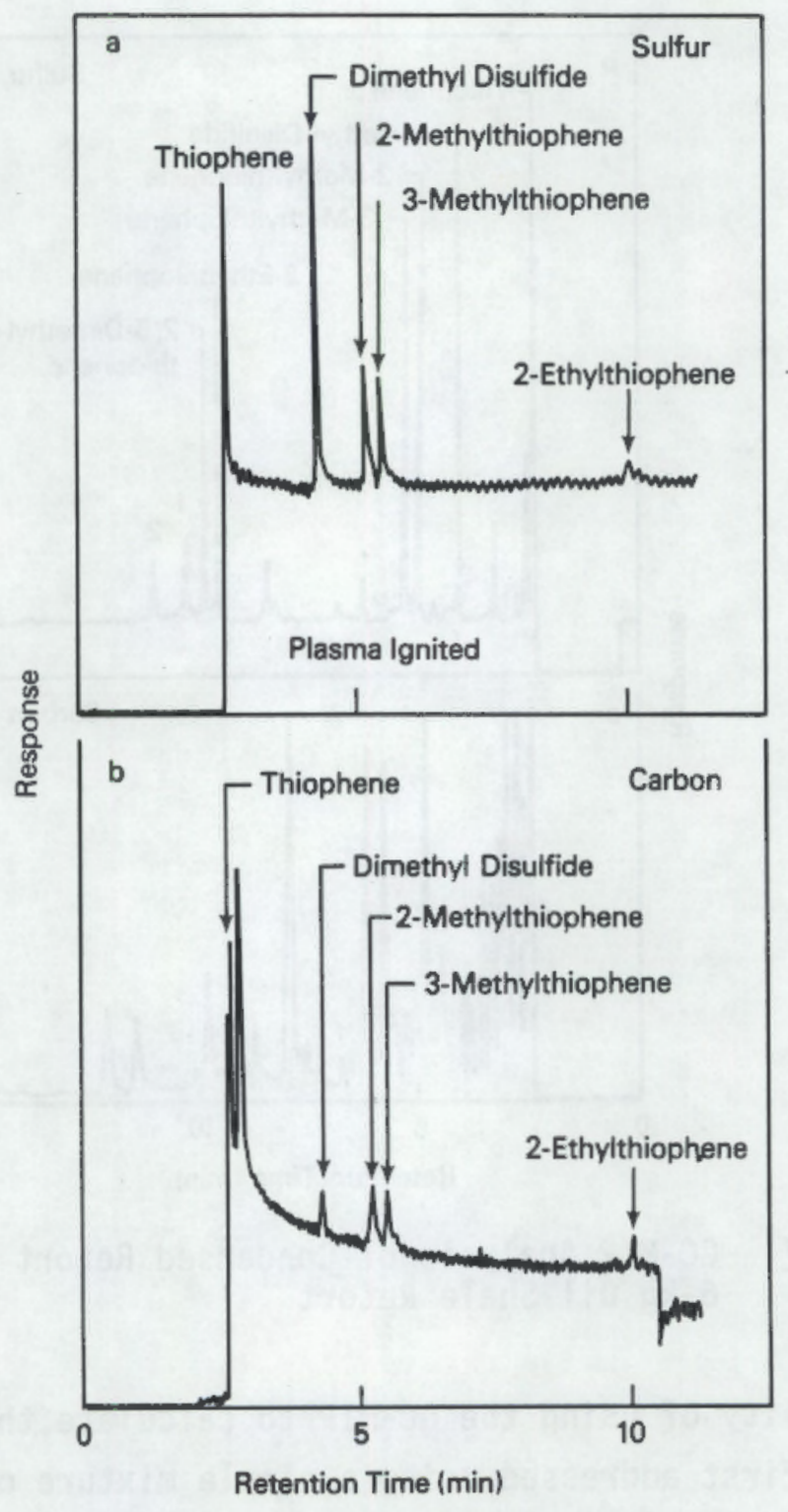

FIGURE 38. Chromatograms of Sulfur Standards by GC-Low-Pressure Beenakker-Echelle (approximately $8 \mathrm{ng}$ of each sulfur standard injected)

chromatograms. The sulfur peak typically corresponded to a shoulder on the carbon peak. In only a few instances did the sulfur peak maximize at the same retention time (within $\pm 0.01 \mathrm{~min}$ ) as the carbon peak. The elemental ratios (C/E) of these components were calculated (Table 15); in three cases, integration of the hydrogen chromatogram was too poor to allow inclusion of hydrogen in the calculations. If we could assume that these components were 

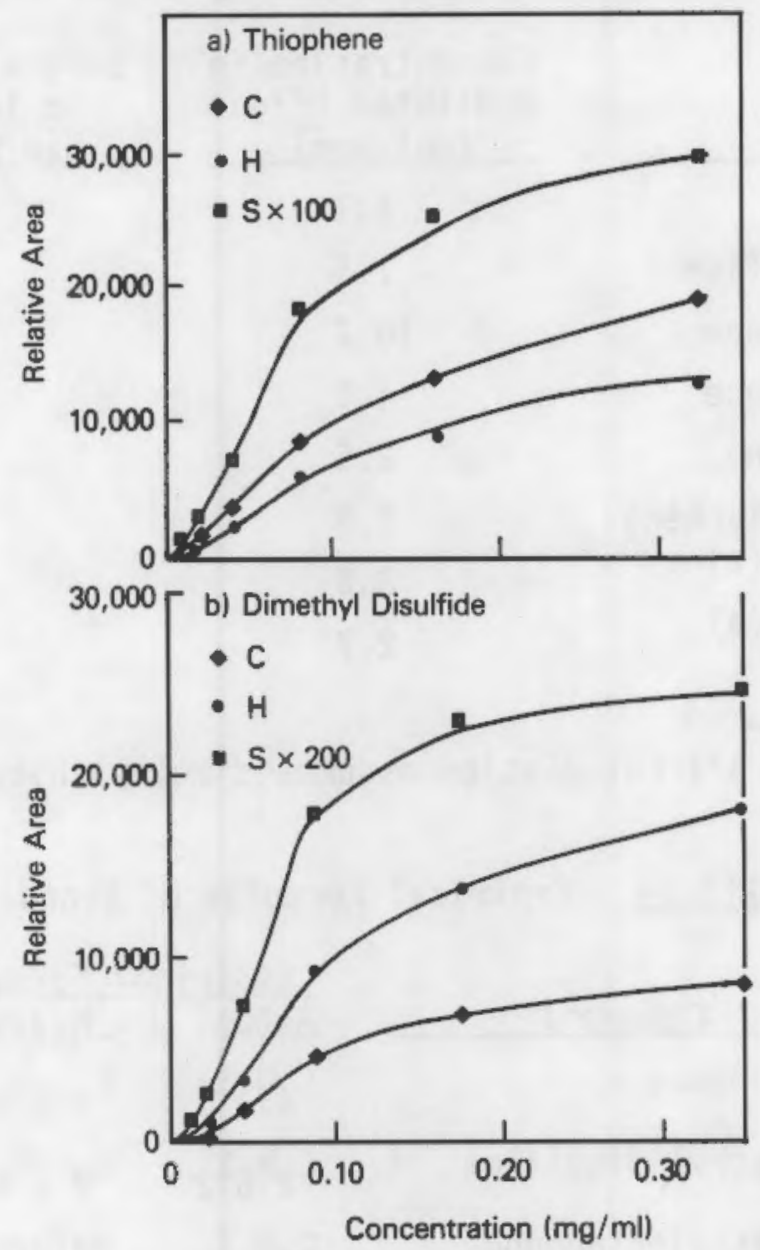

FIGURE 39. Calibration Plot for Sulfur, Carbon, and Hydrogen Response as a Function of the Concentration of Compound Injected

indeed the thiophenes identified by retention time, the $\mathrm{C} / \mathrm{S}$ ratios were generally inaccurate. One explanation was the possibility that another nonsulfur component overlapped with the sulfur component, thereby producing carbon and hydrogen values that were too high. Another explanation was the difficulty in accurately integrating the small carbon peak associated with the sulfur compound in the carbon chromatogram, especially given the uncertainty in estimating the baseline because of the complexity of the carbon chromatogram. Thus, to be able to determine empirical formulae for components of complex mixtures, it appears that the mixtures must be fractionated 
TABLE 13. Sulfur Species Emitted in Retort Gas Condensate

\begin{tabular}{|c|c|c|}
\hline Compound & $\begin{array}{c}\text { Concentration in } \\
\text { Undiluted Offgas } \\
\text { (mol ppm) } \\
\end{array}$ & $\begin{array}{l}\text { Weight Sulfur Relative } \\
\text { to Total Sulfur in } \\
\text { Raw Shale (mg/kg) }\end{array}$ \\
\hline Thiophene & 5.1 & 140 \\
\hline Dimethyl disulfide & 1.5 & 83 \\
\hline 2-Methylthiophene & 10.7 & 290 \\
\hline 3-Methylthiophene & 4.0 & 110 \\
\hline 2-Ethyl thiophene & 2.5 & 68 \\
\hline 2,5-Dimethyl thiophene & 2.8 & 77 \\
\hline Unknown peak $1^{(a)}$ & 3.0 & 81 \\
\hline Unknown peak $2^{(a)}$ & 2.7 & 72 \\
\hline
\end{tabular}

(a) In Figure 37; calculation assumes dimethylthiophene.

TABLE 14. Empirical Formulae of Standards

\begin{tabular}{|c|c|c|}
\hline & \multicolumn{2}{|c|}{ Empirical Formula } \\
\hline Compound & Actual & Measured \\
\hline Thiophene & $\mathrm{C}_{4} \mathrm{H}_{4} \mathrm{~S}$ & $\mathrm{C}_{4.1} \mathrm{H}_{4.1} \mathrm{~S}$ \\
\hline Dimethyl disulfide & $\mathrm{C}_{2} \mathrm{H}_{6} \mathrm{~S}_{2}$ & $\mathrm{C}_{2.1} \mathrm{H}_{6.4} \mathrm{~S}_{2}$ \\
\hline 2-Methylthiophene & $\mathrm{C}_{5} \mathrm{H}_{6} \mathrm{~S}$ & Reference \\
\hline 3-Methylthiophene & $\mathrm{C}_{5} \mathrm{H}_{6} \mathrm{~S}$ & $\mathrm{C}_{4.6} \mathrm{H}_{5.6} \mathrm{~S}$ \\
\hline 2-Ethylthiophene & $\mathrm{C}_{6} \mathrm{H}_{8} \mathrm{~S}$ & $\mathrm{C}_{6.0} \mathrm{H}_{8.5^{\mathrm{S}}}$ \\
\hline 2,5-Dimethylthiophene & $\mathrm{C}_{6} \mathrm{H}_{8} \mathrm{~S}$ & $\mathrm{C}_{6.5} \mathrm{H}_{9.0^{\mathrm{S}}}$ \\
\hline
\end{tabular}

sufficiently to produce simplified carbon and hydrogen chromatograms even when the chromatogram for the element of interest is relatively simple without fractionation. 
TABLE 15. Empirical Formulae of Retort Gas Condensate Components

\begin{tabular}{|c|c|c|}
\hline \multirow[b]{2}{*}{ Presumed Compound } & \multicolumn{2}{|c|}{ Empirical Formula } \\
\hline & Actual & Measured \\
\hline 2-Methyl thiophene & $\mathrm{C}_{5} \mathrm{H}_{6} \mathrm{~S}$ & $C_{5.8} x^{H} S^{(a)}$ \\
\hline 3-Methyl thiophene & $\mathrm{C}_{5} \mathrm{H}_{6} \mathrm{~S}$ & $C_{7.0} \mathrm{H}_{\mathrm{x}}^{\mathrm{S}}$ \\
\hline 2-Ethylthiophene & $\mathrm{C}_{6} \mathrm{H}_{8} \mathrm{~S}$ & $c_{6.5} \mathrm{H}^{\mathrm{H}} \mathrm{S}$ \\
\hline Unknown peak 1 & $\mathrm{C}_{6} \mathrm{H}_{8} \mathrm{~S}^{(\mathrm{b})}$ & $\mathrm{C}_{8.3^{\mathrm{H}} 10.4^{\mathrm{S}}}$ \\
\hline Unknown peak 2 & $\mathrm{C}_{6} \mathrm{H}_{8} \mathrm{~S}^{(\mathrm{b})}$ & $c_{8.7^{H}} 14.6^{S}$ \\
\hline
\end{tabular}

(a) $\mathrm{H}$ chromatogram integration was too poor to be useful.

(b) Assumed to be dimethylthiophene.

\subsection{ANALYSIS OF SHALE OIL AND H-COAL FRACTIONS--DERIVATIZATION OF OXYGEN-CONTAINING SPECIES}

Samples of fractionated shale oil and H-Coal were analyzed by GC-MIP using the low-pressure Beenakker source on both the echelle and MPD-850 systems. A temperature program rate of $5^{\circ} \mathrm{C} / \mathrm{min}$ from 50 to $300^{\circ} \mathrm{C}$ gave reasonable resolution of peaks; slower program rates did not significantly diminish the "hump" observed in a number of the samples. Other instrumental conditions were identical to those in Table 10.

Peaks were observed on the sulfur channel in the low polarity (hexane through toluene) fractions of the shale 011 (Figure 40) and the neutral PAH fraction of the H-Coal as expected. These sulfur peaks probably corresponded to thiophenes and higher molecular weight sulfur heterocyclics. Dibenzothiophene was tentatively identified on the basis of retention time. A comparison was made between the GC-MIP analysis of the shale oil and a GC-MS analys is of the same sample chromatographed under very similar conditions (Figure 40). The sulfur species that were very prominent by GC-MIP proved impossible to identify by GC-MS because of the hydrocarbon predominance and relatively low concentrations of sulfur species. A single ion reconstruct of 

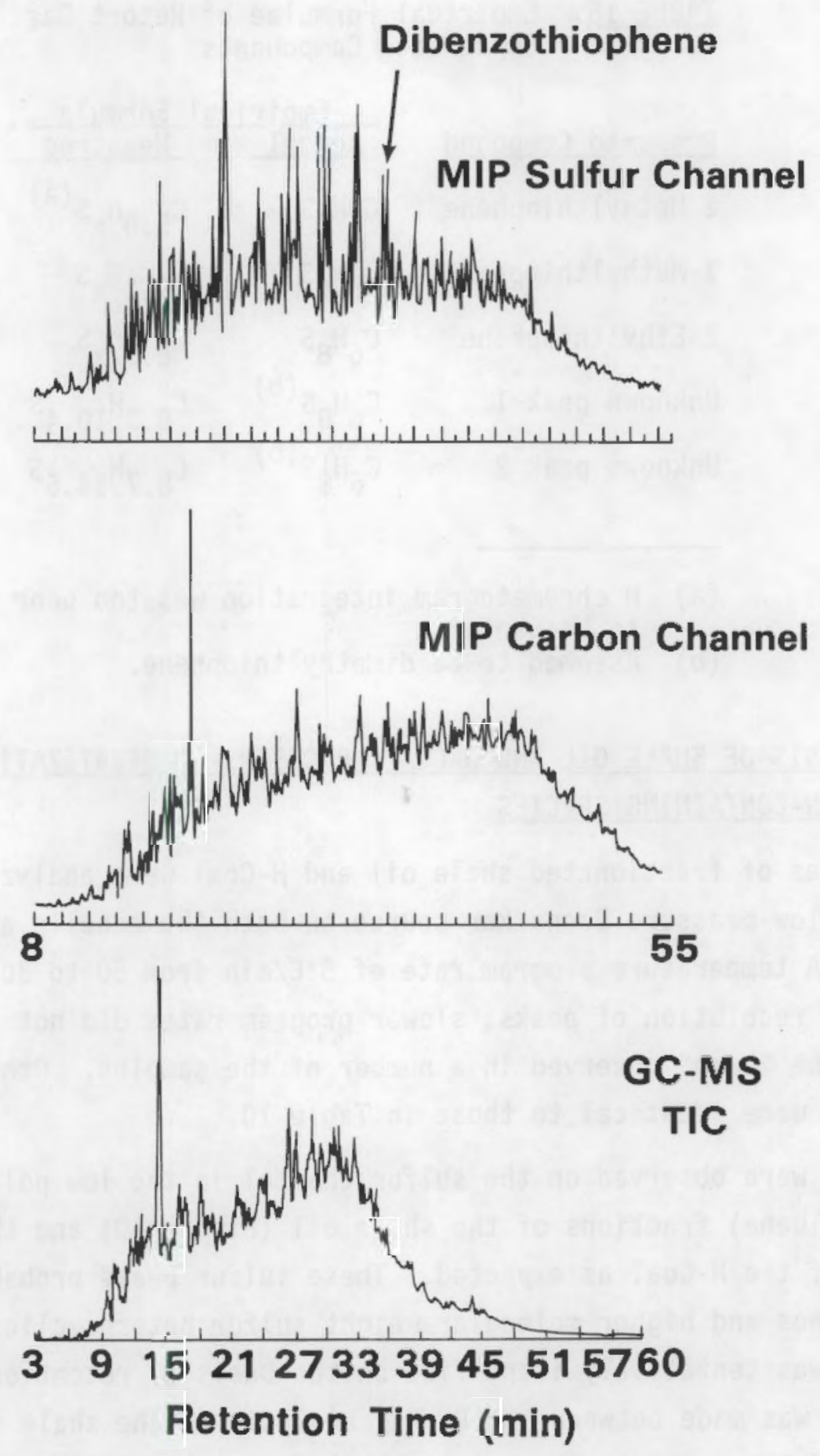

FIGURE 40. Analysis of Western Shale $0 i 1$ High-Sulfur Fraction by GC-MIP Compared with GC-MS Total Ion Chromatogram 
mass 184 was examined for evidence of dibenzothiophene, which had a retention time of about 21 min under the conditions used (Figure 41). The dibenzothiophene peak visible on the MIP sulfur chromatogram was effectively lost in the hydrocarbon noise on the GC-MS. Thus, it appears that the GC-MIP was a very useful screening technique for sulfur species. It was qualitatively comparable to the $f 1$ ame photometric detector (FPD) based on previous analyses of oil shale retort offgases (Sklarew et al. 1984); however, quantitation should have been more reliable with the GC-MIP because it provided a more linear response compared to the nonlinear, compound-dependent power function response of the FPD and it was not subject to hydrocarbon quenching at the concentrations studied (Slatkavitz et al. 1984; Farwell and Barinaga 1986). As with the retort offgas, it was not feasible to compute empirical formulae for the sulfur species because of the complex nature of the chromatograms.

\section{GC-MS $\mathrm{m} / \mathrm{e}=184$}

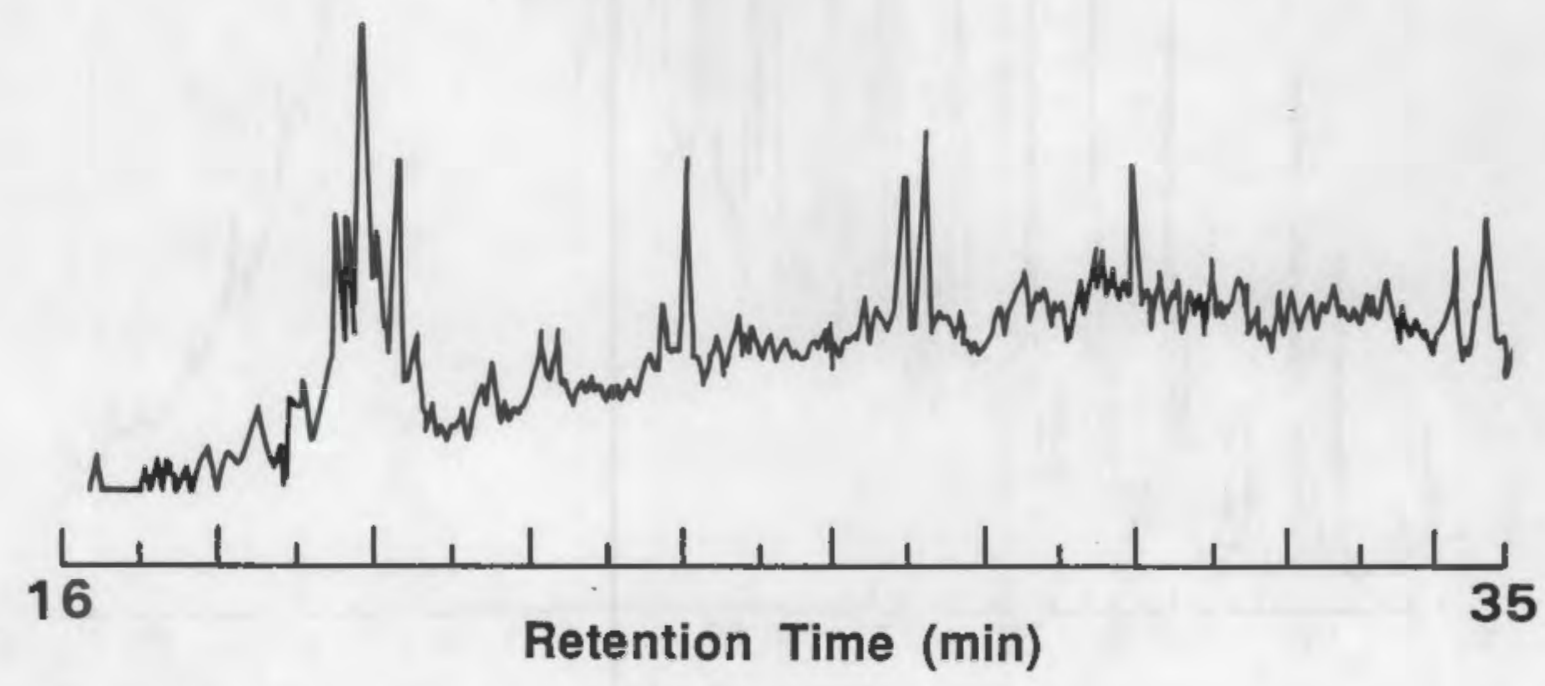

FIGURE 41. GC-MS Analysis of Western Shale 0il High Sulfur Fraction at $\mathrm{m} / \mathrm{e}=184$ (dibenzothiophene parent ion) 
Several of the more polar fractions of the shale oils (methylene chloride, ethyl acetate) contained homologous series that were apparent on the carbon and hydrogen channels (e.g., Figure 42). Unfortunately, the backgrounds on the nitrogen and oxygen channels on both MIP systems were too high to detect these homologous series. However, it was feasible that these series consisted of components that could be derivatized with either Si(trimethylsilyl) or F- (fluoroacyl or pentafluorobenzyl) containing compounds and that these elemental tags could be used instead of nitrogen or oxygen for

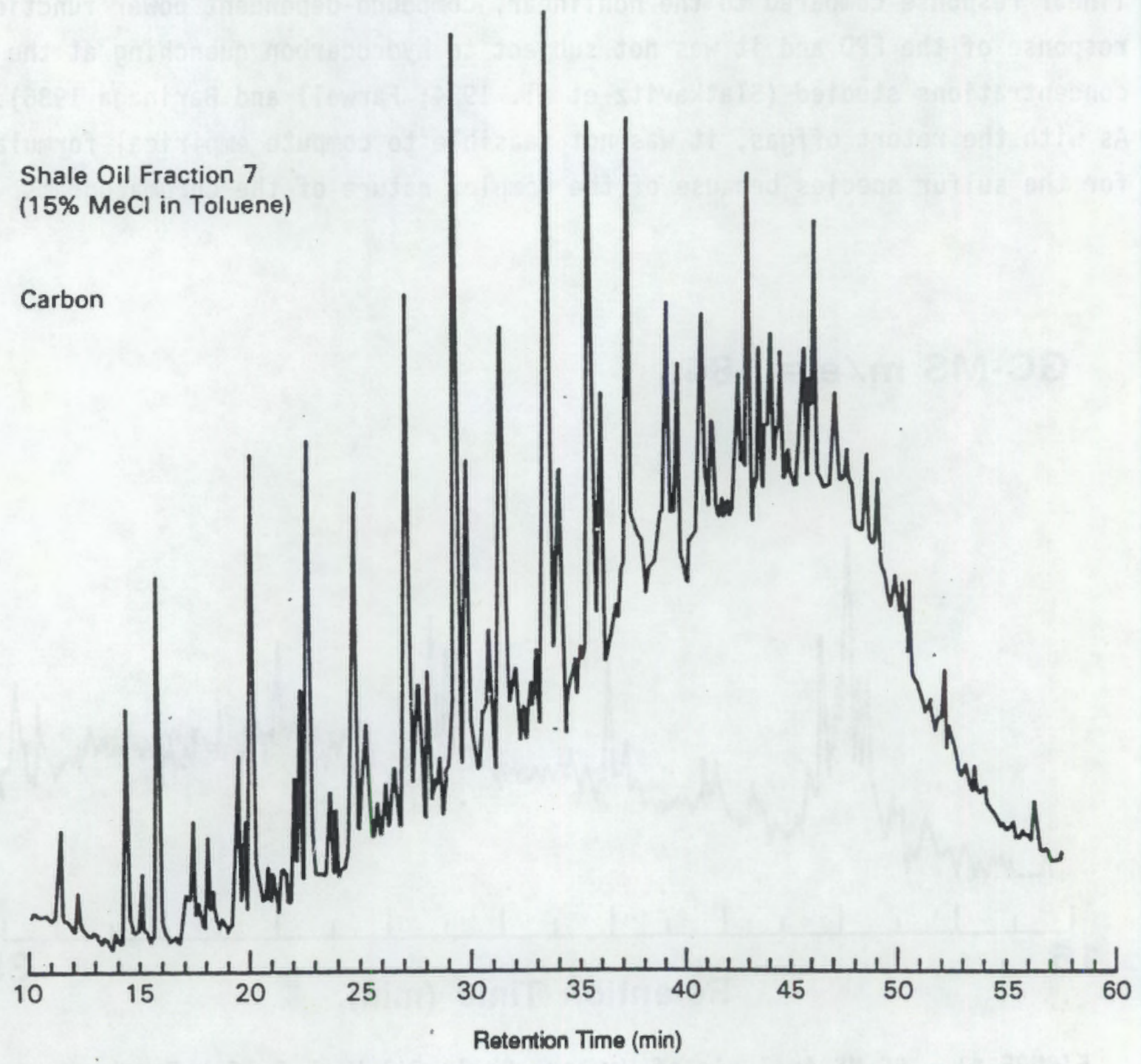

FIGURE 42. Analysis of Western Shale 011 Moderately Polar Fraction by GC-MIP 
analysis of the homologous series. Thus, derivatization techniques were investigated as a method for expanding the utility of the GC-MIP to oxygencontaining compounds.

The atmospheric-pressure Beenakker source and echelle system were considered optimum for silicon and fluorine. In preparation for derivatization experiments, the silicon and fluorine channels on the echelle spectrometer were examined for background and ghosting effects. Backgrounds were low on both channels. Analog ghosting corrections referenced against carbon were carefully calibrated for both channels.

Initial experiments used standard procedures for silylation and fluoracylation of a single compound, namely 1-naphthol. Four TMS reagents (Tri-Sil BSA, MSTFA, BSTFA, and BSTFA + 1\% TMCS) and two fluorinated derivatizing reagents (PFAA for fluoroacylation and PFBBr for pentafluorobenzylation) were used following procedures in the Pierce catalog. All procedures produced one derivatized peak, with corresponding peaks on the $\mathrm{C}, \mathrm{H}$, and $\mathrm{Si}$ or $\mathrm{C}, \mathrm{H}$, and $\mathrm{F}$ channels. In all cases, there was no residual underivatized naphthol in the chromatograms. The PFAA and PFBBr reagents produced a number of peaks that could easily complicate interpretation of samples particularly in the low molecular weight region; the TMS reagent peaks appeared relatively early in the chromatograms resulting in no serious interference. TMSnaphthol has an atomic $\mathrm{C} / \mathrm{Si}$ ratio of 13 ; the measured $\mathrm{C} / \mathrm{Si}$ ratio in the TMS-naphthol was approximately 15 for all four TMS reagents, indicating that the carbon and silicon response factors for the helium plasma were similar. The naphthol-pentafluoropropionic ester has an atomic $\mathrm{C} / \mathrm{F}$ ratio of 2.6, yet the fluorine area was approximately three times that of carbon. Thus, fluorine had a relatively strong response on the plasma system, about eight times that of carbon.

Two of the polar shale oil fractions containing homologous series were derivatized with TMS or PFAA. In both cases, there did not appear to be any significant differences between the derivatized and underivatized fractions indicating that these fractions did not contain derivatizable components. The hydroxy-PAH fraction of the H-Coal, which was known to contain phenols (Wilson et al. 1985), was also derivatized with TMS or PFAA. Both reagents 
appeared to produce satisfactory derivatization reactions based on the shift of the carbon chromatograms to lower retention times (Figure 43). The fluorine chromatogram of the H-Coal, which was blank before derivatization, showed a complex pattern after derivatization (Figure 44). Unfortunately,

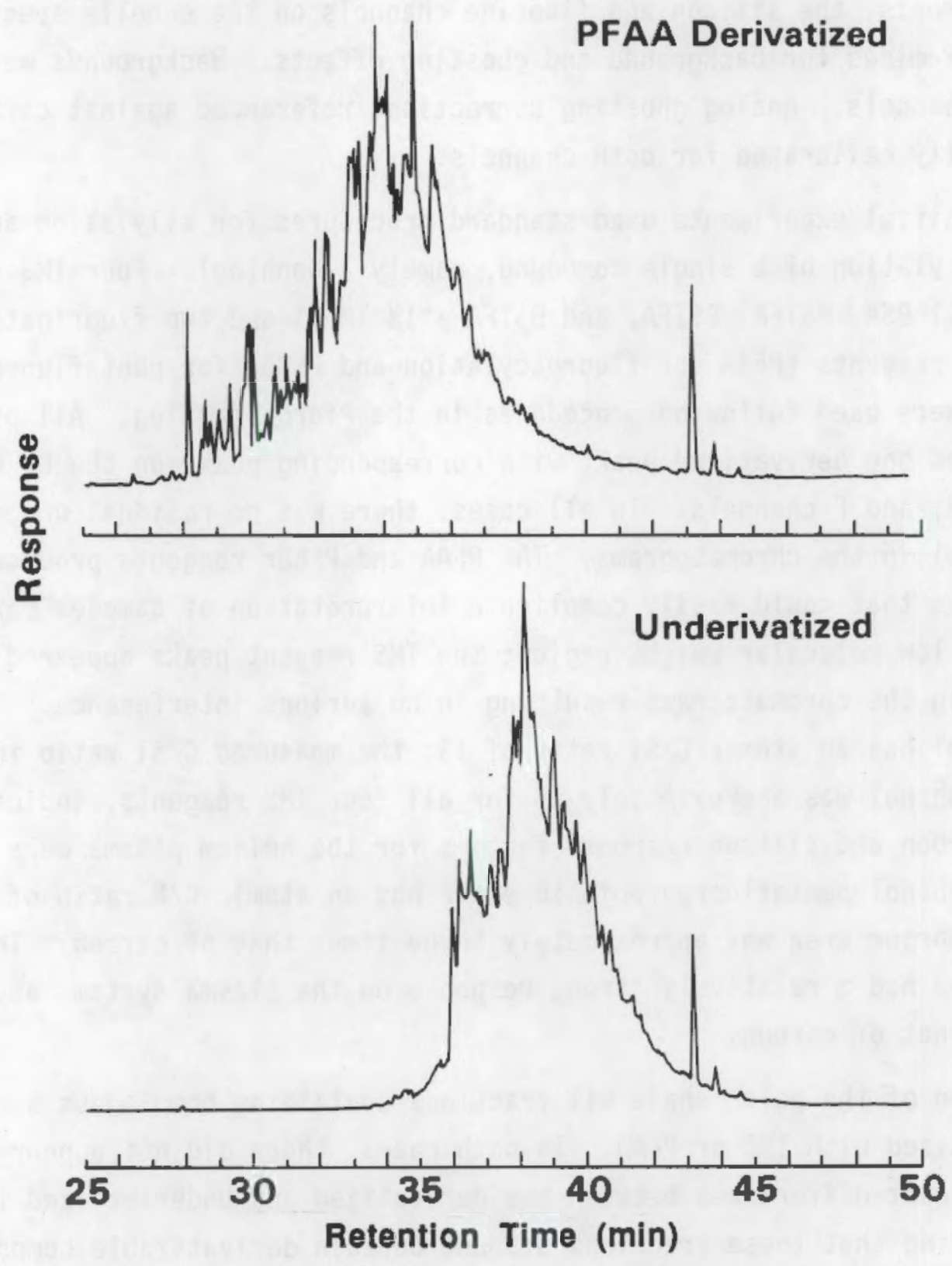

FIGURE 43. Comparison of PFAA-Derivatized H-Coal Distillate Blend Phenolic Fraction with Underivatized Fraction on MIP Carbon Channel 


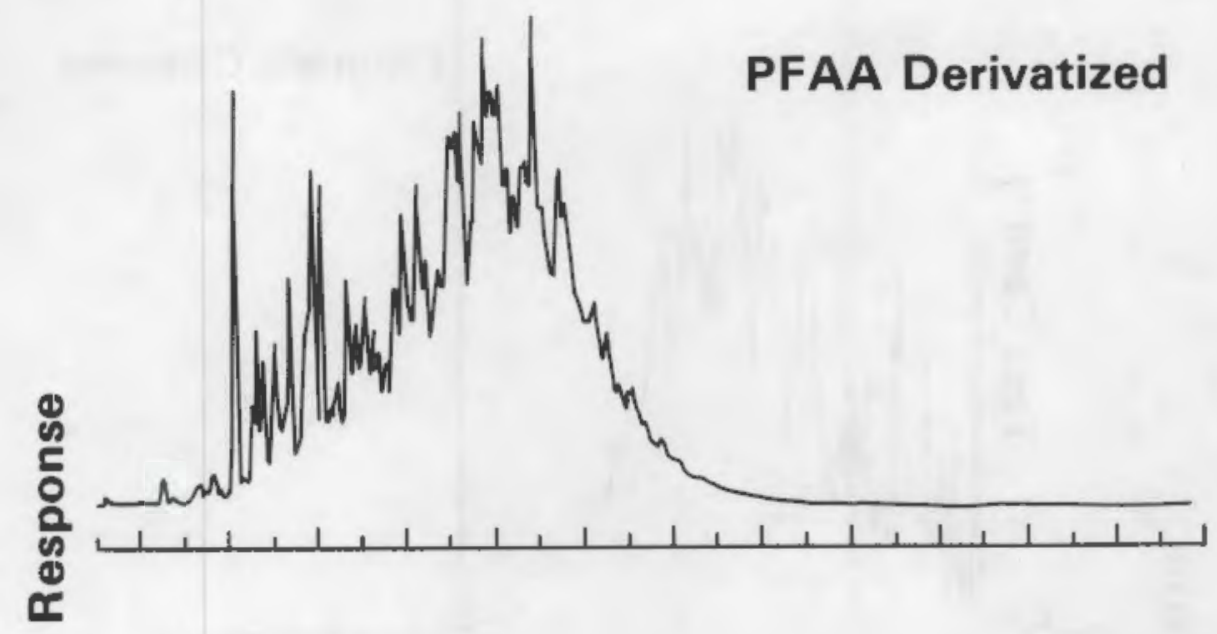

Underivatized

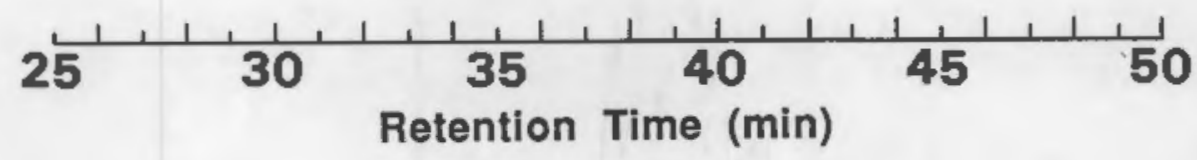

FIGURE 44. Comparison of PFAA-Derivatized H-Coal Distillate Blend Phenolic Fraction with Underivatized Fraction on MIP Fluorine Channel

the TMS derivatization produced no usable response on the silicon channel. Apparently, the sensitivity of the silicon channel was inadequate for this purpose because the typical atomic $\mathrm{C} / \mathrm{Si}$ ratio for derivatized compounds was greater than 10. The PFAA results were far more useful because five fluorine atoms were added per functional group. The $\mathrm{H}$-Coal fraction appeared to consist almost exclusively of phenolic or related compounds (Figure 45).

An attempt was made to determine the empirical formula of one reasonably well-resolved (test case) peak in Figure 45. 1-Naphthol was used as the elemental response standard and 9-phenanthrol was used as a pseudo-unknown (Figure 46). Reasonably good agreement with the known molecular formula was obtained for the phenanthrol pseudo-unknown (within 3.5\% for $C$ and $1.1 \%$ for 

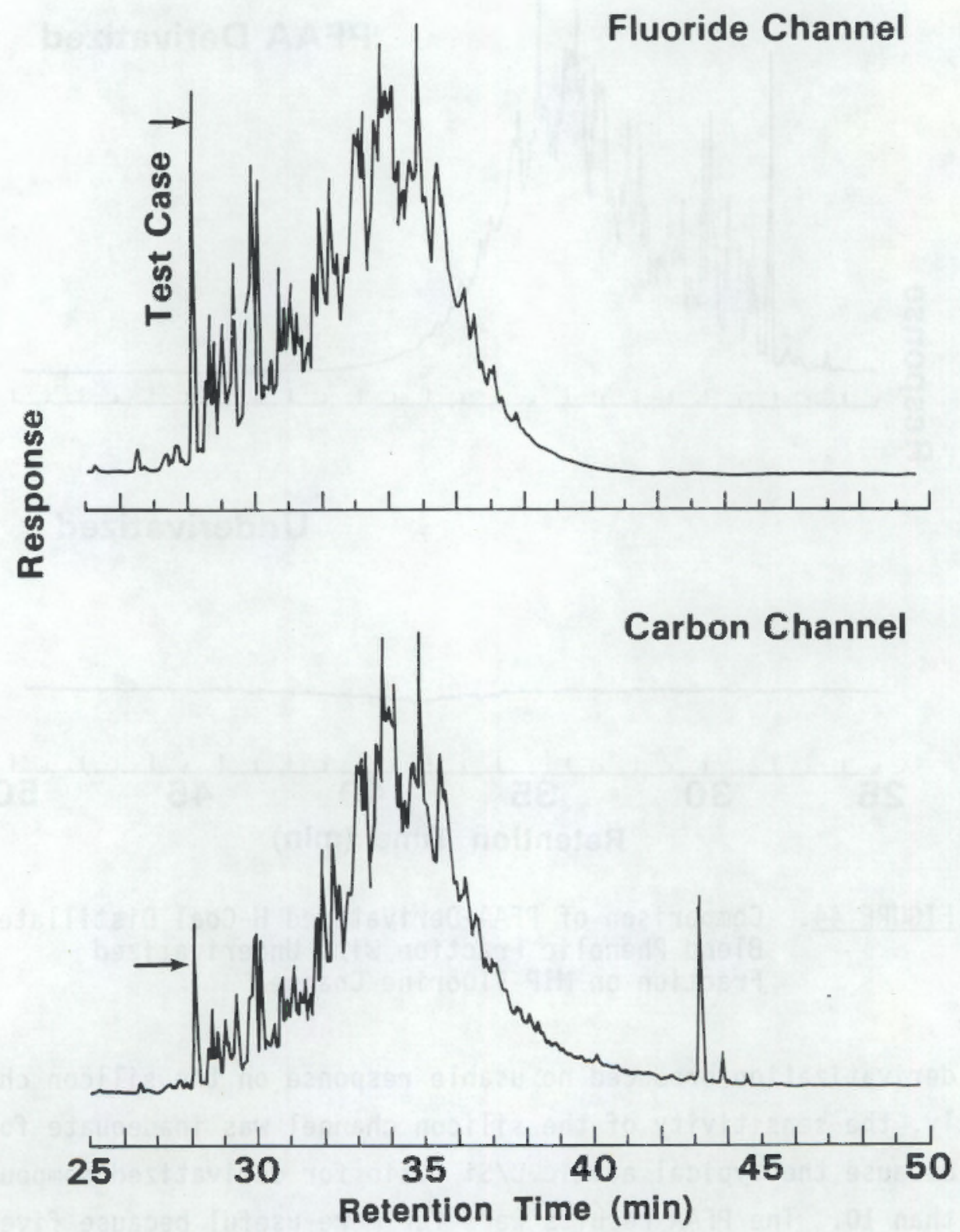

FIGURE 45. PFAA-Derivatized H-Coal Distillate Blend Phenolic Fraction. Comparison of carbon and fluorine channels

H) (Table 16). The test case peak proved to be slightly hydrogen deficient. If an error in the hydrogen number of -1 was assumed (i.e., $\mathrm{H}_{7}$ ) and the carbon number rounded up to $C_{12}$, the parent compound was tentatively identified as indenol. However, this did not appear to be a good identification because 

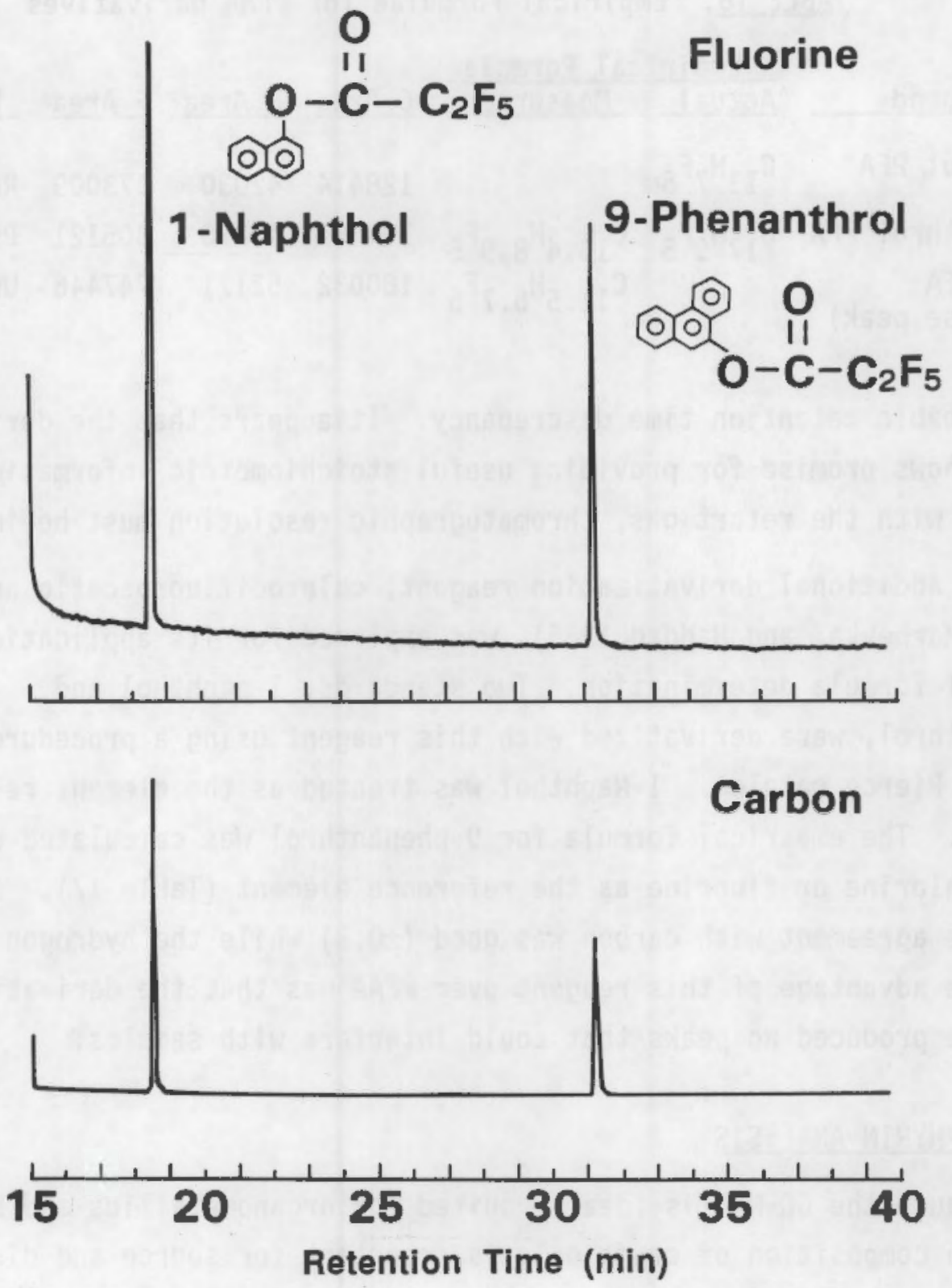

FIGURE 46. Chromatogram of PFAA-Derivatized Phenolic Standards 
TABLE 16. Empirical Formulae for PFAA Derivatives

\begin{tabular}{|c|c|c|c|c|c|c|}
\hline Compound & $\frac{\text { Empiri }}{\text { Actual }}$ & $\begin{array}{c}\text { cal Formula } \\
\text { Measured }\end{array}$ & C Area & H Area & F Area & Description \\
\hline I-Naphthol PFA & $\mathrm{C}_{13} \mathrm{H}_{7} \mathrm{~F}_{5}$ & & 128414 & 42030 & 473009 & Reference \\
\hline 9-Phenanthrol PFA & $\mathrm{C}_{17} \mathrm{H}_{9} \mathrm{~F}_{5}$ & $\mathrm{C}_{16.4} \mathrm{H}_{8.9} \mathrm{~F}_{5}$ & 104297 & 43226 & 305121 & Pseudo-unknown \\
\hline $\begin{array}{l}\text {-Coal PFA } \\
\text { test case peak) }\end{array}$ & & $c_{11.5^{H}} \mathrm{H}_{5.7} \mathrm{~F}_{5}$ & 180032 & 52171 & 747446 & Unknown \\
\hline
\end{tabular}

of a probable retention time discrepancy. It appears that the derivatization method shows promise for providing useful stoichiometric information; however, as with the retort gas, chromatographic resolution must be improved.

One additional derivatization reagent, chlorodifluoroacetic anhydride (Hagen, Marhevka, and Haddad 1985), was explored for its application to empirical formula determination. Two standards, 1-naphthol and 9-phenanthrol, were derivatized with this reagent using a procedure adapted from the Pierce catalog. 1-Naphthol was treated as the element response standard. The empirical formula for 9-phenanthrol was calculated using either chlorine or fluorine as the reference element (Table 17). In each case, the agreement with carbon was good $( \pm 0.3)$ while the hydrogen value was low. One advantage of this reagent over PFAA was that the derivatization procedure produced no peaks that could interfere with samples.

\subsection{PORPHYRIN ANALYSIS}

Because the GC-MIP is ideally suited for organometallics and because porphyrin composition of crude oils is important for source and diagenesis information, analyses of porphyrins were conducted using the echelle system with the atmospheric-pressure Beenakker. The transfer line was eliminated as described in Section 2.4 to facilitate analysis of these high-boiling compounds. Aluminum-clad fused-silica capillary columns $10 \mathrm{~m}$ long and coated with $0.1-\mu \mathrm{m}$ methyl silicone or $5 \%$ phenyl silicone were used because of their ability to withstand temperatures as high as $400^{\circ} \mathrm{C}$. The oven temperature was started at $50^{\circ} \mathrm{C}$ and programmed at $20^{\circ} \mathrm{C} / \mathrm{min}$ to $375^{\circ} \mathrm{C}$ where it was held for 
TABLE 17. Empirical Formula for Chlorodifluoroacetyl Derivative $\frac{\text { Compound }}{\text { 9-Phenanthrol }} \frac{\text { Actual }}{\mathrm{C}_{16} \mathrm{H}_{9} \mathrm{O}_{2} \mathrm{ClF}_{2}} \frac{\mathrm{F} \text { as Reference }}{\mathrm{C}_{15.7} \mathrm{H}_{8.0}\left(\mathrm{O}_{2}\right) \mathrm{ClF}_{2}{ }^{(\mathrm{a})}} \frac{\mathrm{Cl} \text { as Reference }}{\mathrm{C}_{16.2} \mathrm{H}_{8.2}\left(\mathrm{O}_{2}\right) \mathrm{ClF}_{2}{ }^{(\mathrm{a})}}$

(a) Oxygen is not actually determined.

$20 \mathrm{~min}$. On-column and splitless injection were compared and little difference was observed. Porphyrin standards available for analysis included nickel(II)-etioporphyrin-I, vanadyl(IV)-etioporphyrin-I, octaethylporphine OEP, protoporphyrin-IX, vanadyl(IV)-tetrapheny]porphyrin, etioporphyrin-I, and tetra(3-methyl-phenyl)porphyrin; however, only the metallated compounds were useful for the GC-MIP technique. Of the latter compounds, only the nickel(II)-etioporphyrin chromatographed satisfactorily; the vanadyl porphyrins did not chromatograph under the conditions used. Peaks were observed on both the carbon and nickel channels of the spectrometer.

Numerous plasma operating parameters were reviewed to determine the maximum sensitivity for nickel. Both low-pressure and atmospheric-pressure conditions were tested with both argon and helium as plasma support gases. Atmospheric-pressure helium was found to provide the best sensitivity for nickel. The detection limit for nickel(II)-etioporphyrin using the $221.6 \mathrm{~nm}$ emission $l$ ine was $0.2 \mathrm{mg} / \mathrm{mL}$, which was equivalent to $0.02 \mathrm{mg} \mathrm{Ni} / \mathrm{mL}$. Because of these relatively poor detection limits, other potential emission lines were considered. The most promising was the $341.4 \mathrm{~nm} 1$ ine, which is the most sensitive using the $D C$ argon $p l$ asma. Again, atmospheric-pressure helium was found to provide the best sensitivity for nickel with this line. The detection 1 imit was approximately $0.01 \mathrm{mg} \mathrm{Ni} / \mathrm{mL}$. (Similar experiments with vanadium indicated that the $437.9 \mathrm{~nm}$ line was most sensitive for this element with detection limits approximately equal to nickel.) Because the aluminumclad column proved to be very inefficient for hydrocarbons, ghosting corrections were made using a standard polyimide-coated, fused-silica DB-5 column. The nickel(II)-etioporphyrin peak was broad compared to its peak on the aluminum-clad column, probably because of the lower temperatures that were necessary for the former. A large ghost correction was needed for the nickel 
221.6-nm line but no correction was needed for the nickel 341.4-nm line. One disadvantage of the 341.4-nm line was that there was no carbon line available on the same cassette; therefore, all work using this line had to be done in single element mode.

The nickel(II)-etioporphyrin was fractionated according to the same procedure used on the Boscan and Cerro Negro crude oils (01sen et al. 1981). The alumina fractions that contained the porphyrin (as determined visually for the standard) was chromatographed on the aluminum-clad column using the conditions described above. The fraction containing the standard nickel(II)etioporphyrin chromatographed with the same retention time as the original standard, indicating that the system was in good working order. However, no peaks were observed on the nickel channel for any of the crude oil fractions. It appears that the nickel channel either was not sensitive enough to detect nickel-porphyrins in the sample fractions or that it was affected by interferences. 


\subsection{CONCLUSIONS}

The results of this study indicate that the GC-MIP system is useful as a specific-element detector that provides excellent elemental specificity for a number of elements of interest to the analysis of fossil fuels. It can also provide stoichiometric information about components of simple mixtures. It has reasonably good sensitivity for carbon, hydrogen, and sulfur (i.e., on the order of $1 \mathrm{ng}$ injected for each of these elements) and better sensitivity for chlorine and fluorine. Its elemental specificity is sufficient to detect sulfur components in a mixture as complex as a retort offgas condensate, making it a very useful screening technique for sulfur species. Use of chlorine- or fluorine-containing derivatives provides a practical though indirect method of determining derivatizable oxygen or nitrogen species, because of the sensitive and element-specific detection on the chlorine and fluorine channels.

However, the GC-MIP does present a number of difficulties that sti11 need to be solved. Sensitivity is poor for nitrogen and oxygen; undetected leaks or erosion of the plasma tube are suspected to cause this problem. Sensitivity is only moderate for nickel-porphyrins, presumably because of chromatographic difficulties, on the order of $200 \mathrm{ng}$ of porphyrin (or $20 \mathrm{ng}$ of nickel) injected. Furthermore, empirical formula calculations do not work for complex mixtures because of the complexity of the carbon and hydrogen chromatograms, even when the other elemental chromatograms are relatively simple; it is not possible to accurately integrate a component that is the shoulder of another peak on the carbon chromatogram. To make empirical formula calculations feasible and increase sensitivity to minor or trace components of the type of complex mixtures found in fossil fuels, it is necessary to simplify the chromatograms by chemical fractionation. This solution for the GC-MIP system is, of course, the same as is required by most other single-element-specific detectors. However, the GC-MIP system has the advantage over these other detectors of being a multielement detector and, if sufficient simplification of the chromatogram can be achieved, of allowing stoichiometric determinations to be made. 
For empirical formulae of pseudo-unknown components in simple mixtures, results typicaliy deviated from the correct formulae by 5-10\% for hydrogen, sulfur, and chlorine. Precision varied from 1 to $5 \%$. Major sources of error are integration accuracy and the dependence (albeit weak) of $\mathrm{H} / \mathrm{C}$ elemental response ratios on concentration; spectrometer instability contributes about a $1 \%$ fluctuation in precision. These levels of precision and accuracy make it difficult to determine exact empirical formulae; however, it should be noted that even approximate empirical formulae may help with data interpretation when the GC-MIP technique is used in conjunction with GC-MS. Additional work is needed to correct these sources of error.

Aluminum-coated methyl-silicone capillary columns, which could withstand oven temperatures as high as $400^{\circ} \mathrm{C}$, were successfully used to chromatograph several relatively nonvolatile porphyrin compounds. The GC-MIP system was able to detect a nickel(II)-etioporphyrin standard. However, it was not able to detect nickel porphyrins in the appropriate fractions of two crude oils. It appears that the nickel channel either was not sensitive enough for nickel-porphyrins or that it was affected by interferences.

A low-pressure Beenakker source was designed and constructed for this study. This new source provided better overall characteristics for the needs of this program than did the two standard sources typically used in recent years (the atmospheric-pressure Beenakker and the low-pressure Evenson) because of its good stability and sensitivity to carbon, hydrogen, and sulfur. Optimal operating parameters were determined for this new source for $\mathrm{C}, \mathrm{H}, \mathrm{N}, \mathrm{S}$, and $\mathrm{Cl}$; a compromise between sensitivity and stability was achieved for most of these elements.

A major instrument manufacturer has recently developed a commercial GC-MIP instrument, which should encourage the use of this method. The techniques used and results obtained in this program should prove beneficial to the implementation of this technique. 


\subsection{REFERENCES}

Bache, C. A., and D. J. Lisk. 1971. "Gas Chromatographic Determination of Organic Mercury Compounds by Emission Spectrometry in a Helium Plasma." Anal. Chem. 43:950-952.

Beenakker, C. I. M. 1976. "A Cavity for Microwave-Induced Plasmas Operated in Helium and Argon at Atmospheric Pressure." Spectrochim. Acta 31B: 483-486.

Beenakker, C. I. M. 1977. "Evaluation of a Microwave-Induced Plasma in Helium at Atmospheric Pressure as an Element-Selective Detector for Gas Chromatography." Spectrochim. Acta 32B: 173-187.

Bonnekesse1, J., and M. Klier. 1978. "Daten-Erfassung und -Verarbeitung eines Mikrowellenplasmadetektors für die Gas-Chromatographie." Ana]. Chim. Acta 103:29-42.

Brenner, K. S. 1978. "Practical Experience with a Microwave Plasma Detector: Limits of Measurement and Examples of Application." J. Chromatogr. $167: 365-380$.

Carnahan, J. W., K. J. Mulligan, and J. A. Caruso. 1981. "Element-Selective Detection for Chromatography by PTasma Emission Spectrometry." Anal. Chim. Acta 130:227-241.

Chiba, K., and H. Haraguchi. 1983. "Determination of Halogenated Organic Compounds in Water by Gas Chromatography/Atmospheric Pressure Helium Microwave-Induced Plasma Emission Spectrometry with a Heated Discharge Tube for Pyrolysis." Anal. Chem. 55:1504-1508.

Dagna11, R. M., S. J. Pratt, T. S. West, and D. R. Means. 1970. "A Microwave-Excited Emissive Detector for Gas Chromatography. Further Studies with Sulfur Compounds." Ialanta 17:1009-1013.

Dagnal1, R. M., T. S. West, and P. Whitehead. 1972. "Use of the MicrowaveExcited Emissive Detector for Gas Chromatography for Quantitative Measurement of Inter-Element Ratios." Ana]. Chem. 44:2074-2078.

Dingjan, H. A., and H. J. deJong. 1981. "A Comparative Study of Two Cavities for Generating a Microwave Induced Helium or Argon as a Detector in Gas Chromatography." Spectrochim. Acta 36B:325-331.

Eckhoff, M. A., T. H. Ridgway, and J. A. Caruso. 1983. "Polychromator System for Multielement Determination by Gas Chromatography with Helium Plasma Atomic Emission Spectrometric Detection." Anal. Chem. 55:1004-1009.

Estes, S. A., P. C. Uden, and R. M. Barnes. 1981. "Microwave-Excited Atmospheric Pressure Helium Plasma Emission Detection Characteristics in Fused Silica Capillary Gas Chromatography." Anal. Chem. 53:1829-1837. 
Estes, S. A., P. C. Uden, and R. M. Barnes. 1982. "Determination of n-Butylated Trialkyllead Compounds by Gas Chromatography with Microwave Plasma Emission Detection." Anal. Chem. 54:2402-2405.

Evans, J. C., K. B. Otsen, and D. S. Sklarew. 1987. "A Low-Pressure Beenakker-Type Microwave-Induced Helium Plasma Source as a Simultaneous Multi-Element Gas Chromatographic Detector." AnaT. Chim. Acta 194:247-260.

Farwel1, S. 0., and C. J. Barinaga. 1986. "Sulfur-Selective Detection with the FPD: Current Enigmas, Practical Usage, and Future Directions." $\underline{\mathrm{J}}$. Chromatogr. Sci. 24:483-494.

Hagen, D. F., J. Belisle, J. D. Johnson, and P. Venkateswarlu. 1981. "Characterization of Fluorinated Metabolites by a Gas Chromatographic-

Helium Microwave Plasma Detector -- The Biotransformation of $1 \mathrm{H}, \mathrm{lH}, 2 \mathrm{H}, 2 \mathrm{H}-$ Perfluorodecanol to Perfluorooctanoate." Anal. Biochem. $118: 336-343$.

Hagen, D. F., J. S. Marhevka, and L. C. Haddad. 1985. "Multi-Element Taggant and Dual Homolog Derivatization Concepts in GC/MED." Spectrochim. Acta 40B:335-347.

Hanie, T., S. CouTombe, M. Moisan, and J. Hubert. 1981. "Evaluation of an Atmospheric Pressure Helium Microwave Plasma as a Gas Chromatography Detector for Pesticides." In Developments in Atomic Plastna Spectrochemical Analysis, Proceedings of the International Winter Conference, ed., R. M. Barnes, pp. 337-344, Heyden Publishers, Philade]phia, Pennsylvania.

Lipsky, S. R., and M. L. Duffy. 1986. "High Temperature Gas Chromatography: The Development of New Aluminum Clad Flexible Fused Silica Glass Capiliary Columns Coated with Thermostable Nonpolar Phases: Part 2." J.High Res. Chromatogr. \& Chromatogr. Comm. 9:725-730.

McCormack, A. J., S. C. Tong, and W. D. Cooke. 1965. "Sensitive Selective Gas Chromatography Detector Based on Emission Spectrometry of Organic Compounds." Anal. Chem. 37:1470-1476.

01 sen, K. B., D. S. Sklarew, and J. C. Evans. 1985. "Detection of Organomercury, Selenium and Arsenjc Compounds by a Capillary Column Gas Chromatography-Microwave Plasma Detector System." Spectrochim. Acta $40 \mathrm{~B}: 357-365$.

01 sen, K. B., J. C. Evans, D. C. Girvin, D. S. Sklarew, and C. L. Nelson. 1984. Testing and Performance of the Pacific Northwest Laboratory 6-kg Retort. PNL-5055, Pacific Northwest Laboratory, Richland, Washington.

01 sen, K. B., J. C. Evans, D. S. Sklarew, D. C. Girvin, C. L. Nelson, E. A. Lepe1, D. E. Robertson, and R. W. Sanders. 1985. Characterization of Mercury, Arsenic, and Selenium in the Product Streams of the Pacific Northwest Laboratory $6-\mathrm{kg}$ Retort. PNL-5658, Pacific Northwest Laboratory, Richland, Washington. 
01 sen, K. B., C. L. Wilkerson, A. P. Toste, and D. J. Hayes. 19B1. "Isolation of Metallic Complexes in Shale 0il and Shale $0 i 1$ Retort Waters." Paper presented at the DOE/NBS Workshop on Environmental Speciation and Monitoring Needs, May 18-20, Gaithersburg, Maryland.

Quimby, B. D., M. F. Delaney, P. C. Uden, and R. M. Barnes. 1979. "Determination of Trihalomethanes in Drinking Water by Gas Chromatography with a Microwave Plasma Emission Detector." Ana]. Chem. 51:875-8B0.

Quimby, B. D., M. F. Delaney, P. C. Uden, and R. M. Barnes. 1980. "Determination of the Aqueous Chlorination Products of Humic Substances by Gas Chromatography with Microwave Emission Detection." Anal. Chem. 52:259-263.

Rice, G. W., A. P. D'Silva, and V. A. Fassel. 1985. "A New He DischargeAfterglow and Its Application as a Gas Chromatographic Detector."

Spectrochim. Acta 40B:1573-1584.

Sklarew, D. S., D. J. Hayes, M. R. Petersen, K. B. 01sen, and C. D. Pearson. 1984. "Trace Sulfur-Containing Species in the Offgas from Two 0i] ShaTe Retorting Processes." Environ. Sci. Technol. 18:592-600.

Slatkavitz, K. J., P. C. Uden, and R. M. Barnes. 1986. "Consideration of an Atmospheric Pressure Microwave-Induced Helium Plasma as an Oxygen-Selective Gas Chromatographic Detector." J. Chromatogr. 355:117-126.

Slatkavitz, K. J., P. C. Uden, L. D. Hoey, and R. M. Barnes. 1984.

"Atmospheric-Pressure Microwave-Induced Helium Plasma Spectroscopy for Simultaneous Multielement Gas Chromatographic Detection." J. Chromatogr. $302: 277-287$.

Smith, R. D., S. L. Frye, C. R. Yonker, and R. W. Gale. 1987. "Solvent Properties of Supercritical Xenon and $\mathrm{SF}_{6} . "$ J. Phys. Chem. 91:3059-3062.

Talmi, Y. 1975. "The Rapid Sub-Picogram Determination of Volatile OrganoMercury Compounds by Gas Chromatography with a Microwave Emission Spectrometric Detector System." Anal. Chim. Acta 74:107-117.

Talmi, Y., and D. T. Bostick. 1975. "Determination of A1kylarsenic Acids in Pesticide and Environmental Samples by Gas Chromatography with a Microwave Emission Spectrometric Detection System." Anal. Chem. 47:2145-2150.

Uden', P. C., K. J. Slatkavitz, R. M. Barnes, and R. L. Deming. 1986. "Empirical and Molecular Formula Determination by Gas Chromatography/ Microwave-Induced Plasma Atomic Emission Spectrometry." Anal. Chim. Acta $180: 401-416$.

Wasik, S. P., and F. P. Schwarz. 1980. "Application of a Microwave-Induced Helium Plasma Detector at Atmospheric Pressure for Gas Chromatographic Capillary Columns." J. Chromatogr. Sci. 18:660-663. 
Wilson, B. W., D. W. Later, C. W. Wright, and D. L. Stewart. 1985. Chemical Analysis and Mutational Assay of Distilled 0ils from the $\mathrm{H}$-Coal Direct Liquefaction Process: A Status Report. PNL-5288, Pacific Northwest Laboratory, Richland, Washington.

Windsor, D. L., and M. B. Denton. 1979. "Empirica] Formula Determination with an Inductively Coupled Plasma Gas Chromatographic Detector." Anal. Chem. 51:1116-1119.

Zerezghi, M., K. J. Mulligan, and J. A. Caruso. 1984. "Application of a Rapid Scanning Plasma Emission Detector and Gas Chromatography for MultiElement Quantification of Halogenated Hydrocarbons." J. Chromatogr. Sci. $22: 348-352$. 
DISTRIBUTION

No. of

Copies

\section{QFFSITE}

10 DOE/0ffice of Scientific and Technical Information

W. D. Peters

Bartlesville Project Office

U.S. Department of Energy

P.0. Box 1398

Bartlesville, OK 74005

M. S. Brooks

Office of Fossi] Energy

U.S. Department of Energy

FE-14 C180

Germantown, MD 20545

E. Ferrero

Office of Fossil Energy

U.S. Department of Energy

FE-14 C180

Germantown, MD 20545

A. Hartstein

Office of Fossil Energy

U.S. Department of Energy

FE-33 D122

Germantown, MD 20545

D. Uthus

Office of Clean Coal

U.S. Department of Energy

Forrestal Building

1000 Independence Ave.

FE-221 3E-042

Washington, D.C. 20585
No. of

Copies

P. C. Uden

Department of Chenistry

University of Massachusetts

Anherst, MA 01003

\section{ONSITE}

DOE Richland Operations Office

E. C. Norman

J. J. Sutey

29 Pacific Northwest Laboratory

J. C. Evans (5)

J. W. Falco

J. M. Gephart

M. J. Graham

J. M. Hales

P. C. Hays

K. B. 01 sen (5)

R. G. Riley

D. S. Sklarew (5)

J. A. Stott Temyre

R. E. Wildung

Publishing Coordination

Technical Report Files (5) 


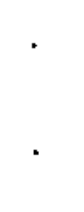

